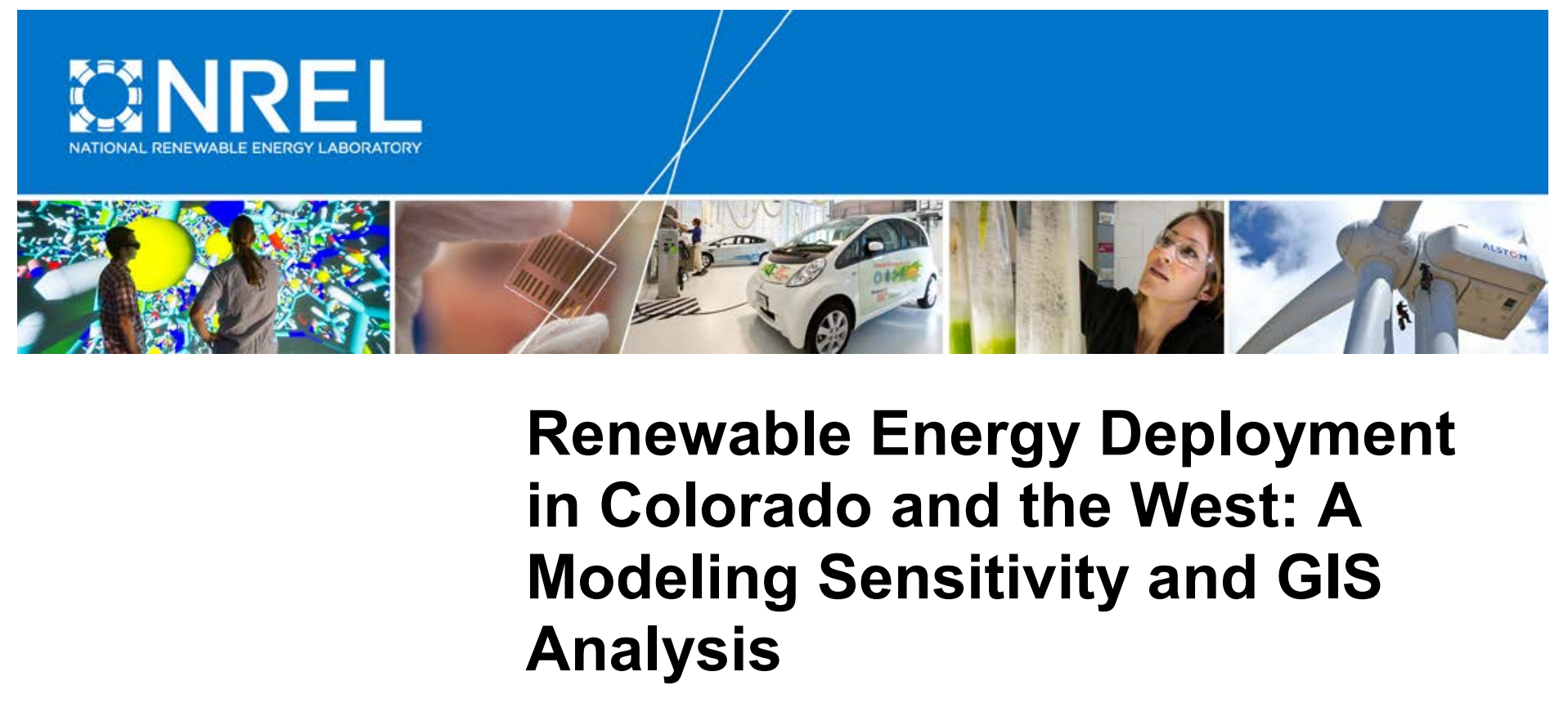

Clayton Barrows, Trieu Mai, Scott Haase, Jennifer Melius, and Meghan Mooney National Renewable Energy Laboratory

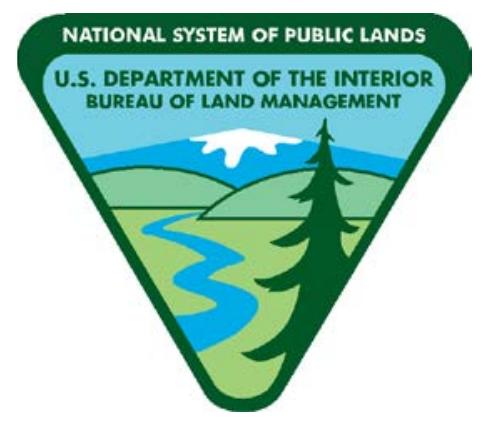

NREL is a national laboratory of the U.S. Department of Energy Office of Energy Efficiency \& Renewable Energy Operated by the Alliance for Sustainable Energy, LLC

This report is available at no cost from the National Renewable Energy Laboratory (NREL) at www.nrel.gov/publications.

Technical Report

NREL/TP-6A20-65350

March 2016

Contract No. DE-AC36-08G028308 


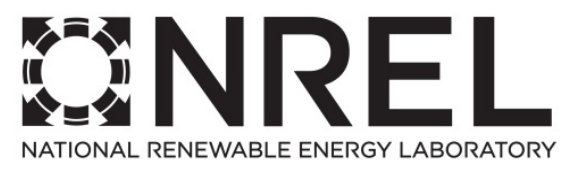

\section{Renewable Energy Deployment in Colorado and the West: A Modeling Sensitivity and GIS Analysis}

Clayton Barrows, Trieu Mai, Scott Haase, Jennifer Melius, and Meghan Mooney National Renewable Energy Laboratory

Prepared under Task No. WFGN.1001

NREL is a national laboratory of the U.S. Department of Energy Office of Energy Efficiency \& Renewable Energy Operated by the Alliance for Sustainable Energy, LLC

This report is available at no cost from the National Renewable Energy Laboratory (NREL) at www.nrel.gov/publications.

National Renewable Energy Laboratory 15013 Denver West Parkway Golden, CO 80401 303-275-3000 • www.nrel.gov
Technical Report

NREL/TP-6A20-65350

March 2016

Contract No. DE-AC36-08G028308 


\section{NOTICE}

This report was prepared as an account of work sponsored by an agency of the United States government. Neither the United States government nor any agency thereof, nor any of their employees, makes any warranty, express or implied, or assumes any legal liability or responsibility for the accuracy, completeness, or usefulness of any information, apparatus, product, or process disclosed, or represents that its use would not infringe privately owned rights. Reference herein to any specific commercial product, process, or service by trade name, trademark, manufacturer, or otherwise does not necessarily constitute or imply its endorsement, recommendation, or favoring by the United States government or any agency thereof. The views and opinions of authors expressed herein do not necessarily state or reflect those of the United States government or any agency thereof.

This report is available at no cost from the National Renewable Energy Laboratory (NREL) at www.nrel.gov/publications.

Available electronically at SciTech Connect http:/www.osti.gov/scitech

Available for a processing fee to U.S. Department of Energy and its contractors, in paper, from:

U.S. Department of Energy

Office of Scientific and Technical Information

P.O. Box 62

Oak Ridge, TN 37831-0062

OSTI http://www.osti.gov

Phone: 865.576.8401

Fax: 865.576.5728

Email: reports@osti.gov

Available for sale to the public, in paper, from:

U.S. Department of Commerce

National Technical Information Service

5301 Shawnee Road

Alexandria, VA 22312

NTIS http://www.ntis.gov

Phone: 800.553 .6847 or 703.605 .6000

Fax: 703.605.6900

Email: orders@ntis.gov 


\section{Acknowledgments}

For their valuable contributions, the authors would like to thank Joe Vieira, Nancy Keohane, and John Smines from the Colorado BLM, and Elaine Hale, Brady Stoll, Anthony Lopez, Jonathan Dubinsky, and David Hurlbut from the National Renewable Energy Laboratory, Sean Ong from EMI Consulting, and two anonymous reviewers for their valuable input and comments in the completion of this report. The authors would also like to thank ABB for permission to include GIS layers from "The Velocity Suite" in the maps displayed in this report. 


\section{Foreword}

The Bureau of Land Management (BLM) is pleased to present this solar and wind energy analysis for the State of Colorado as completed by the National Renewable Energy Laboratory (NREL). BLM has completed national programmatic studies over the last decade to most effectively allocate public lands in several regions, including Colorado, for the generation of utility-scale solar and wind projects. BLM is aware that there exist complex drivers of solar and wind energy development and renewable energy capacity expansion that encompass both private and public lands, broader energy markets, transmission infrastructure, and such federal and/or state policies as climate change adaptation and renewable energy portfolio standards (RPS), among others. BLM requested an NREL solar and wind energy potential modeling analysis based on varied scenarios and their interpretation at a necessary geographic scale to help the agency and general public understand where in the Colorado landscape solar and wind energy could develop during the next 15-years. The enclosed study provides the framework for a deeper predictive understanding of renewable energy expansion based on business as usual, natural gas prices, increased RPS, and carbon price scenarios with specific focus on the BLM Eastern Colorado Resource Management Planning Area. 


\section{List of Acronyms}

AEO
BA
BLM
CSP
DOE
EPA
ECRMP
GAMS
GIS
NERC
NG
NREL
PSCO
PV
RGFO
RMP
RPM
RPS
TEPPC
TES
VG
WACM
WECC
WWSIS

Annual Energy Outlook

balancing area

U.S. Bureau of Land Management

Concentrating Solar Power

U.S. Department of Energy

Environmental Protection Agency

BLM Eastern Colorado Resource Management Plan

General Algebraic Modeling System

Geographic Information System

North American Electric Reliability Corporation

natural gas

National Renewable Energy Laboratory

Public Service Company of Colorado

photovoltaic

Royal Gorge Field Office

Resource Management Plan

Resource Planning Model

Renewable Portfolio Standard

Transmission Expansion Planning Policy

Committee

Thermal Energy Storage

variable generation

Western Area Power Administration, Colorado, and

Missouri BA

Western Electricity Coordinating Council

NREL Western Wind and Solar Integration Study 


\section{Glossary}

Alternating Current (AC)

Balancing Area

Balancing Authority

Boundary interactions

Buses

Capacity

Capacity Credit

Capacity Expansion Model

Combined Cycle (CC, NG-CC)

Combustion Turbine (CT, NG-CT)

Curtailment

Cycling

Direct Current (DC)

Dispatch modeling

Electrical buses

Electric infrastructure

Electric network

Fixed tilt photovoltaic

GIS analysis

Grid
The standard for electricity transmission, where the flow of electric charge periodically reverses direction

Regional grouping of generators, loads and transmission lines whereby aggregate generation and load are balanced (also referred to as Balancing Authority Area)

Responsible party for balancing load and generation within a balancing area

see Interregional Flows

see Electrical Buses

The maximum generating capability of a generating unit

The fraction of a generating unit's nameplate capacity counted towards meeting system reliability reserves

Computational tool used to simulate electric system deployment

A power plant where a combustion turbine and steam turbine are combined and fueled by natural gas

A natural gas fired power plant driven by an internal combustion engine with an upstream rotating compressor and a downstream turbine

Unused energy, usually from variable generation sources

An electrical generator's transition between online and offline status

The unidirectional flow of electric charge. Direct current is produced by photovoltaic and battery devices

see Operations Modeling

Electric network node, representing transmission line connections, generator connection point, or substation

Physical electric system components (transmission lines, generators, transformers, substations, etc.)

The electric grid, composed of transmission lines, transformers, and substations that transport electricity between generators and loads

Solar photovoltaic generators mounted on a tilted, non-tracking structure

Geographic Information System analysis to enhance location-based result description see Electric Network 
Load

Megawatt $(M W)$

Operating reserve requirements

Operational constraints

Operations modeling

Photovoltaic (PV)

Power system

Reliability (electric)

Renewable capacity expansions

Renewable generation

Renewable resources

Renewable interconnection cost

Single-axis tracking photovoltaic

Transmission congestion

Utility service territory

Utility-scale generation

Variable generation

Western Electric Coordinating Council
Electricity demand

The standard unit of measure of power (e.g., for a power plant output)

Generation scheduling requirements to maintain reliable system operations

Constraints that govern electric system operation (e.g., generator and transmission line operating parameters, security constraints, physical laws)

Simulation of generator scheduling for hourly operation to maintain balanced generation and load and system reliability

Semiconductor-based technology that converts solar energy into electricity

The system, comprised of electrical infrastructure components, that serves to convert and deliver energy in the form of electrical power

The ability of the electric system to continue uninterrupted service

Renewable generation capacity deployment Electricity generation from resources that are naturally replenished on human timescales

The location-dependent energy resources that could potentially be utilized to generate electricity through renewable generation technologies

The cost associated with connecting a renewable generating facility with existing infrastructure (based on distance between renewable generation site and interconnection bus)

Solar photovoltaic generators mounted on a structure that rotates along one axis designed to track the daily relative motion of the sun and the earth

The inability of the electrical grid to facilitate additional electricity transmission due to transmission line flow limits

The load buses served by an electrical utility or load serving entity

Ground mounted generation connected directly to the electrical transmission system (not connected through a distribution feeder).

Electrical generation that depends upon variable energy sources (e.g. wind and solar generation)

WECC - the regional entity that exists to assure a reliable electric system for the Western Interconnection power system 


\section{Executive Summary}

Future renewable power plant development in Colorado will be determined by a combination of market and policy demands as well as the economic competitiveness of renewable technologies relative to other generation options, such as natural gas. However, the amount of renewable generation capacity deployed is driven by the availability and quality of local energy resources and their relative location to transmission infrastructure or metropolitan and other areas with high electricity consumption. An informed outlook of the future electricity system in Colorado will require detailed considerations of these dynamics and constraints. Such an outlook can be useful for utility and land planners in assessing investment and policy decisions over the next two decades.

The Royal Gorge Field Office of the U.S. Department of Interior's Bureau of Land Management (BLM) commissioned the National Renewable Energy Laboratory (NREL) to conduct an assessment of potential trends in future renewable energy technology development within the state of Colorado. BLM requested analysis to help the agency and general public understand the locations of potential solar and wind energy developments over a 15-year horizon in Colorado. This analysis uses a combination of electric system capacity expansion modeling and geographic information system (GIS) tools and is intended to help inform the BLM during the multi-year development of a new Eastern Colorado Resource Management Plan (ECRMP). ${ }^{1}$ RPM results highlight trends in Colorado that will help BLM identify areas to consider for renewable energy development allocations in resource management plans.

More specifically, our analysis highlights regions within Colorado where future utility-scale wind and solar generation development might take place based on scenarios developed using NREL's Resource Planning Model (RPM). We use RPM to simulate multiple scenarios of the future power system in Colorado and the U.S. West through 2030. These scenarios include a Reference scenario and scenarios that span a range of potential natural gas price projections developed by the U.S. Energy Information Administration (EIA). On the low end, this range captures a future where delivered natural gas prices remain below $\$ 4 / \mathrm{MMBtu}$ for all years through 2030 and on the high end, natural gas prices consistently grow after 2015 , reaching about $\$ 8 / \mathrm{MMBtu}$ in $2030 .^{2} \mathrm{We}$ also model two scenarios that represent proxies for future energy policies that would support a move towards renewable or other low-carbon generation: a scenario wherein $\mathrm{CO}_{2}$ prices grow to about $\$ 32$ per metric ton $\mathrm{CO}_{2}$ by 2030 and a scenario with an effective $50 \%$ renewable energy standard in Colorado that would be achieved by 2030 . These scenarios do not imply any policy recommendations, but are modeled to assess - as is common in utility portfolio planning-how renewable development might increase given heightened policy support for lower-carbon generation. ${ }^{3}$ More generally, none of the scenarios should be interpreted as predictions or forecasts from NREL or the U.S. Department of Energy.

\footnotetext{
${ }^{1}$ The ECRMP region consists of land areas in Colorado east of the continental divide.

${ }^{2}$ Unless otherwise noted, we use real 2010 dollars throughout.

${ }^{3}$ The modeling analysis included energy policies and regulations as of January 1, 2015. As such, it does not include the EPA's CPP finalized in August 2015, nor does it include the extended federal renewable energy tax credits passed in December 2015. Future work is needed to assess the impacts of these policies on renewable development in Colorado.
} 
RPM is designed to represent the integrated effects of multiple complex factors (e.g., load growth, plant retirements, policy demands, renewable grid integration, etc.) that will affect electric infrastructure investments. However, it does not consider factors outside the sector such as the impact on local employment, productivity, health, ecological impact, or other more general economic interactions. Additionally, RPM does not capture differences in permitting, siting, and other challenges associated with land ownership types (e.g., public, private, BLM).

We supplement the RPM analysis with a GIS analysis that enables visual inspection of model results and development opportunities on lands categorized under four distinct ownership types: BLM-administered, non-BLM federal, private, and other. ${ }^{4}$ To this end we analyze RPMgenerated future portfolios in the context of three different land development preference assumptions. These assumptions specify which land types are used for renewable generation capacity development in order of priority:

- Proportional preference. Assumes that new generation capacity simulated in the RPM scenarios is built on each of the four categories of land ownership proportional to the distribution of suitable land area of each ownership type within each model region.

- BLM preference. Assumes that development takes place with the following priority order: BLM-administered land, non-BLM federal, other ${ }^{4}$, and private land.

- Private preference. Assumes that development takes place with the following priority order: private land, other, non-BLM federal, and BLM-administered lands.

The purpose of these land development preference assumptions is to provide a reasonable range of BLM-administered land areas that could be used for future renewable development.

Application of the land development preference assumptions provides bounding estimates of the possible land area requirements for renewable development within each of the four land ownership categories across all modeled scenarios. In addition to the GIS assessment of the RPM scenario results, we also present high-resolution GIS-based data of suitable land areas for wind and solar development and their proximity to existing transmission infrastructure for multiple regions within Colorado.

\section{Key findings:}

- In the modeled scenarios, RPM finds that new capacity additions are dominated by renewable technologies across the Western Interconnection and in Colorado:

- Under a Reference scenario in the Western Interconnection, 35,000 MW of new wind and 48,000 MW of new solar capacity are estimated between 2011 and 2030. Wind and solar are estimated to produce $19 \%$ of all generation in 2030 .

- Wind technologies comprise the dominant share of all new Colorado capacity with 4,428 MW of new wind during 2011-2030 (1,558 MW of new solar) in the

\footnotetext{
4 “Other" land ownership includes jointly owned, non-governmental organization, regional/local, state, tribal, and unknown.
} 
Reference scenario. In 2030, wind and solar are estimated to contribute $30 \%$ of Colorado in-state generation.

- The low gas price sensitivity yields similar results to the Reference scenario; however, under higher gas prices, much greater renewable development is observed. Under the High Gas price scenario, 6,395 MW of new wind and 2,638 MW of new solar is estimated between 2011 and 2030 in Colorado.

- The clean energy policy sensitivities explored show greater renewable technology development. Under the scenario which imposes a $\mathrm{CO}_{2}$ price, we find 10,002 $\mathrm{MW}$ of new wind and 1,635 MW of new solar in Colorado by 2030. With an expanded $(50 \%$ by 2030$)$ renewable requirement, we estimate $5,758 \mathrm{MW}$ of new wind and 1,572 MW of new solar in Colorado.

- Across all modeled scenarios, the geographic distribution of new renewable capacity additions in Colorado is limited to a relatively few resource regions within the state where the resource quality is high.

- New utility-scale solar capacity additions are estimated to take place predominantly in the southern part of the state, e.g., in the San Luis Valley. (Rooftop PV installations are more widespread, but are assumed to be somewhat concentrated in the relative population-dense Front Range.)

- New wind capacity additions are concentrated in the northeast and, to a lesser degree, southeast regions of the state.

- The amount of Colorado land area needed to accommodate new renewable capacity additions through 2030 range from 336,000 to 824,000 acres across all five modeled scenarios.

- In the ECRMP region (Eastern Colorado), the estimated use of most of the required land area is for wind development. For example, under the highest wind development scenario $\left(\mathrm{CO}_{2}\right.$ price scenario), 822,000 acres of land are needed for wind development.

- Wind development is consistently estimated in and near Huerfano County across all scenarios due to the region's high-quality wind resource potential and proximal location of existing transmission infrastructure.

- Under most scenarios, a more limited amount of land area is needed for utilityscale solar development ( $\sim 50$ acres in all of Colorado). With high natural gas prices, land area requirements for solar grows to 4,181 acres in the state; however, the vast majority of this area is outside the ECRMP region.

- The greatest opportunities for renewable energy development appear to exist on private lands. BLM-administered lands are not necessarily needed to accommodate new renewable capacity additions across any of the scenarios in any of the regions. 
- When prioritizing private lands, no BLM-administered lands will be needed to accommodate future renewable development estimated in the RPM scenarios.

O On the other hand, when applying a BLM preference to land development, we find that the most aggressive RE development scenario $\left(\mathrm{CO}_{2}\right.$ price scenario $)$ could use up to 53,600 acres of BLM land in Colorado, of which 52,000 acres are in the ECRMP region, to support new renewable (primarily wind) capacity additions.

- A proportional distribution of land ownership preferences would lower estimated BLM land area for renewable development to up to 1,070 acres in Colorado, virtually all of which is in the ECRMP region.

- The limited need for BLM-administered lands to be used for renewable capacity additions can be explained through the relative difference in the amount of renewablesuitable land areas that are BLM-administered and privately owned.

- BLM-administered, wind-suitable land area within 10 miles of the nearest transmission infrastructure totals 45,000 acres (capable of supporting $~ 500 \mathrm{MW}$ ) in the ECRMP region compared to 9,000,000 acres (capable of supporting $100,000 \mathrm{MW})$ that are privately owned.

- BLM-administered, utility-scale, solar-suitable land area within 10 miles of the nearest transmission infrastructure totals 16,000 acres in the ECRMP region compared to $10,000,000$ acres of private land.

These findings are derived using the methodologies and assumptions presented in the report. Our methods do not attempt to comprehensively consider the siting or permitting steps undertaken to develop renewable or other power generation capacity. In addition, energy policies and markets often evolve rapidly, and thus uncertainties in the effects of markets and policies on renewable generation deployment exist over the full study horizon. Because of these limitations and uncertainties, as well as other caveats associated with the methods, the local development estimates should not be considered predictive forecasts of renewable energy deployment, but rather scenarios exploring how market and policy conditions will impact future renewable energy deployment. Nonetheless, our analysis identifies some general trends that could help inform electric infrastructure and land planning in and around the state of Colorado. 


\section{Table of Contents}

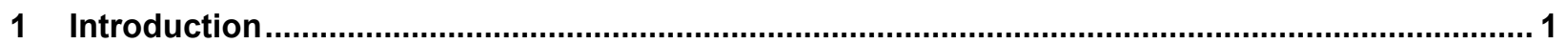

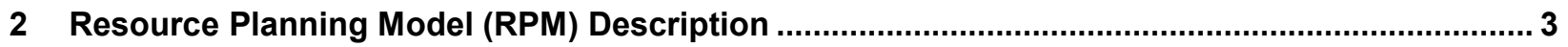

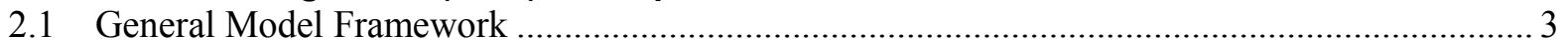

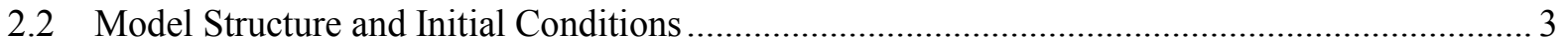

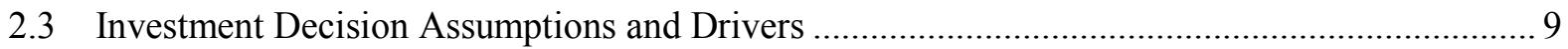

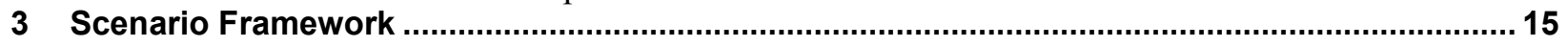

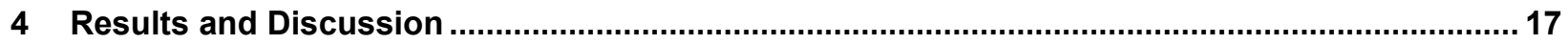

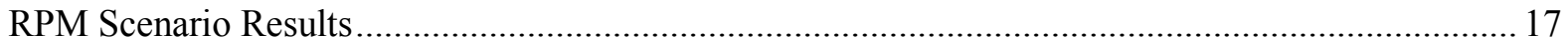

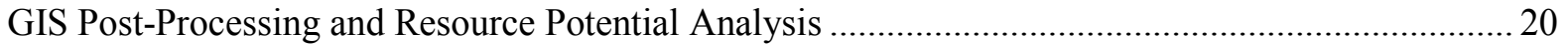

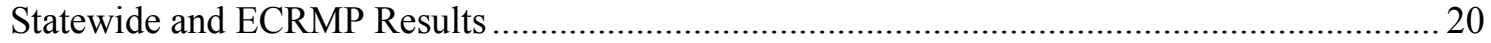

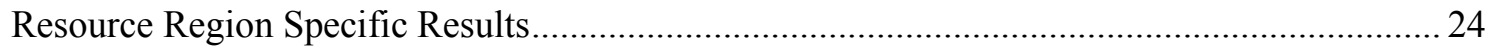

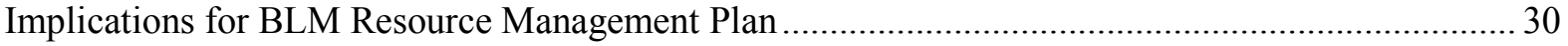

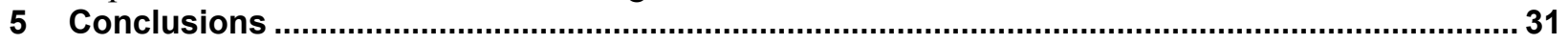

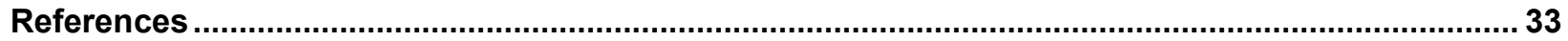

Appendix

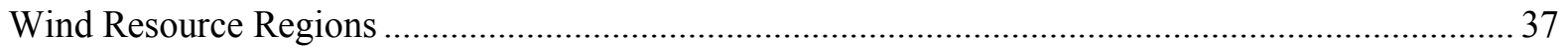

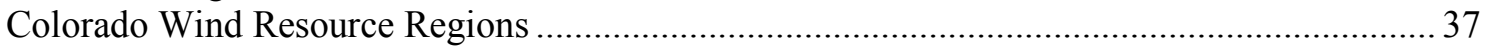

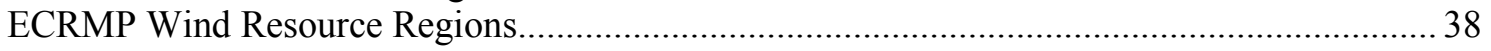

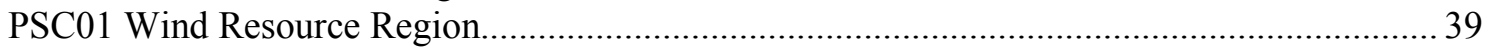

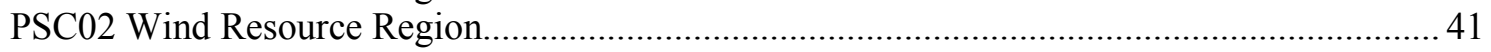

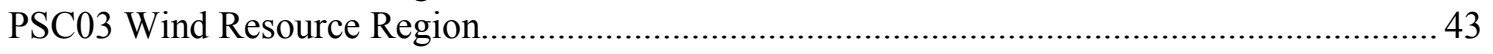

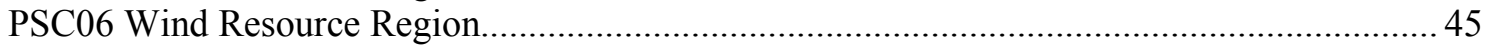

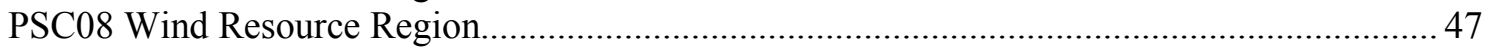

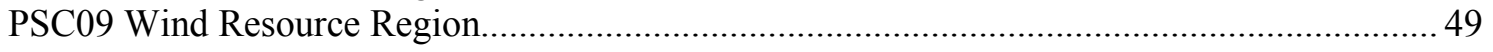

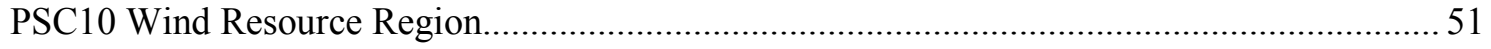

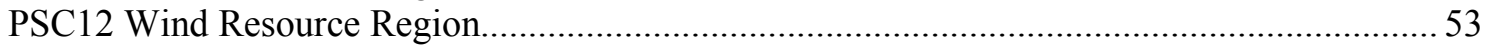

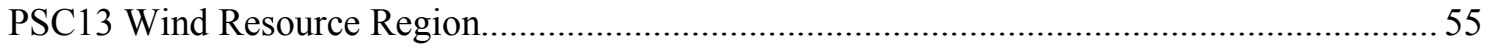

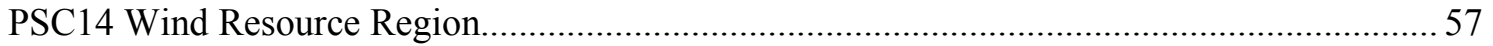

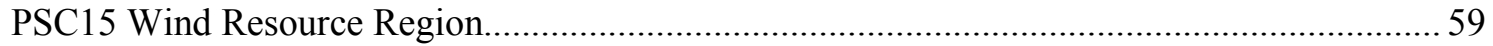

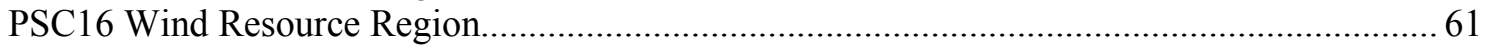

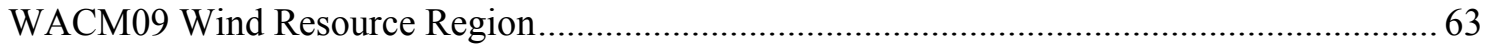

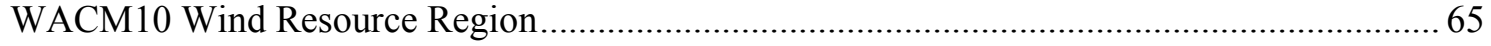

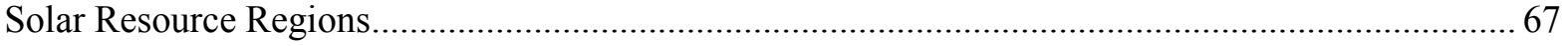

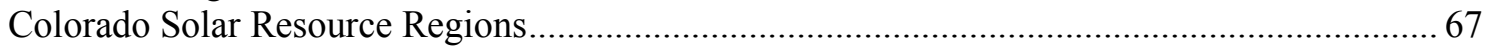

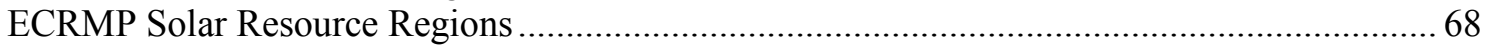

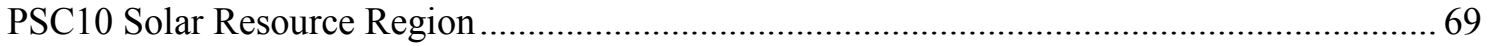

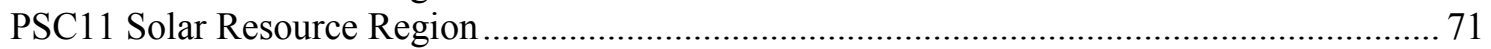

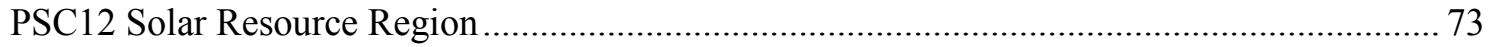

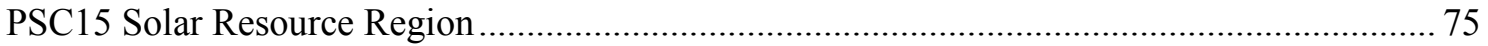

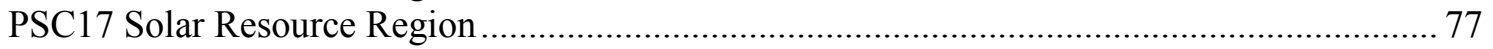

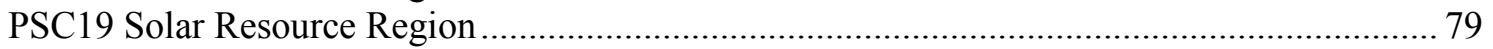

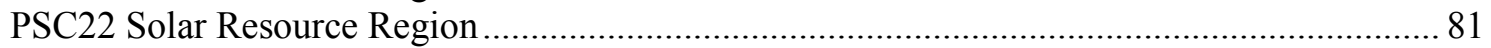

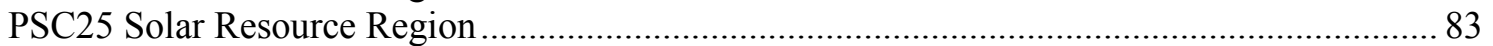




\section{List of Figures}

Figure 1. Combined zonal/nodal structure used for the CO-centric version of RPM ............................... 5

Figure 2. Solar (left) and wind (right) resource regions modeled in the CO-centric version of RPM......... 9

Figure 3. Assumed delivered natural gas, coal, and uranium AEO 2015 price trajectories from 2010 to 2030 (EIA 2015)

Figure 4. Assumed reference, low, and high AEO 2015 natural gas price trajectories (EIA 2015)

Figure 5. Assumed median $\mathrm{CO}_{2}$ price...................................................................................... 16

Figure 6. Installed generation capacity in the Western Interconnection for the reference scenario ........... 17

Figure 7. Installed generation capacity in the Colorado-centric focus region for the reference scenario... 18

Figure 8. Differences in 2030 capacity in the Western Interconnection with respect to the reference scenario

Figure 9. Differences in 2030 capacity in the Colorado-centric focus region with respect to the reference scenario

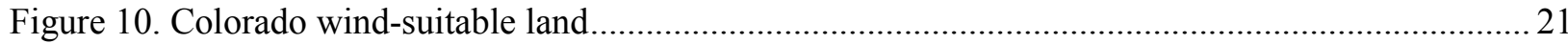

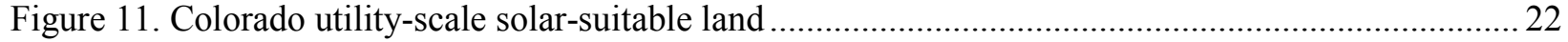

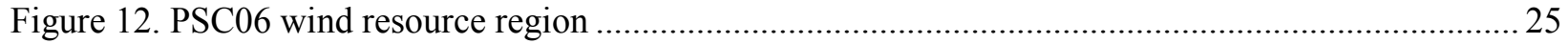

Figure 13. Wind: PSC06 - proportional development preference ….................................................... 26

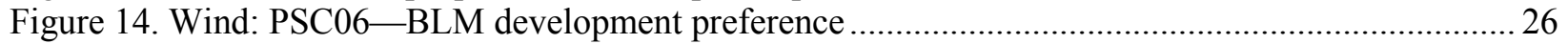

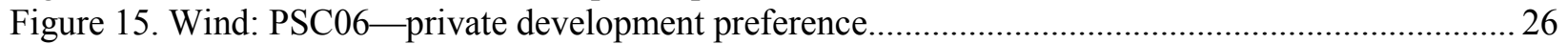

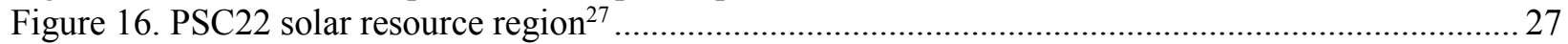

Figure 17. Solar: PSC22 - proportional development preference ……................................................ 28

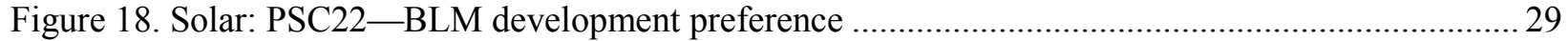

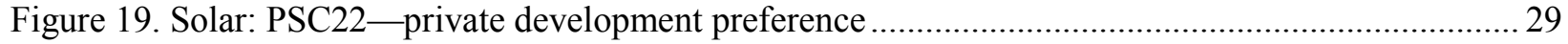

\section{List of Tables}

Table 1. Balancing Areas (BAs) Modeled in the Resource Planning Model............................................. 6

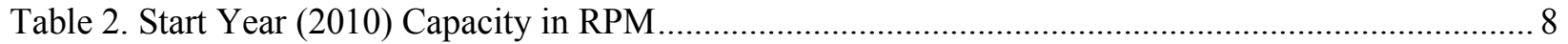

Table 3. Technology Cost and Performance Assumptions for New Generation Capacity ........................ 11

Table 4. Colorado-Wind-Suitable Land: Area and MW Potential ....................................................... 21

Table 5. Colorado-Solar-Suitable Land: Area and MW Potential........................................................ 22

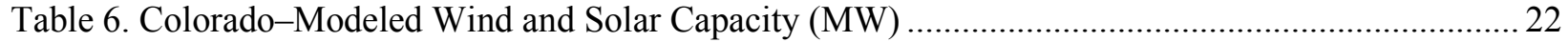

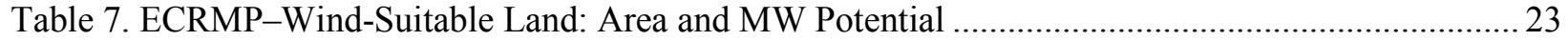

Table 8. ECRMP-Solar-Suitable Land: Area and MW Potential ............................................................2 23

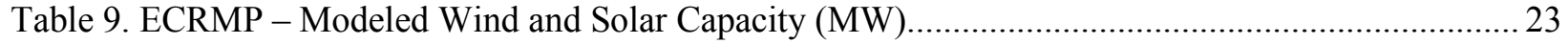

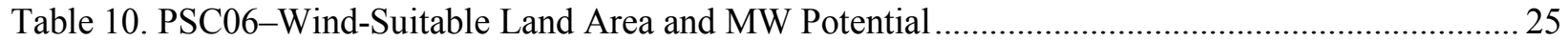

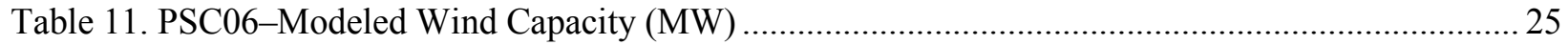

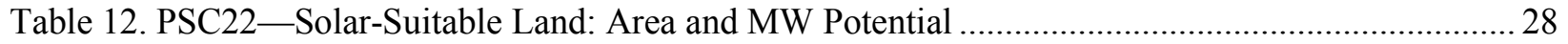

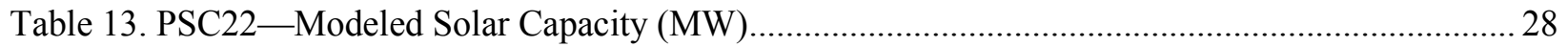




\section{Introduction}

The United States Bureau of Land Management (BLM) is responsible for managing public lands and natural resource values. The BLM develops comprehensive land use plans called Resource Management Plans (RMP) to guide management decisions and actions on BLM-administered public lands. Currently, the Royal Gorge Field Office of the BLM is in the multi-year process of developing a new Eastern Colorado Resource Management Plan (ECRMP). This plan will address the full range of activities that occur on public lands, including off-highway vehicle (OHV) use, wildland fire management, wildlife management, mineral development, and livestock grazing. RMPs also direct management of areas on public lands that require special protection, such as areas of critical environmental concern (ACECs), research natural areas (RNAs), and potential additions to the National Wild and Scenic River (WSR) System. Renewable energy development is one of the aspects that will be analyzed in the RMP and this report will help inform the decisions that are made by highlighting likely trends for renewable energy deployment within Colorado.

Recent and anticipated trends indicate that renewable resources, particularly wind and solar energy, will continue to provide a growing contribution to the Colorado and western United States power systems (Mai et al. 2012; WECC 2011a). These renewable resources are variable and uncertain by nature and their geographical distribution and potential impacts on electric system expansion and operation need to be properly accounted for in electric system planning models.

The National Renewable Energy Laboratory's (NREL's) Resource Planning Model (RPM) has high spatial and temporal resolution that can be used for mid- and long-term scenario planning of regional power systems across broad geographic regions. RPM simulates the addition of new generation and transmission to meet projected future electricity demand reliably and at the least cost, subject to a set of constraints and assumptions that define the future scenario being modeled. A detailed description of RPM is provided by Mai et al. (2015) and the modeling assumptions used in this study can be found in Section 2.

As a part of the multi-year BLM RMP process, this study was requested by the ECRMP planning staff to analyze a suite of issues around renewable energy deployment in Colorado, including:

- Potential demand for renewable energy ${ }^{5}$ in Colorado between 2015 and 2030, and the geographic regions of the state where future renewable energy and transmission corridor enhancement is likely to take place based on a number of factors including resource potential, access to load, access to existing transmission and corridors, and overall costs of production.

\footnotetext{
${ }^{5}$ RPM simulations and analysis focus on utility-scale renewable energy deployment. For the analysis presented here, the model simulates deployment of land-based wind, and utility-scale solar. While geothermal, hydropower, biopower and other renewable technology deployment are all possible; they have not received the same level of deployment in recent years and their expansion is not modeled in RPM. For rooftop solar power, we use an exogenously-defined deployment projection from a separate model (Sigrin et al. forthcoming).
} 
- The suitability and potential likelihood that some of those future renewable energy and/or transmission projects might be sited on BLM surface lands within Colorado in general and the ECRMP planning region in particular.

- How future changes in state or federal policies, or fuel prices (e.g., Colorado's Renewable Portfolio Standard increases to $40 \%$, a range of environmental policies, a range of natural gas prices) impact the potential need for renewables and transmission.

We model two balancing areas (BAs) that maintain electricity supply-demand balance in and around Colorado (see Table 1): Public Service Company of Colorado (PSC), and Western Area Colorado Missouri (WACM). ${ }^{6}$ A description of the model, including the structure and definition of the geographic regions, key assumptions used, and detail on how the optimizes expansion and operation of the electricity system is presented in Section 2. A description of the scenarios exploring a range of future natural gas prices and energy and environmental policies is presented in Section 3. The analysis, summarized in Section 4, focuses on 2015-2030 planning scenarios for renewable technology deployment on BLM lands within Colorado. Additional regional detail is provided in the Appendix. We conclude in Section 5.

\footnotetext{
${ }^{6}$ The WACM and PSC balancing areas include regions and infrastructure from rural electric cooperatives and other load-serving entities in Colorado and neighboring states.
} 


\section{Resource Planning Model (RPM) Description}

The NREL's Resource Planning Model (RPM) simulates the evolution of regional electric power systems. The model represents the capitol and operational costs associated with building and operating electrical infrastructure. RPM draws from a variety of datasets to represent existing electricity generation and transmission infrastructure, land use and availability, weather patterns, demand and cost projections, and energy and environmental policies and regulations. Model results can be used to analyze the effects of policy, technology advancement, and economic futures in terms of the type and location of electricity production and new infrastructure. Descriptions of RPM structure, scope, inputs, and assumptions are included in the remainder of this section.

\subsection{General Model Framework}

The NREL's Resource Planning Model (RPM) is a capacity expansion model designed for a regional power system, such as a utility service territory, state, or balancing authority. It includes an optimization model that finds the least-cost investment and dispatch solution over a 20 -year horizon. The model investment decisions are made for multiple conventional and renewable generation technologies, storage technologies, and transmission. The model uses a highly spatially disaggregated representation of grid infrastructure and generation resources (down to the individual unit and line) and multiple solar and wind spatial resource regions. Dispatch modeling within RPM is conducted using hourly time-steps sampled throughout a year, and the model considers energy balance, reserves, and many generator performance and operational constraints. Transmission constraints are represented with a transport (pipe-flow) model. RPM is designed for analysis that focuses on a specific region while maintaining a representation of inter-regional transactions. A simplified representation of the rest of the interconnection in which the region of interest resides is included in the model to account for boundary interactions. We designed RPM specifically to consider the characteristics of wind and solar technology resources - that is, location-dependence, variability, and uncertainty - in its investment decisions; it accounts for renewable interconnections, endogenously-estimated capacity credits, increased operating reserve requirements, curtailment, transmission congestion, and cycling costs.

RPM formulates an optimization problem that minimizes overall system cost, including capital costs, fixed and variable operation and maintenance (O\&M) costs, fuel costs, and start-up costs. All costs in the objective function, including operating costs (e.g., fuel and variable O\&M costs) and fixed costs (e.g., amortized capital and fixed O\&M costs), are annualized. Several constraints are designed to characterize power plant operation, transmission dispatch, grid reliability, and capacity expansion. Sections 2.2, 2.3, and 2.4 summarize the key features of the model and highlight those that differ from the version described in (Mai et al. 2013).

\subsection{Model Structure and Initial Conditions}

RPM models the Western Interconnection electricity system, which includes all or parts of 13 western states in the United States, two western provinces in Canada, and a small northern region of Mexico. Data from modeling in the Western Wind and Solar Integration Study (WWSIS) 
Phase 2 study (Lew et al. 2013) ${ }^{7}$ comprise the underlying data for the existing (2010) infrastructure modeled in RPM. ${ }^{8}$ These data include 17,521 nodes, 4,300 generation units, and 21,086 transmission lines. ${ }^{9}$ While the spatial extent of RPM covers a wide geographic area, the model is designed for a particular "focus region," with all other regions treated in a simplified manner; that is, RPM is a combined nodal (for nodes within the focus region) and zonal model (for zones outside the focus region). For this analysis, we use a Colorado-centric focus region that includes PSC and WACM balancing areas. Figure 1 shows the zonal structure of BAs outside the focus region along with the nodal structure within the Colorado-centric focus region. Nodes represent electrical buses connected to individual generators and loads, or buses that serve as connection points between transmission elements, e.g., transmission lines and transformers. There are 36 model BAs throughout the Western Interconnection (see Table 1). For this study, we aggregate nodes within the $34 \mathrm{BAs}$ outside of the Colorado-centric focus region to form the zones. $^{10}$

\footnotetext{
${ }^{7}$ The WWSIS Phase 2 study relied on data from the Western Electricity Coordinating Council (WECC) Transmission Expansion Planning Policy Committee (TEPPC) 2020 Common Case (WECC 2011b) with updates from the TEPPC 2022 Common Case (WECC 2013) along with other revisions as described by (Lew et al. 2013). ${ }^{8}$ While the model start year begins in 2010 , the data for the 2015 solve year includes many recent capacity additions and retirements. In addition, our analysis is primarily focused on 2015-2030.

${ }^{9}$ Only transmission lines greater than $69 \mathrm{kV}$ are included in the database.

${ }^{10}$ In addition to zonal transmission treatment, generators are aggregated for most technology types for each BA zone to further simplify the model outside of the focus region.
} 


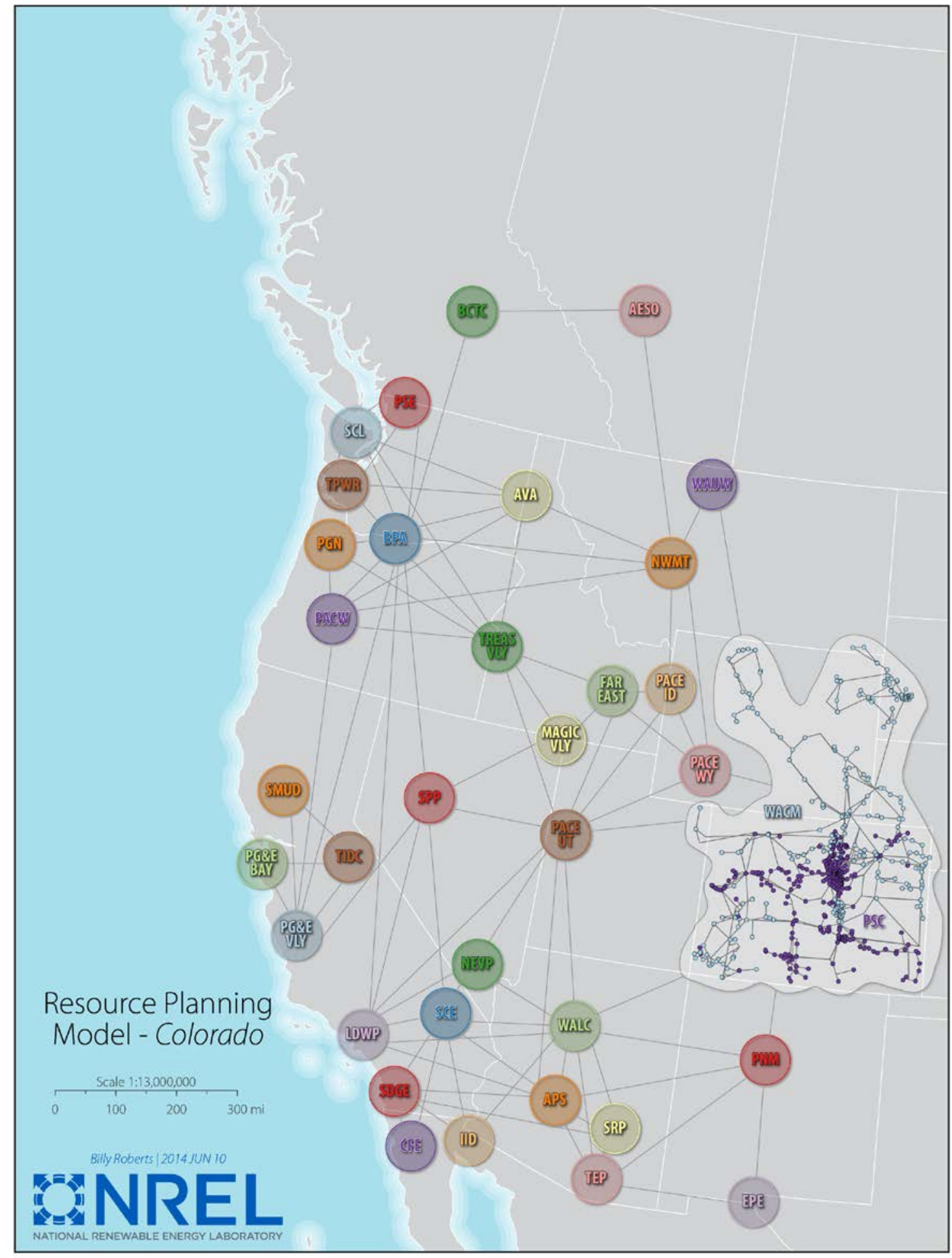

Figure 1. Combined zonal/nodal structure used for the CO-centric version of RPM 
Table 1. Balancing Areas (BAs) Modeled in the Resource Planning Model

\begin{tabular}{|c|c|c|c|c|c|}
\hline \multicolumn{2}{|c|}{ Focus Region BAs } & \multicolumn{4}{|c|}{ Other BAs } \\
\hline PSC & $\begin{array}{l}\text { Public Service } \\
\text { Company of Colorado }\end{array}$ & AESO & $\begin{array}{l}\text { Alberta Electric } \\
\text { System Operator }\end{array}$ & $\begin{array}{l}\text { PG\&E_BA } \\
Y\end{array}$ & $\begin{array}{l}\text { Pacific Gas \& Electric } \\
\text { Bay Area }\end{array}$ \\
\hline WACM & $\begin{array}{l}\text { Western Area Power } \\
\text { Administration } \\
\text { Colorado/Missouri }\end{array}$ & APS & Arizona Public Service & $\begin{array}{l}\text { PG\&E_VL } \\
Y\end{array}$ & $\begin{array}{l}\text { Pacific Gas \& Electric } \\
\text { Valley Area }\end{array}$ \\
\hline & & AVA & Avista & PGN & $\begin{array}{l}\text { Portland General } \\
\text { Electric }\end{array}$ \\
\hline & & ВСТC & $\begin{array}{l}\text { British Columbia } \\
\text { Transmission } \\
\text { Corporation }\end{array}$ & PNM & $\begin{array}{l}\text { Public Service New } \\
\text { Mexico }\end{array}$ \\
\hline & & BPA & $\begin{array}{l}\text { Bonneville Power } \\
\text { Administration }\end{array}$ & PSE & Puget Sound Energy \\
\hline & & CFE & $\begin{array}{l}\text { Comisión Federal de } \\
\text { Electricidad }\end{array}$ & SCE & $\begin{array}{l}\text { Southern California } \\
\text { Edison }\end{array}$ \\
\hline & & EPE & $\begin{array}{l}\text { El Paso Electric } \\
\text { Company }\end{array}$ & SCL & Seattle City Light \\
\hline & & FAR_EAST & Far East & SDGE & $\begin{array}{l}\text { San Diego Gas \& } \\
\text { Electric }\end{array}$ \\
\hline & & IID & $\begin{array}{l}\text { Imperial Irrigation } \\
\text { District }\end{array}$ & SMUD & $\begin{array}{l}\text { Sacramento Municipal } \\
\text { District }\end{array}$ \\
\hline & & LDWP & $\begin{array}{l}\text { Los Angeles } \\
\text { Department of Water } \\
\text { and Power }\end{array}$ & SPP & Sierra Pacific Power \\
\hline & & $\begin{array}{l}\text { MAGIC_VL } \\
Y\end{array}$ & Magic Valley & SRP & Salt River Project \\
\hline & & NEVP & Nevada Power & TEP & Tucson Electric Power \\
\hline & & NWMT & Northwestern Montana & TIDC & $\begin{array}{l}\text { Turlock Irrigation } \\
\text { District }\end{array}$ \\
\hline & & PACE_ID & Pacificorp East - Idaho & TPWR & Tacoma Power \\
\hline & & PACE_UT & Pacificorp East Utah & $\begin{array}{l}\text { TREAS_V } \\
\text { LY }\end{array}$ & Treasure Valley \\
\hline & & PACE_WY & $\begin{array}{l}\text { Pacificorp East } \\
\text { Wyoming }\end{array}$ & WALC & $\begin{array}{l}\text { Western Area Power } \\
\text { Administration Lower } \\
\text { Colorado }\end{array}$ \\
\hline & & PACW & Pacificorp West & WAUW & $\begin{array}{l}\text { Western Area Power } \\
\text { Administration Upper } \\
\text { Missouri }\end{array}$ \\
\hline
\end{tabular}


For our analysis, the focus region includes the PSC and WACM BAs. Throughout the report, we refer to this region as the CO-centric focus region, because these two balancing authorities primarily serve loads in Colorado (CO). ${ }^{11}$ The CO-centric focus region includes 1,406 nodes and 1,840 transmission lines, and includes 376 individual generators representing a total of 16,805 MW of installed capacity during the model start year (2010). Outside the focus region, 34 model BAs are represented zonally. The entire Western Interconnection system includes 224,244 MW of generating capacity for the model start year. Interactions between BAs are constrained by interface limits assumed by (Lew et al. 2013). Interactions between nodes within the focus region consider nodal transmission constraints defined by the thermal power flow limits on transmission lines. Figure 1 shows the combined zonal and nodal structure of RPM and the Colorado-centric focus region analyzed here.

Table 2 shows the capacity mix by technology category as represented in RPM for the 2010 start year for the focus region and the entire Western Interconnection. Note that while the technology categories are generalized in Table 2, individual unit characteristics (e.g., ramp rates, heat rates, and maximum generation points) from (Lew et al. 2013) are used in RPM explicitly for the focus region and averaged by technology category for the BAs in the rest of the Western Interconnection.

\footnotetext{
${ }^{11}$ The PSCO and WACM BAs also include nodes in Wyoming, Montana, Nebraska, South Dakota, and Utah.
} 
Table 2. Start Year (2010) Capacity in RPM ${ }^{12}$

\begin{tabular}{|c|c|c|}
\hline Generator Type & $\begin{array}{l}\text { PSCO and WACM Focus } \\
\text { Region (MW) }\end{array}$ & $\begin{array}{l}\text { Entire Western } \\
\text { Interconnection (MW) }\end{array}$ \\
\hline Coal & 7,331 & 38,529 \\
\hline Coal Cogeneration & 0 & 289 \\
\hline Natural Gas Combined Cycle (NG-CC) & 2,778 & 45,505 \\
\hline $\begin{array}{l}\text { Natural Gas Combustion Turbine (NG- } \\
\text { CT) }\end{array}$ & 3,223 & 16,659 \\
\hline Gas Cogeneration & 0 & 3,821 \\
\hline Gas Steam & 222 & 19,601 \\
\hline Nuclear & 0 & 9,681 \\
\hline Biomass & 0 & 1,559 \\
\hline Geothermal & 0 & 3,054 \\
\hline Hydropower - Fixed & 1,188 & 17,395 \\
\hline Hydropower - Flexible & 87 & 52,593 \\
\hline Pumped Hydropower Storage & 560 & 3,787 \\
\hline Solar Photovoltaic (PV) - Fixed-Tilt & 8 & 74 \\
\hline Solar PV - Single-Axis Tracking & 0 & 0 \\
\hline Solar PV - Rooftop & 3 & 1,098 \\
\hline $\begin{array}{l}\text { Concentrating Solar Power (CSP) } \\
\text { without Thermal Energy Storage (TES) }\end{array}$ & 0 & 428 \\
\hline CSP with TES & 0 & 0 \\
\hline Wind & 1,405 & 10,171 \\
\hline Total & 16,805 & 224,244 \\
\hline
\end{tabular}

In addition to nodes and model BAs, RPM includes additional spatial layers to represent the resource potential and electricity production capability of solar and wind technologies. These renewable generation resources are considered by RPM as options to meet future electrical load, subject to capital, interconnection, and operations costs. To apply greater resolution to the COcentric focus region, the focus region contains 40 solar and 40 wind resource regions (see Figure 2) while the remaining 60 solar and 60 wind regions reside in the rest of the Western Interconnection. Renewable resource potential (in acres of land area), performance (annual and hourly capacity factors), and grid interconnection distances are used to characterize the solar or wind resources available for capacity expansion in each renewable region. ${ }^{13}$ A detailed description of the clustering methods used to generate wind and solar resource regions is provided in (Getman et al. 2015).

\footnotetext{
${ }^{12}$ The system simulated in 2010 represents existing infrastructure only. Capacity expansions are not allowed until the next simulated year (2015).

${ }^{13}$ Multiple interconnection points (buses) are available to connect any individual wind or solar resource region. The specific interconnection point or points used is a model decision.
} 

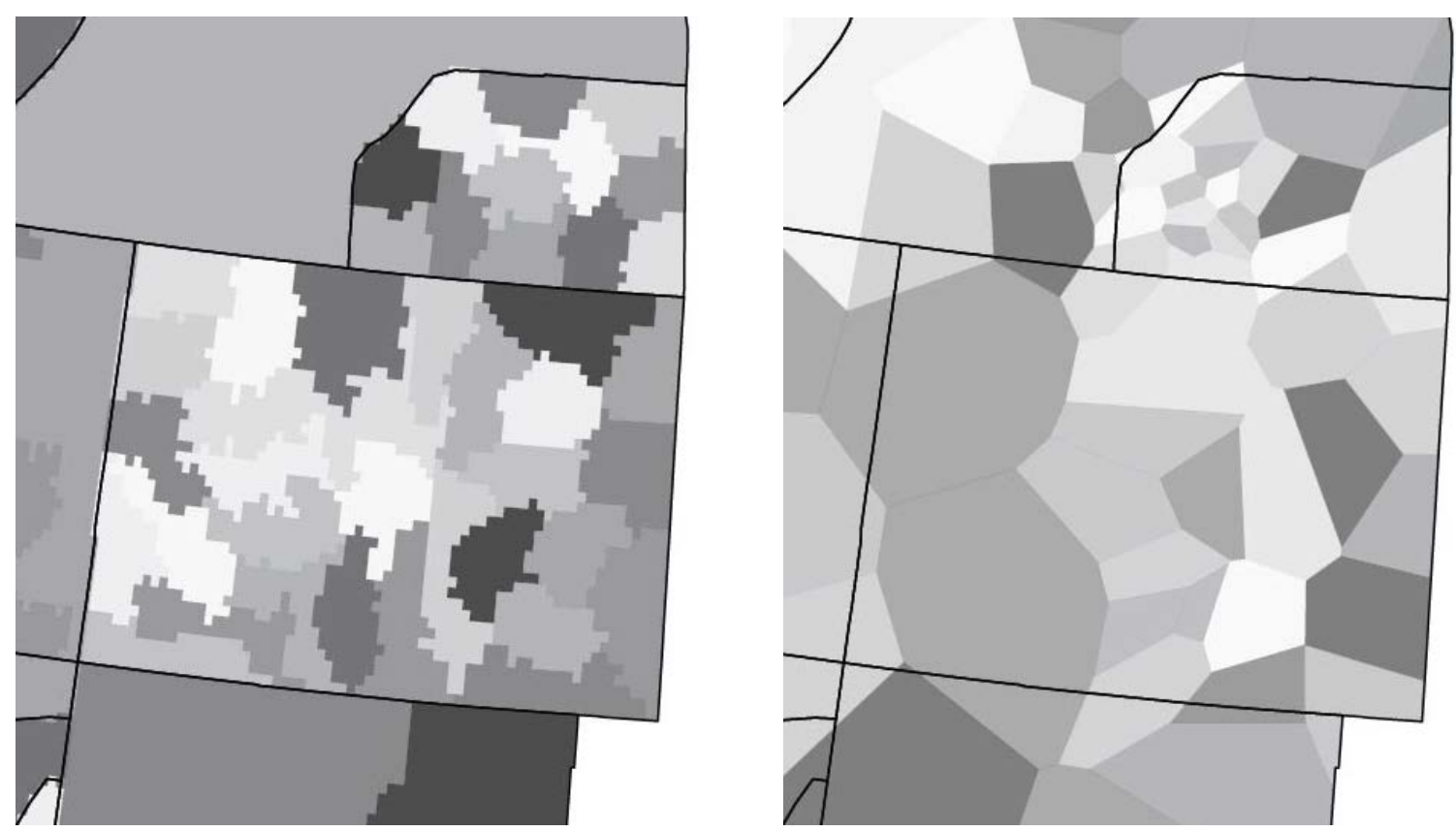

Figure 2. Solar (left) and wind (right) resource regions modeled in the CO-centric version of RPM

RPM is a sequential optimization model that starts in 2010 and ends in 2030, advancing in 5-year increments. Thus, RPM simulates the electric system in 2010, 2015, 2020, 2025, and 2030. For the 2010 simulation, the optimal solution is based solely on simulating existing system operations and excludes any investment decisions. ${ }^{14}$ In other words, the 2010 installed capacity reflects the infrastructure as represented in the model database from (Lew et al. 2013), and we allow RPM to dispatch that capacity subject to dispatch constraints. A detailed description of constraints and a comparison with actual 2010 generation data are provided in (Mai et al. 2015). For all future solve years $(2015,2020,2025$, and 2030), new capacity investment decisions are considered in the model (see Section 2.4).

\subsection{Investment Decision Assumptions and Drivers}

Investment decisions in RPM are made simultaneously with the dispatch modeling. In this section, we briefly describe the model treatment of certain topics that directly influence investment decisions, and we provide the key assumptions used in our analysis for the key technologies relevant to our analysis, including natural gas-fired, wind, and solar PV technologies. ${ }^{15}$ The restriction to this small set of technologies are motivated by deployment trends in recent years and to accommodate computational tractability. We acknowledge that this is a model limitation and that deployment of new capacity from other technologies is expected, at least to limited amounts.

\footnotetext{
${ }^{14}$ For projects that either have been installed since 2010 or are in later stages of development, we exogenously include them in RPM. Similarly, retirements and announced retirements are exogenously considered as well. ${ }^{15}$ RPM includes many other technologies as shown in Table 2, some of which may play important roles in the future. Nonetheless, our analysis is restricted to new natural gas-fired, wind, and solar PV technologies.
} 
Table 3 shows the assumed technology costs and performance used in our analysis. Data for natural gas-fired technologies are consistent with those found in the National Renewable Energy Laboratory's Annual Technology Baseline (Blair et al. 2015), which relies on data from the Annual Energy Outlook 2015 Reference scenario (EIA 2015) for natural gas-fired technologies, DOE reports (Margolis, Coggeshall, and Zuboy 2012) for solar technologies, and the DOE Wind Vision Study (DOE 2015) for wind technologies. The overnight capital costs shown in Table 3 include costs of all equipment up to the plant gate and do not include the spur line and financing costs, which are included separately in the model. ${ }^{16}$ Spur line or interconnection costs for new renewable capacity vary between resource regions and depend on the distance between the centroid of the wind or solar resource region and the connected bus. RPM also includes financing costs (Sullivan et al. 2015) that vary between technologies to account for differences in construction periods, accelerated tax depreciation rules, and investment tax credits. ${ }^{17}$

Other plant parameters, particularly for NG plants, are also used in RPM and are described in (Mai et al. 2015). Reference scenario assumed fuel costs are shown in Figure 3 and are based on national fuel projections from the Annual Energy Outlook 2015 Reference scenario (EIA 2015). Additional fuel cost trajectories for scenario analysis are described in Section 3. Fuel costs are assumed to be uniform across regions and without seasonal or diurnal variations within each solve year. While volatility and uncertainty exists for fuel prices, particularly for natural gas, fuel sensitivities are not included in our analysis. We do not include foresight, such as for fuel price forecasts, in RPM.

\footnotetext{
${ }^{16}$ Real 2010 dollars are used throughout this report unless otherwise noted.

${ }^{17}$ RPM uses technology-specific fixed charge rates. Fixed charge rates for NG-CC, NG-CT, wind, and solar PV are $0.117,0.111,0.098$, and 0.084 , respectively, for all years with the exception of a fixed charge rate of 0.062 for solar $\mathrm{PV}$ in 2015 to represent the 30\% investment tax credit available before 2017 (the analysis was completed before tax credit extensions were passed in December 2015). These fixed charge rates are used to calculate amortized capital over 20 years using a nominal weighted average cost of capital of $8.1 \%$.
} 
Table 3. Technology Cost and Performance Assumptions for New Generation Capacity

\begin{tabular}{|c|c|c|c|c|}
\hline & 2015 & 2020 & 2025 & 2030 \\
\hline \multicolumn{5}{|c|}{ Overnight Capital Costs $(2010 \$ / k W)$} \\
\hline Natural Gas-Combined Cycle & 900 & 890 & 880 & 860 \\
\hline Natural Gas-Combustion Turbine & 770 & 750 & 740 & 720 \\
\hline Wind (resource class dependent) & $1,530-1,650$ & $1,480-1,630$ & $1,440-1,620$ & $1,430-1,620$ \\
\hline PV Fixed-Tilt & 1,740 & 1,410 & 1,160 & 910 \\
\hline PV Single-Axis Tracking & 1,830 & 1,510 & 1,260 & 1,010 \\
\hline \multicolumn{5}{|l|}{ Fixed O\&M (2010\$/kW-yr) } \\
\hline Natural Gas-Combined Cycle & 13 & 13 & 13 & 13 \\
\hline Natural Gas-Combustion Turbine & 7 & 7 & 7 & 7 \\
\hline Wind (all) & 47 & 46 & 45 & 44 \\
\hline PV (all) & 15 & 8 & 8 & 8 \\
\hline \multicolumn{5}{|l|}{ Variable O\&M (2010\$/MWh) } \\
\hline Natural Gas-Combined Cycle & 3 & 3 & 3 & 3 \\
\hline Natural Gas-Combustion Turbine & 12 & 12 & 12 & 12 \\
\hline Wind (all) & 0 & 0 & 0 & 0 \\
\hline PV (all) & 0 & 0 & 0 & 0 \\
\hline \multicolumn{5}{|l|}{ Heat Rate (MMBtu/MWh) } \\
\hline Natural Gas-Combined Cycle & 6.68 & 6.62 & 6.57 & 6.57 \\
\hline Natural Gas-Combustion Turbine & 10.0 & 9.76 & 9.50 & 9.50 \\
\hline \multicolumn{5}{|l|}{ Fuel Cost (2010\$/MMBtu) } \\
\hline Natural Gas & 4.38 & 5.43 & 6.91 & 8.20 \\
\hline \multicolumn{5}{|l|}{ Capacity Factor (\%) } \\
\hline Wind (resource class dependent) & $52 \%-33 \%$ & $54 \%-35 \%$ & $55 \%-36 \%$ & $56 \%-37 \%$ \\
\hline PV Fixed-Tilt & $12-22 \%$ & $12-22 \%$ & $12-22 \%$ & $12-22 \%$ \\
\hline PV Single-Axis Tracking & $14-28 \%$ & $14-28 \%$ & $14-28 \%$ & $14-28 \%$ \\
\hline
\end{tabular}

Note: PV capacity is represented in DC terms and PV costs are represented in AC terms. PV capacity factor reflects $A C$ output over DC capacity. AC capacity and output are used for all other technologies. In the table, PV refers to utility PV only; rooftop PV trajectories and performance characteristics are from the dSolar model (Sigrin et al., forthcoming). 


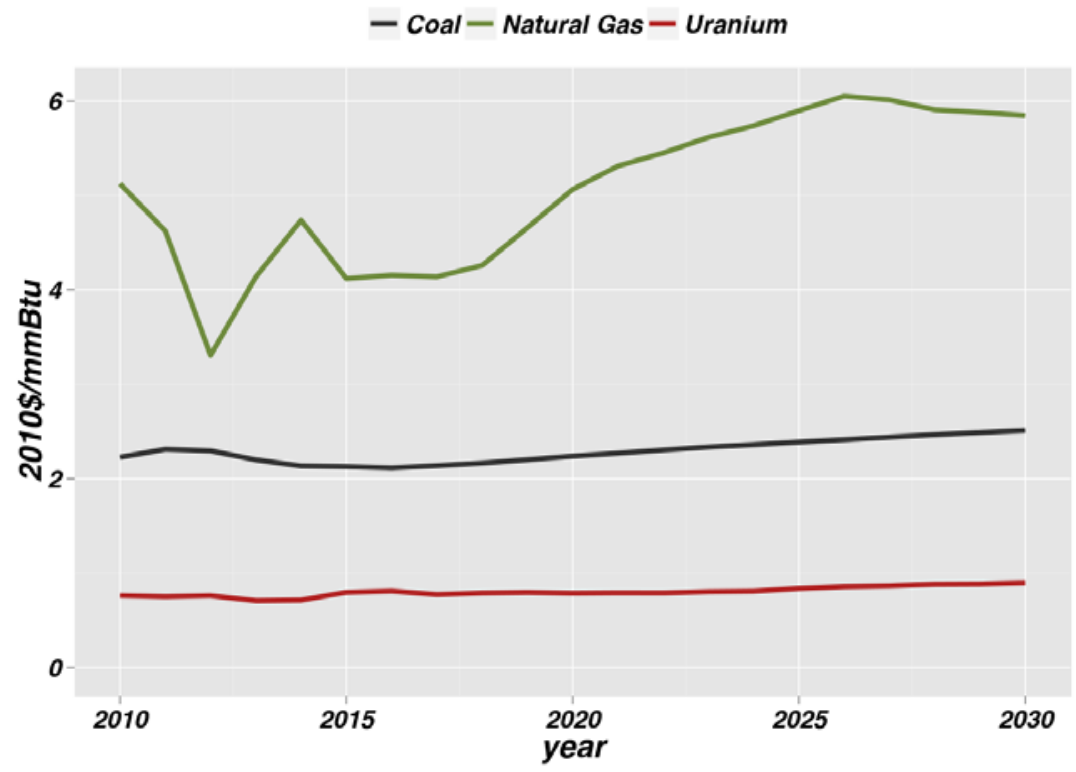

Figure 3. Assumed delivered natural gas, coal, and uranium AEO 2015 price trajectories from 2010 to 2030 (EIA 2015)

With the exception of rooftop PV capacity, new solar capacity deployment is restricted by the technical potential of the resource in each resource region and is driven by the economic potential of particular resources. The technical potential assessment uses the same methodology and exclusions as in (Lopez et al. 2012). Wind and solar suitable land exclusions include: slopes greater than 3\% (solar) and 20\% (wind), contiguous areas less than $1 \mathrm{~km}^{2}$ (solar), lands within 1 $\mathrm{km}$ distance to other exclusions (wind), water, wetlands, urban areas, BLM areas of critical environmental concern, National Parks, Fish and Wildlife lands, Federal Parks, wilderness, National Monuments, National Battlefields, Federal Wildlife Areas and other federally identified protected lands. Rooftop PV capacity adoption is defined exogenously and updated after each solve year using NRELs dSolar model (Sigrin et al., forthcoming). The primary factors, beyond fuel and technology costs, that drive RPM's investment decisions relate to demand growth, planning reserves, and state renewable portfolio standard (RPS) requirements. Planning reserve constraints are applied to ensure North American Electric Reliability Corporation (NERC) resource adequacy reference margins (NERC 2013) are met. We set a planning reserve requirement for each of four NERC sub-regions ${ }^{18}$ in the Western Interconnection to be the peak demand in that region plus a reserve margin (NERC 2013). ${ }^{19}$ All non-variable generators are assumed to contribute their full nameplate capacity to the planning reserve requirement; a capacity credit of one is assumed for all thermal capacity, hydropower, CSP with thermal energy storage (TES), and storage. For variable generation, including wind, solar PV, and CSP without TES, we endogenously estimate the capacity credit using a capacity factor-based approximation

\footnotetext{
18 The regions are WECC-CAMX, WECC-NWPP, WECC-RMRG, and WECC-SRSG.

${ }^{19}$ For the WECC-CAMX region, we assume 11,000 MW and 5,000 MW of capacity are available from the NWPP and SRSG sub-regions, respectively, to meet planning reserve requirements for all years. We assume that the deductions from NWPP and SRSG are not available to supply capacity reserves in their respective regions. This representation follows the Maximum Import Capacity considered by the California Independent System Operator. Planning reserve requirements are met by local resources only for the other three sub-regions.
} 
The modeling analysis was completed using data and assumptions available in early 2015 . For energy policies, this includes state renewable portfolio standards (RPSs) at that time and as reflected in DSIRE. ${ }^{20}$ However, we note that further work is needed to more rigorously apply RPS rules and incentives in the model, including trading rules and existing contracts from out-ofstate projects that qualify for RPS compliance. The results reflect a simplified representation of RPS policies. We also include the federal tax incentives for wind and solar that were in effect at the time this analysis was conducted: an investment tax credit for commercial and utility-scale solar equivalent to $30 \%$ of eligible capital costs, declining to $10 \%$ of total eligible costs after 2016 , and a wind production tax credit of $\$ 23 / \mathrm{MWh}$ for facilities under construction prior to 2015. However, the tax credit extensions included in the Consolidated Appropriations Act of 2016 are not included in the analysis ${ }^{21}$. In addition, the present version of RPM does not include a representation of state carbon cap and trade systems (e.g. California Assembly Bill 32) or the recent 50\% RPS by 2030 policy in California. ${ }^{22}$ We do not include the Environmental Protection Agency's (EPA) Clean Power Plan (CPP) in any of the modeled scenarios. Finally, we do not model any changes to policies surrounding public land administration. While these omitted policies are expected to significantly alter results from our Reference scenario, we model a suite of policy sensitivity scenarios, including expanded RPS policies and a carbon price scenario which can lead to similar investment and deployment behavior as recently implemented legislation and regulations (see Section 3). Future work will explore additional policy sensitivities including the CPP.

Due to the optimization problem formulated in RPM, simulation results are particularly sensitive to capital cost assumptions, and as our modeling results show, the large majority of capacity additions in the west are comprised of renewable generation and natural gas combined cycle generation. As a result, the cost and performance assumptions used for these technologies have significant implications on results. Recently, the solar generation technologies have experienced significant cost reductions and improvements in performance (Barbose and Darghouth 2015; Bolinger and Seel 2015) and while there is uncertainty on how these cost reductions might continue into the future, DOE goals (Margolis, Coggeshall, and Zuboy 2012) indicate significantly greater reductions are possible, relative to the cost reductions modeled. Additionally, RPM does not endogenously consider residential rooftop PV development due to the difficulty in representing homeowner PV adoption behavior. As such, deployment results (see Section 1) may underestimate future solar deployment in Colorado and potentially the Western Interconnection. Future sensitivities, including those with lower relative RE development costs, are needed to broaden the range of potential expected outcomes and a forthcoming study to analyze these and other sensitivities is planed.

\footnotetext{
${ }^{20}$ See www.dsireusa.org/.

${ }^{21}$ Model simulations for the analysis presented here were completed in the fall of 2015 . Due to uncertainties surrounding policy extensions at the time of simulation, tax credit extensions included in congressional bills in December 2015 are excluded from this analysis.

${ }^{22}$ Emissions or renewable policies such as California Assembly Bill 32, primarily affect capacity expansion and operations results near the policy location and locations where contracted imports are likely. Therefore, omissions of these policies are unlikely to significantly affect the results of this analysis.
} 
Recent (2010-2014) and expected new transmission and generation capacity additions and retirements are exogenously included in RPM based on data from Ventyx (2010) and SolarPaces $(2014)^{23}$. The optimization in RPM does not explicitly consider any other retirements, such as economic retirements.

${ }^{23}$ In particular, two solar generation developments totaling $206 \mathrm{MW}$ in Colorado have recently been announced that are not included in RPM ("Broomfield Firm to Build Colorado's Largest Solar Farm near Pueblo" 2016; "Xcel Energy Flips the Switch on Colorado Solar Power Plant” 2016) 


\section{Scenario Framework}

We modeled long-term capacity expansion and electricity system operations under a core reference scenario (REF) and four sensitivity scenarios designed to highlight a range of possible policy and economic futures. To address the uncertainties of future natural gas prices, we use natural gas price projections (see Figure 4) from the Energy Information Administration Annual Energy Outlook to inform high (HI-NG) (EIA 2014) and low (LO-NG) (EIA 2015) model scenarios. In addition, we model a $\mathrm{CO}_{2}$ price sensitivity where the investment and dispatch decisions in RPM are influenced by an effective price on combustion-related $\mathrm{CO}_{2}$ emissions of the various generator types modeled. We calculate a median non-zero $\mathrm{CO}_{2}$ price trajectory (see Figure 5) based upon data collected for the Resource Planning Portal ("RPP" 2015) ${ }^{24}$. The $\mathrm{CO}_{2}$ price sensitivity is not intended to directly represent any particular policy. Rather, it is included to represent the effect of how the Western Interconnection might evolve under a clean energy legislation or regulations aimed at curbing greenhouse gas emissions, such as EPA's CPP (US EPA 2015). ${ }^{25}$ Finally, we model a variant of the reference scenario where the state of Colorado amends its current RPS that mandates the provision of load with at least $30 \%$ renewable generation by 2020, with an additional RPS policy that raises that level to $50 \%$ by 2030 .

With the following exceptions, all scenarios use a common set of input assumptions documented in Section 2, including zero $\mathrm{CO}_{2}$ price, currently in-place RPS policies, and the reference case natural gas price trajectory shown in Figure 3:

- The high natural gas price scenario (HI-NG) follows the high natural gas price trajectory in Figure 4

- The low natural gas price scenario (LO-NG) follows the low natural gas price trajectory in Figure 4

- The $\mathrm{CO}_{2}$ price scenario $(\mathrm{CO} 2)$ applies the median non-zero $\mathrm{CO}_{2}$ price trajectory to carbon emissions from electricity generators starting in 2017

- The high renewable portfolio standard scenario (HI-RPS) assumes that the State of Colorado adopts a more aggressive RPS standard that mandates 50\% renewable generation in 2030 .

None of these scenarios represent a forecast or prediction. The scenarios do not reflect a policy or other recommendation pertaining to the formation of BLM resource management plans, but instead aim to capture a range of possible futures. These scenarios are intended to simulate the

\footnotetext{
${ }^{24} \mathrm{CO}_{2}$ prices are based on integrated resource plans created between 2010 and 2013 by 14 load serving entities in the western United States as collected for Lawrence Berkeley National Laboratory's Resource Planning Portal (http://resourceplanning.lbl.gov). The median trajectory shown here was calculated from the IRP scenarios with non-zero $\mathrm{CO}_{2}$ prices.

${ }^{25}$ At the time model simulations were executed, the CPP was proposed, but not finalized. Therefore, the greenhouse gas emissions limits required by the CPP are not included in the results presented here. Ongoing RPM development will enable explicit representation of CPP legislation in future simulations.
} 
broader trends in the future western electricity system, with the results quantifying potential demands on various lands owned by the BLM, other federal agencies, private and other entities.

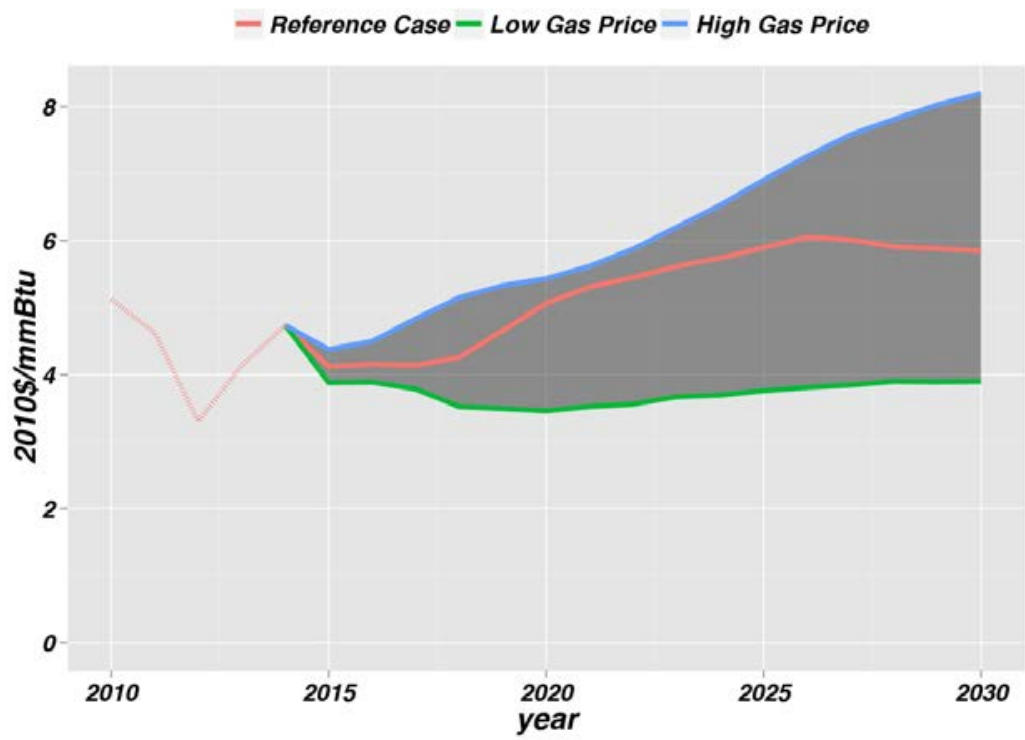

Figure 4. Assumed reference, low, and high AEO 2015 delivered natural gas price trajectories (EIA 2015)

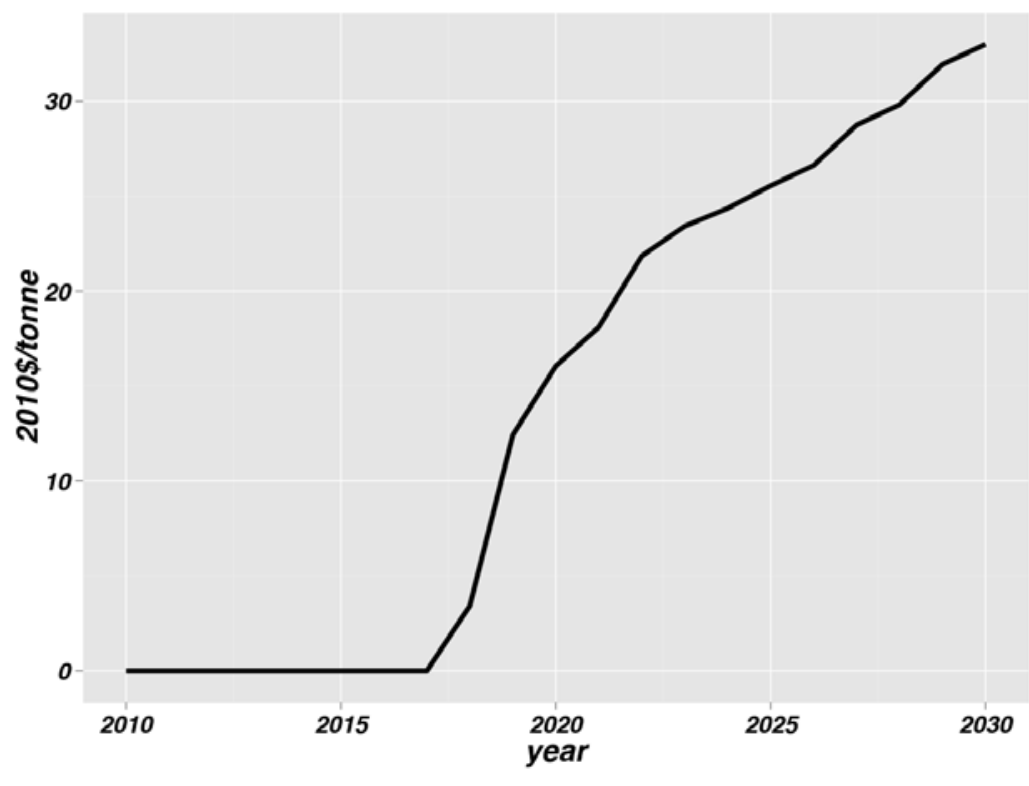

Figure 5. Assumed median $\mathrm{CO}_{2}$ price 


\section{Results and Discussion}

\section{RPM Scenario Results}

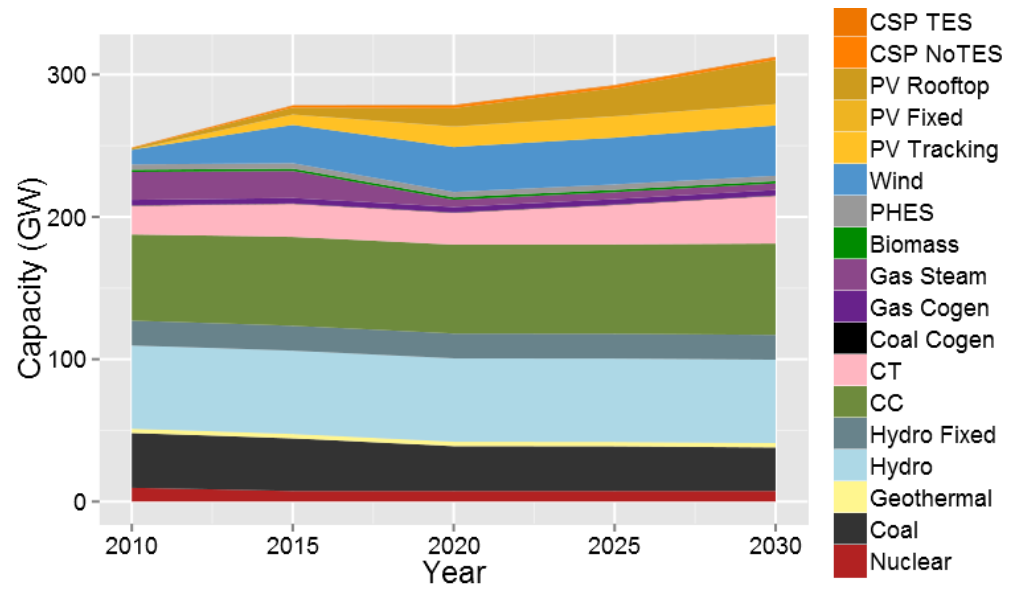

Figure 6. Installed generation capacity in the Western Interconnection for the reference scenario

The simulated scenarios represent a range of modeled outcomes under a variety of policy and future economic assumptions. The results demonstrate that the magnitudes and distributions of renewable energy development in Colorado are sensitive to various policy and economic drivers. Figure 6 shows the Wester Interconnection-wide capacity mix over time from the reference scenario; Figure 7 shows the capacity mix through time for the Colorado-centric focus region. Changes in capacity under the reference scenario are largely driven by load growth assumptions and existing RPS policies. Under the reference scenario 35,000 MW of new wind, 15,000 MW of new utility-scale solar, and 33,000 MW of new rooftop solar capacity are added between 2011 and 2030 in the Western Interconnection. With this new capacity, wind and solar are estimated to comprise $19 \%$ of all generation in 2030 .

Figure 7 shows that wind technologies comprise the dominant share of all new capacity in the Colorado-centric focus region - wind additions total 4,428 MW, while new rooftop solar totals 1,440 MW and only new utility-scale solar, $118 \mathrm{MW}$ during 2011-2030. As a result of these capacity additions, by 2030 wind and solar make up 30\% of Colorado in-state generation under the reference scenario. 


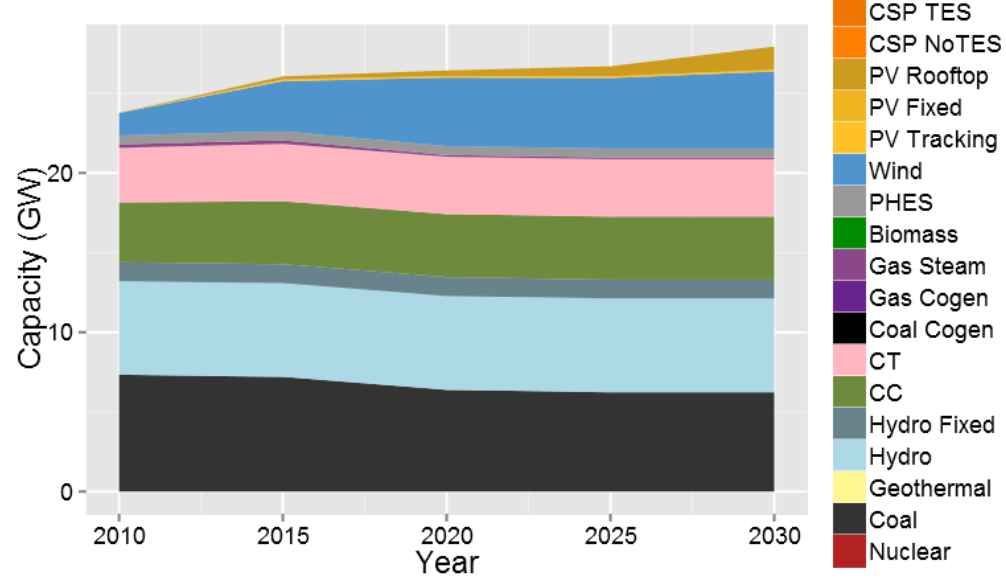

Figure 7. Installed generation capacity in the Colorado-centric focus region for the reference scenario

Differences in the capacity mix between the reference scenario and the four sensitivity scenarios are shown for the Western Interconnect in Figure 8 and for the Colorado-centric focus region in Figure 9. Figure 8 demonstrates that both the high natural gas prices and a $\mathrm{CO}_{2}$ price in the HI$\mathrm{NG}$ and $\mathrm{CO} 2$ scenarios, respectively, create some additional incentive for wind and PV capacity in the Western United States, and therefore lead to higher penetrations of wind and solar capacity. Similarly, Figure 9 shows that the HI-NG, CO2, and HI-RPS ${ }^{26}$ scenarios lead to greater wind capacity builds in the focus region (CO) than in the reference scenario. Total 2030 wind capacity additions in Colorado (excluding the Wyoming portions of the focus region) are 6,395 MW, 10,002 MW, and 5,758 MW, for the HI-NG, CO2, and HI-RPS scenarios, respectively. The additional Colorado solar capacity observed under the HI-NG scenario creates a total of 1,198 MW of new utility-scale solar, and 1,440 MW of new rooftop solar by 2030.

\footnotetext{
${ }^{26}$ Figure 9 only shows a marginal increase in focus region wind capacity over the reference scenario despite the significant increase in annual generation required to meet the 50\% RPS in Colorado in the HI-RPS scenario in 2030. The increased annual renewable generation is achieved in the HI-RPS scenario by building more wind in Colorado and less wind in Wyoming. Thus the Colorado-centric focus region, which includes Colorado and much of Wyoming, has minimal net renewable capacity increase.
} 


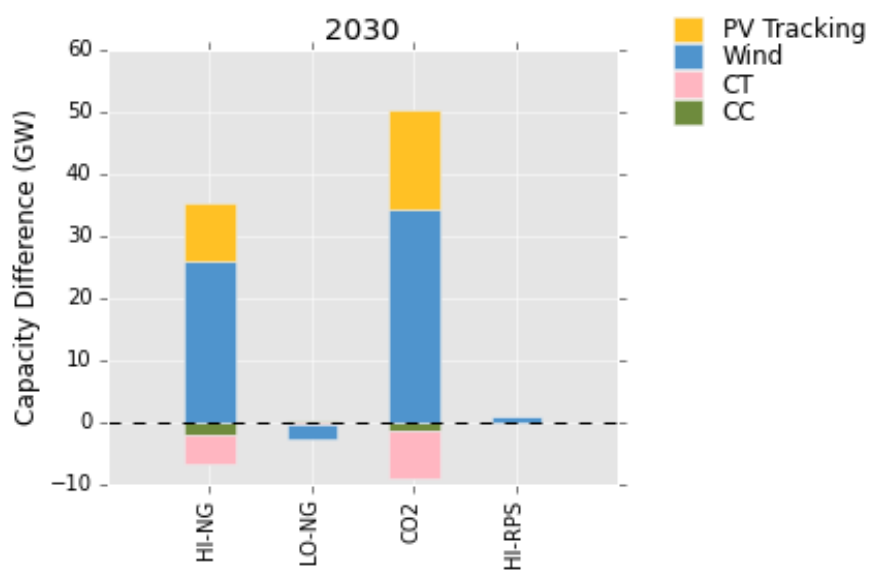

Figure 8. Differences in 2030 capacity in the Western Interconnection with respect to the reference scenario

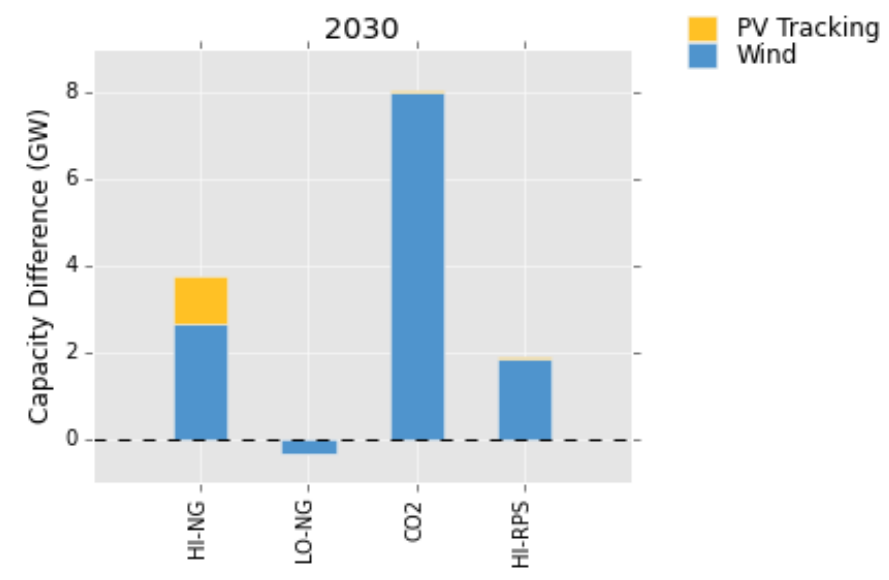

Figure 9. Differences in 2030 capacity in the Colorado-centric focus region with respect to the reference scenario

Cross-scenario differences in the focus region capacity mix can be attributed to the different input assumptions and policies represented in each scenario. For instance, the HI-NG scenario assumes that natural gas prices follow a higher price trajectory than in the reference scenario. This places a premium on operating natural gas fired generation, such as NG-CC and NG-CT generators. Increased operating costs for natural gas fired generation make wind and PV generation more cost competitive, thus increasing simulated capacity additions. Similarly, the $\mathrm{CO} 2$ scenario simulates an additional cost to operating carbon dioxide emitting generating resources. The non-zero $\mathrm{CO}_{2}$ price primarily affects coal-fired, and to a lesser extent NG-fired generators. The results of the $\mathrm{CO} 2$ scenario shown in Figure 9 suggests that additional wind capacity makes up the majority of reduced coal-fired generation in the Colorado-centric focus region. Figure 7 shows that the reference scenario results in significant wind and solar capacity expansions in Colorado and parts of Wyoming. Figure 9 shows that, when compared to the reference scenario, the HI-RPS scenario only needs an additional $2 \mathrm{GW}$ of focus region wind capacity to achieve the $50 \%$ renewable generation requirement. 


\section{GIS Post-Processing and Resource Potential Analysis}

\section{Statewide and ECRMP Results}

Despite the fact that significant wind and solar capacity additions are occur across the range of scenarios explored, suitable land availability within Colorado remains abundant through 2030. The amount of Colorado land area needed to accommodate modeled renewable capacity additions through 2030 range from 336,000 to 824,000 acres across all five modeled scenarios. Figure 10 and Figure 11 show Colorado lands suitable for wind and solar energy development, respectively. Suitable land availability is analyzed by land ownership within four 'Distance to Transmission' bins, summarized in Table 4 and Table 5. Transmission distances are calculated between each suitable land grid cell $\left(10 \mathrm{~km}^{2}\right)$ and the closest transmission bus. ${ }^{27}$ Suitable land area, in acres, is calculated after applying exclusions described in Lopez et al. (2012) and the MW capacity potential is calculated by applying technology specific land use intensities found in Denholm et al. (2009).

${ }^{27}$ Transmission buses considered in this analysis include existing and WECC planned infrastructure at or above 69 $\mathrm{kV}$ nominal voltage ratings. 

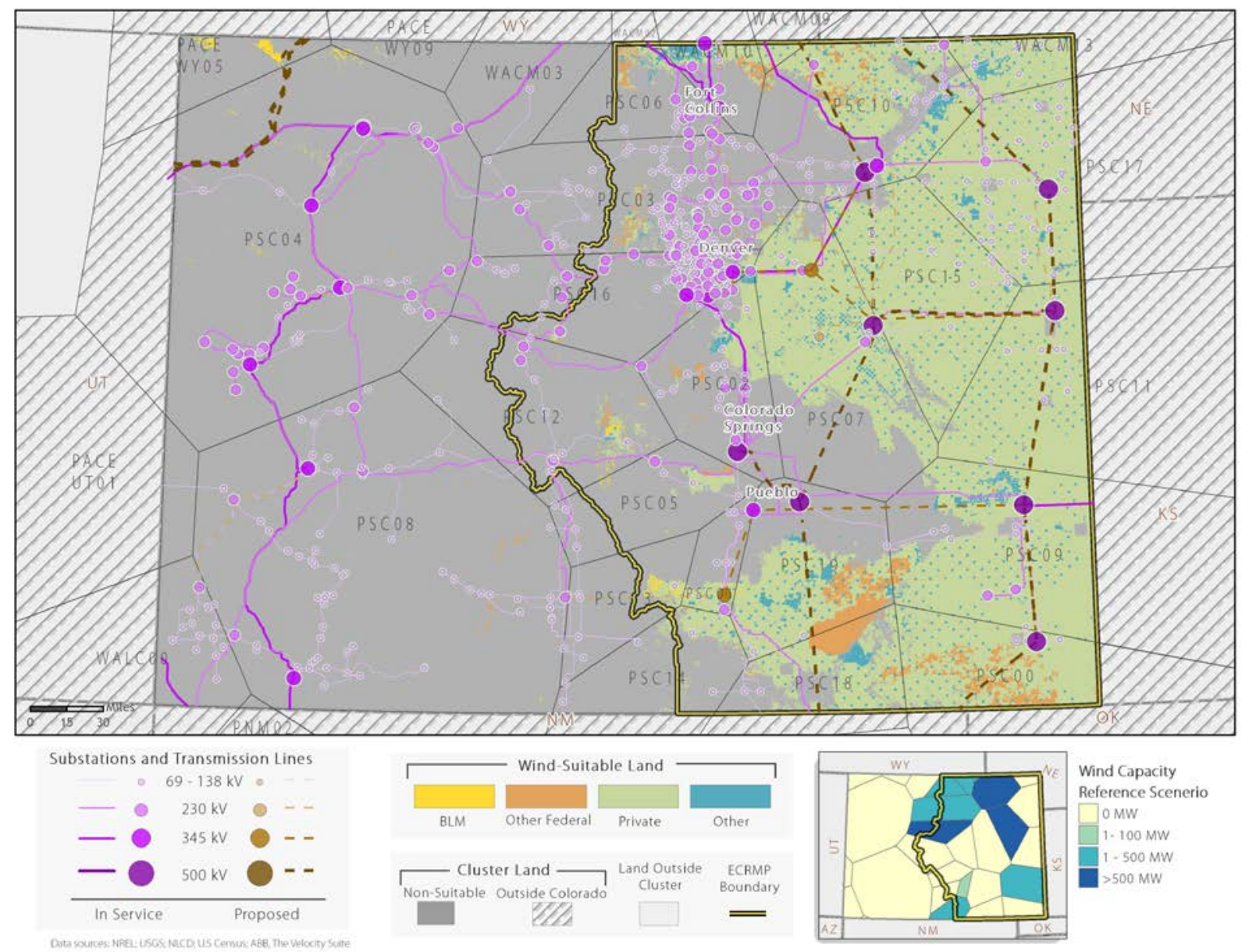

Figure 10. Colorado wind-suitable land

Table 4. Colorado-Wind-Suitable Land: Area and MW Potential

\begin{tabular}{c|cc|cc|cc|cc}
\hline \hline \multirow{2}{*}{ Distance to } & \multicolumn{2}{|c|}{$\mathbf{0 - 1}$ Miles } & \multicolumn{2}{|c|}{$\mathbf{1 - 5}$ Miles } & \multicolumn{2}{c|}{$\mathbf{5 - 1 0}$ Miles } & \multicolumn{2}{c}{$>$ 10 Miles } \\
Transmission & Acres & MW & Acres & MW & Acres & MW & Acres & MW \\
\hline BLM & 676 & 8 & 10,742 & 130 & 35,485 & 431 & 85,689 & 1,040 \\
Federal & 286 & 3 & 35,028 & 425 & 152,692 & 1,854 & 747,768 & 9,078 \\
Other & 14,855 & 180 & 286,770 & 3,482 & 403,691 & 4,901 & 630,510 & 7,655 \\
Private & 170,090 & 2,065 & $3,482,771$ & 42,283 & $5,609,683$ & 68,105 & $8,660,317$ & 105,141 \\
\hline \hline
\end{tabular}




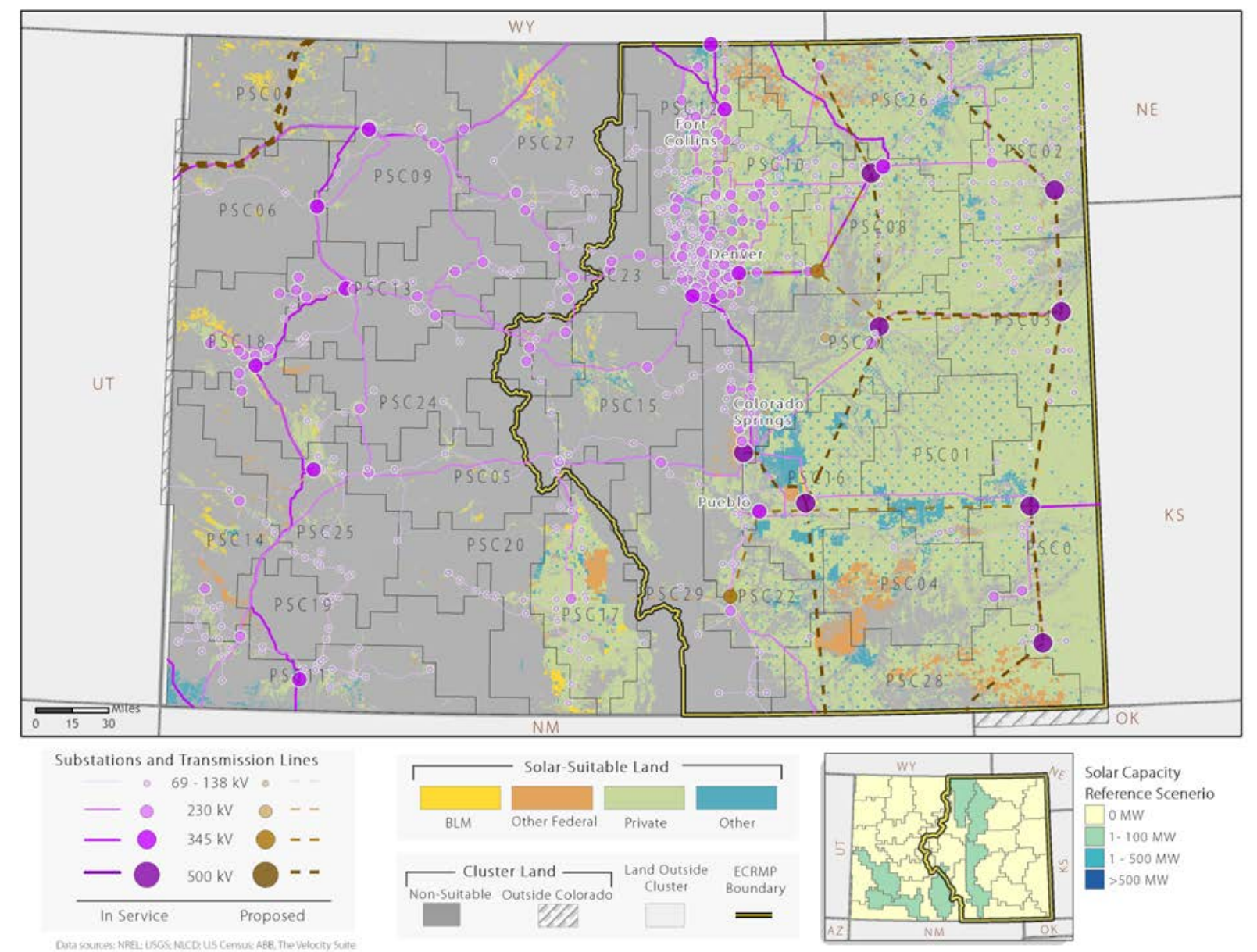

Figure 11. Colorado utility-scale solar-suitable land

Table 5. Colorado-Solar-Suitable Land: Area and MW Potential

\begin{tabular}{c|cc|cc|cc|cc}
\hline \hline \multirow{2}{*}{ Distance to } & \multicolumn{2}{|c|}{$\mathbf{0 - 1}$ Miles } & \multicolumn{2}{|c|}{$\mathbf{1 - 5}$ Miles } & \multicolumn{2}{c|}{$\mathbf{5 - 1 0}$ Miles } & \multicolumn{2}{c}{$>$ >10 Miles } \\
Transmission & Acres & MW & Acres & MW & Acres & MW & Acres & MW \\
\hline BLM & 542 & 155 & 53,225 & 15,251 & 111,854 & 32,050 & 259,125 & 74,248 \\
Federal & 936 & 268 & 65,781 & 18,848 & 212,993 & 61,030 & 605,166 & 173,400 \\
Other & 18,784 & 5,382 & 321,219 & 92,040 & 489,051 & 140,129 & $1,050,674$ & 301,053 \\
Private & 311,631 & 89,293 & $5,025,581$ & $1,439,995$ & $5,892,545$ & $1,688,408$ & $9,035,090$ & $2,588,851$ \\
\hline \hline
\end{tabular}

Table 6. Colorado-Modeled Wind and Solar Capacity (MW)

\begin{tabular}{l|ccccc}
\hline \hline & Ref & HI-NG & LO-NG & C02 & HI-RPS \\
Wind & 4,428 & 6,395 & 4,080 & 10,002 & 5,758 \\
Solar & 118 & 1,198 & 112 & 195 & 132 \\
\hline \hline
\end{tabular}


The solar and wind capacity additions modeled through 2030 for each scenario are described in Table 6 . The results demonstrated that wind capacity additions largely outpace solar capacity additions in Colorado. With the exception of the HI-NG scenario, utility-scale solar developments across all other scenarios use only about 450 acres in all of Colorado. Depending on the scenarios, statewide land usage for wind development ranges from about 365,000 to 824,000 acres. A comparison of the results presented in Table 6 and the availability of suitable land by ownership in Table 4 demonstrates a statewide abundance of wind-suitable private land and solar-suitable lands of all ownership types. These results suggest that Colorado could accommodate significantly more RE development than is simulated across the range of scenarios, even if development was prohibited on some lands

The ECRMP region is comprised of the eastern portion of the state and is bounded by the continental divide on the west and state borders on the north, east, and south (see yellow border in Figure 10). Table 7 and Table 8 show the wind and solar-suitable land availability in the ECRMP. Comparison of the ECRMP-suitable land availability with the Colorado land availability demonstrates that the majority of wind-suitable land in Colorado exists within the ECRMP boundary. Table 9 shows that all of the RPM simulated wind capacity, except $16 \mathrm{MW}$ in the CO2 scenario, are allocated inside the ECRMP boundary. Despite an abundance of solarsuitable land in the ECRMP, RPM simulates the majority of Colorado solar capacity expansions in the western portion of the state.

Table 7. ECRMP-Wind-suitable Land: Area and MW Potential

\begin{tabular}{c|cc|cc|cc|cc}
\hline \hline \multirow{2}{*}{ Distance to } & \multicolumn{2}{|c|}{$\mathbf{0 - 1}$ Miles } & \multicolumn{2}{|c|}{$\mathbf{1 - 5}$ Miles } & \multicolumn{2}{c|}{$\mathbf{5 - 1 0}$ Miles } & \multicolumn{2}{c}{$>$ 10 Miles } \\
Transmission & Acres & MW & Acres & MW & Acres & MW & Acres & MW \\
\hline BLM & 660 & 8 & 10,262 & 125 & 33,696 & 409 & 22,132 & 269 \\
Federal & 276 & 3 & 33,679 & 409 & 148,468 & 1,802 & 732,313 & 8,891 \\
Other & 14,855 & 180 & 286,284 & 3,476 & 403,365 & 4,897 & 624,398 & 7,581 \\
Private & 169,934 & 2,063 & $3,479,603$ & 42,244 & $5,595,939$ & 67,938 & $8,625,066$ & 104,713 \\
\hline \hline
\end{tabular}

Table 8. ECRMP-Solar-suitable Land: Area and MW Potential

\begin{tabular}{c|cc|cc|cc|cc}
\hline \hline \multirow{2}{*}{ Distance to } & \multicolumn{2}{|c|}{$\mathbf{0 - 1}$ Miles } & \multicolumn{2}{|c|}{$\mathbf{1 - 5}$ Miles } & \multicolumn{2}{c}{$\mathbf{5 - 1 0}$ Miles } & \multicolumn{2}{c}{$>\mathbf{1 0}$ Miles } \\
Transmission & Acres & MW & Acres & MW & Acres & MW & Acres & MW \\
\hline BLM & 43 & 12 & 3,296 & 945 & 12,376 & 3,546 & 24,173 & 6,926 \\
Federal & 731 & 209 & 47,607 & 13,641 & 117,043 & 33,537 & 549,218 & 157,369 \\
Other & 17,180 & 4,923 & 289,844 & 83,050 & 425,478 & 121,914 & 877,034 & 251,299 \\
Private & 264,183 & 75,697 & $4,292,574$ & $1,229,964$ & $5,237,288$ & $1,500,655$ & $8,428,131$ & $2,414,937$ \\
\hline \hline
\end{tabular}

Table 9. ECRMP-Modeled Wind and Solar Capacity (MW)

\begin{tabular}{l|ccccc}
\hline \hline & Ref & HI-NG & LO-NG & C02 & HI-RPS \\
Wind & 4,428 & 6,395 & 4,080 & 9,986 & 5,758 \\
Solar & 17 & 107 & 17 & 29 & 28 \\
\hline \hline
\end{tabular}




\section{Resource Region Specific Results}

To provide additional detail on wind and solar resource availability and the locations of RPM simulated RE developments, the following figures and tables present information on specific wind and solar resource regions within Colorado. The maps are designed to portray the location of lands suitable for wind and solar development, while the bar charts are designed to portray the results of RPM scenarios within three possible land development preferences. The figures also demonstrate the proximity of lands to existing and planned transmission infrastructure to give a sense of the relative costs that might be incurred for RE development on various lands. Here, we present the analysis for two Colorado resource regions within the ECRMP boundary, one wind and one solar. Other resource regions where RPM simulates wind or utility-scale solar capacity additions are presented in the Appendix.

Figure 12 highlights lands with wind energy development potential within the PSC06 wind region. Additionally, Table 10 summarizes the wind-suitable land area and MW potential in the PSC06 wind resource region by land ownership type. Table 10 also describes the distance to transmission infrastructure for lands with wind energy development potential. Transmission distances are calculated between each suitable land grid cell $\left(10 \mathrm{~km}^{2}\right)$ and the closest transmission bus, regardless of whether or not the bus resides within the resource region boundary. Figure 12 and Table 10 demonstrate that the majority of wind energy development opportunities in the PSC06 region exist on private lands and that wind-suitable land is primarily located at distances greater than 10 miles away from existing transmission infrastructure. 


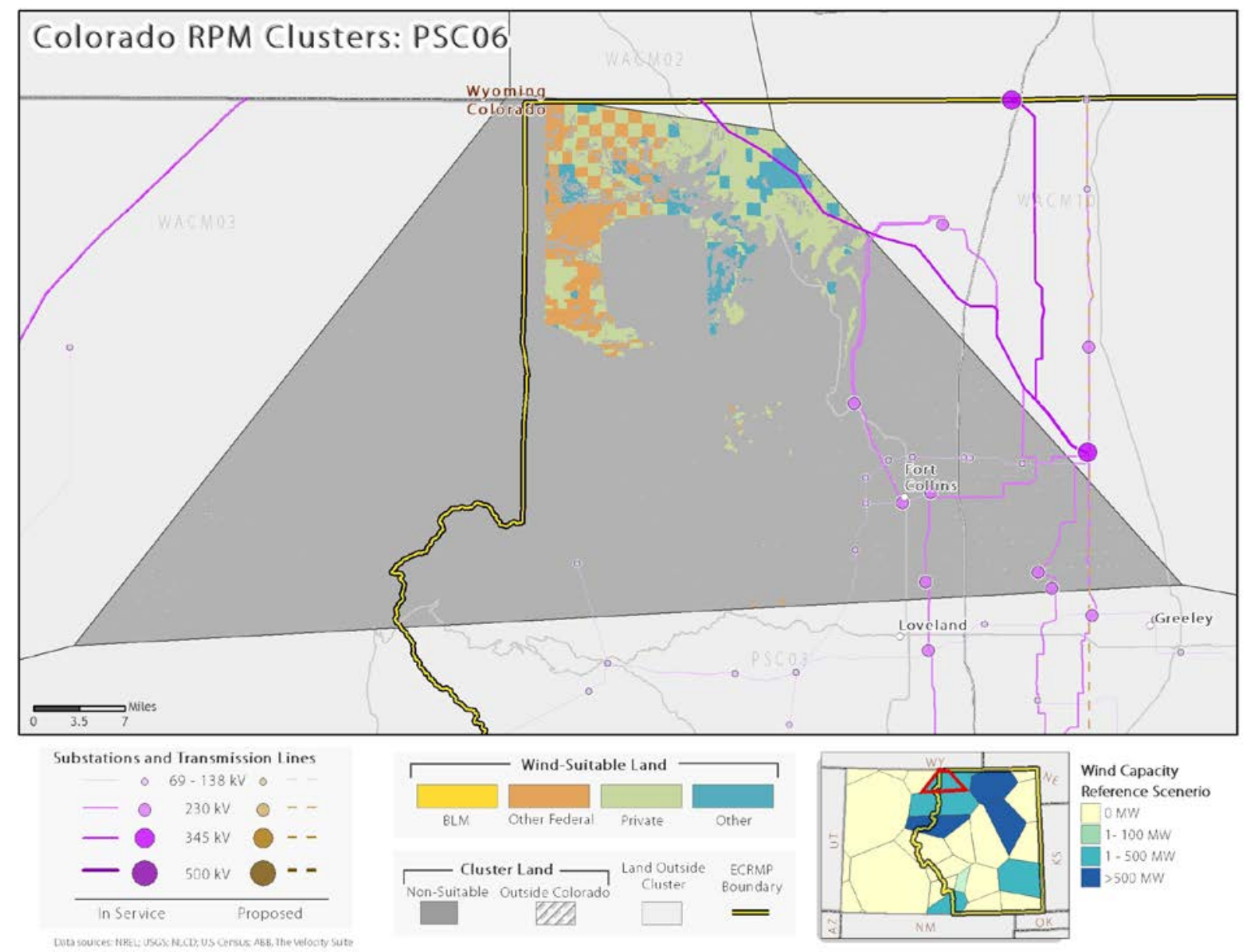

Figure 12. PSC06 wind resource region ${ }^{28}$

Table 10. PSC06-Wind-suitable Land Area and MW Potential

\begin{tabular}{c|cc|cc|cc|cc}
\hline \hline Distance to & \multicolumn{2}{|c|}{$\mathbf{0 - 1}$ Miles } & \multicolumn{2}{|c|}{$\mathbf{1 - 5}$ Miles } & \multicolumn{2}{c|}{$\mathbf{5 - 1 0}$ Miles } & \multicolumn{2}{c}{$>\mathbf{1 0}$ Miles } \\
Transmission & Acres & MW & Acres & MW & Acres & MW & Acres & MW \\
\hline BLM & 0 & 0 & 0 & 0 & 16 & 0 & 0 & 0 \\
Federal & 0 & 0 & 0 & 0 & 283 & 3 & 34,608 & 420 \\
Other & 0 & 0 & 0 & 0 & 1,184 & 14 & 19,870 & 241 \\
Private & 0 & 0 & 183 & 2 & 8,824 & 107 & 58,789 & 714 \\
\hline \hline
\end{tabular}

Table 11. PSC06-Modeled Wind Capacity (MW)

\begin{tabular}{ccccc}
\hline \hline Ref & HI-NG & LO-NG & C02 & HI-RPS \\
277 & 965 & 224 & 1,171 & 670 \\
\hline \hline
\end{tabular}

\footnotetext{
${ }^{28}$ For a complete description of the various information displayed, refer to the text at the beginning of the Appendix.
} 


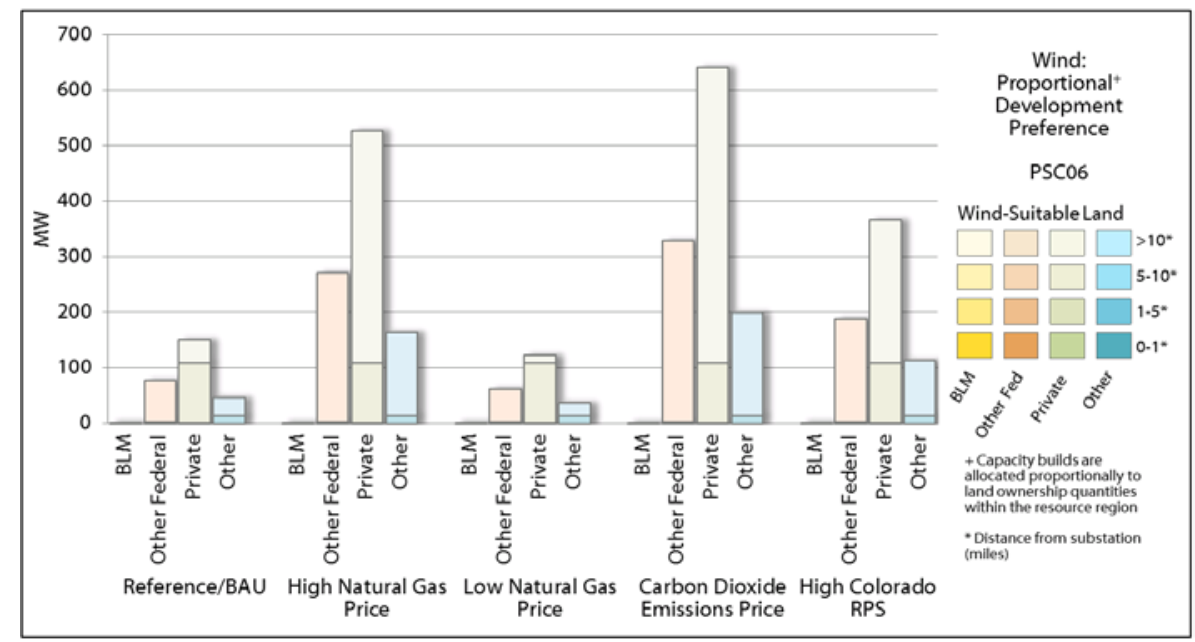

Figure 13. Wind: PSC06_proportional development preference

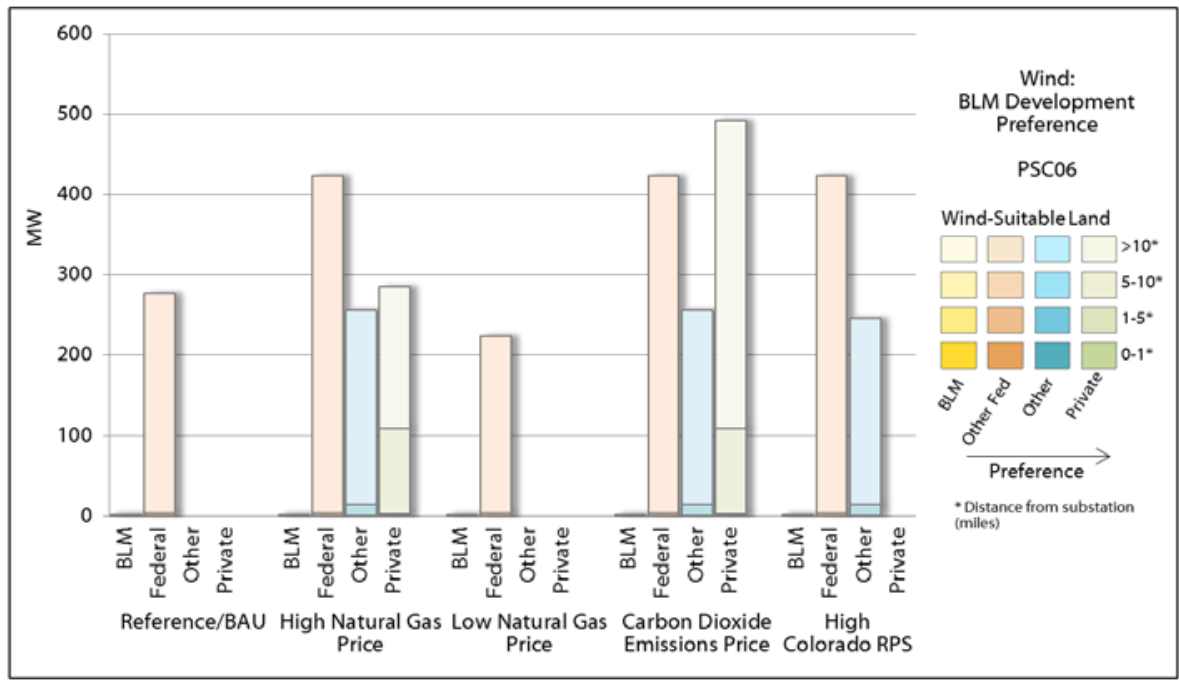

Figure 14. Wind: PSC06-BLM development preference

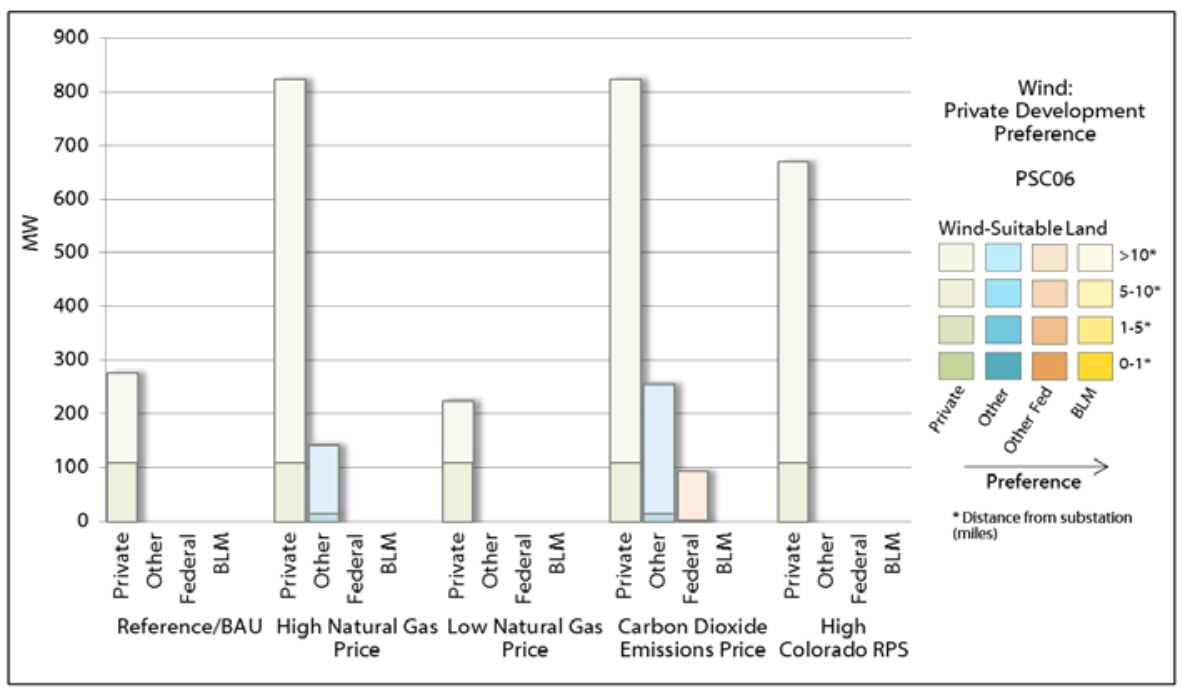

Figure 15. Wind: PSC06—private development preference 
Despite the relatively long transmission connection distances of wind-suitable lands in PSC06, Table 11 shows significant wind capacity additions in PSC06 across the full suite of scenarios explored. By comparing the results presented in Table 11 and the availability of suitable land by ownership, we describe three potential wind development pathways in Figure 13, Figure 14, and Figure 15. Figure 13 shows the land allocation of RPM wind capacity additions for each scenario assuming that development takes place proportionally to the amount of wind-suitable land available within the PSC06 wind resource region. Figure 14 shows the allocation of wind capacity additions to different land ownership types assuming development takes place with the following priority order: BLM-administered land gets developed first, and other federal lands, other and private land, get developed second, third and last. Conversely, Figure 15 describes the allocation of wind capacity additions assuming the opposite development preference order where private land gets developed with greatest priority. Figure 15 shows that private land in PSC06 could accommodate all of the RPM-simulated capacity additions in each scenario without utilizing any BLM, other federal, or other land for wind development.

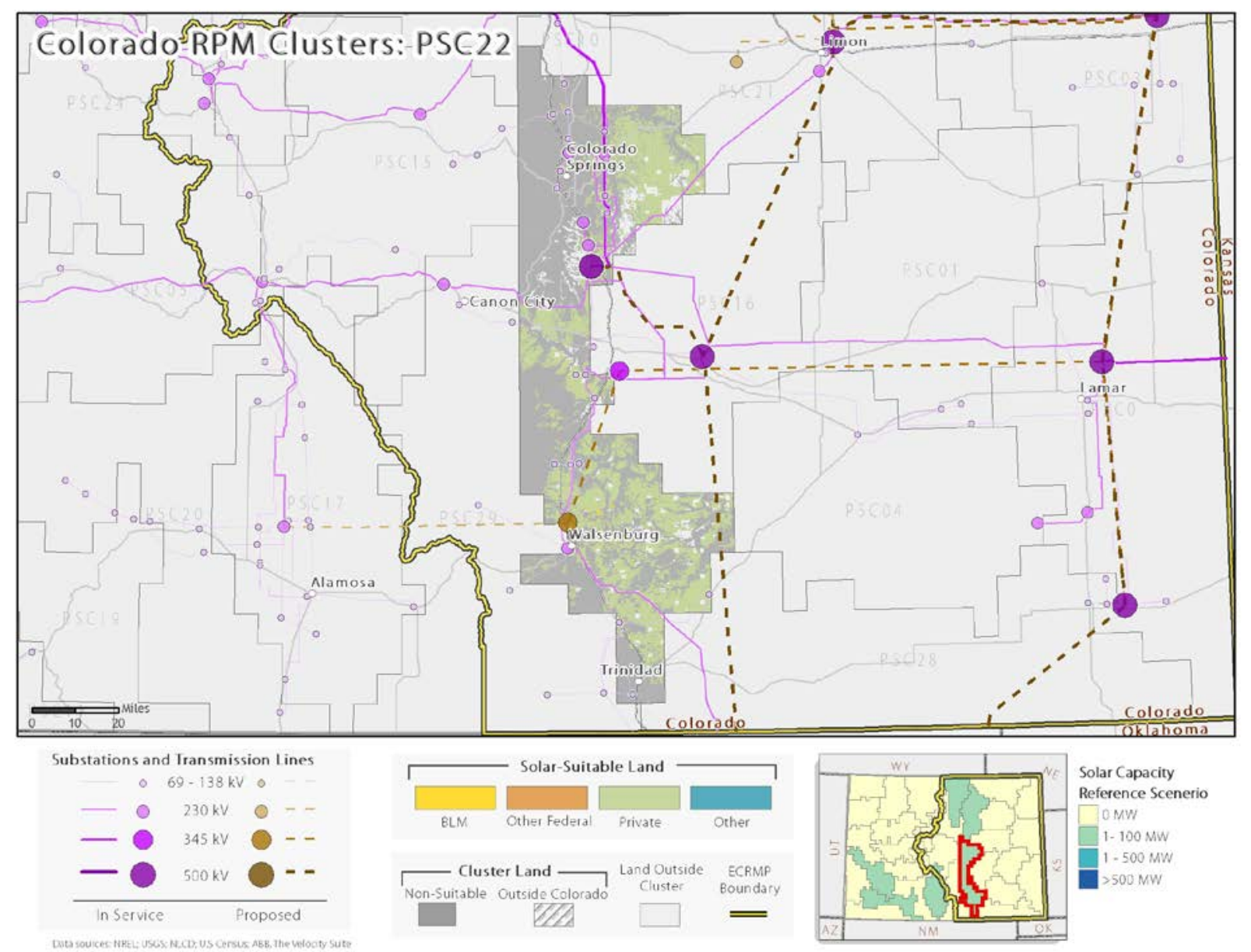

Figure 16. PSC22 solar resource region ${ }^{28}$ 
Table 12. PSC22-Solar-suitable Land: Area and MW Potential

\begin{tabular}{c|cc|cc|cc|cc}
\hline \hline \multirow{2}{*}{$\begin{array}{c}\text { Distance to } \\
\text { Transmission }\end{array}$} & \multicolumn{2}{|c|}{$\mathbf{0 - 1}$ Miles } & \multicolumn{2}{c|}{$\mathbf{1 - 5}$ Miles } & \multicolumn{2}{c|}{$\mathbf{5 - 1 0}$ Miles } & \multicolumn{2}{c}{$>$ 10 Miles } \\
Acres & MW & Acres & MW & Acres & MW & Acres & MW \\
\hline BLM & 0 & 0 & 506 & 145 & 1,651 & 473 & 718 & 206 \\
Federal & 14 & 4 & 17,372 & 4,978 & 12,380 & 3,547 & 2,879 & 825 \\
Other & 613 & 176 & 17,010 & 4,874 & 26,880 & 7,702 & 55,287 & 15,842 \\
Private & 15,939 & 4,567 & 209,334 & 59,981 & 301,807 & 86,478 & 311,033 & 89,121 \\
\hline \hline
\end{tabular}

Table 13. PSC22-Modeled Solar Capacity (MW)

\begin{tabular}{ccccc}
\hline \hline Ref & HI-NG & LO-NG & C02 & HI-RPS \\
8 & 8 & 8 & 8 & 8 \\
\hline \hline
\end{tabular}

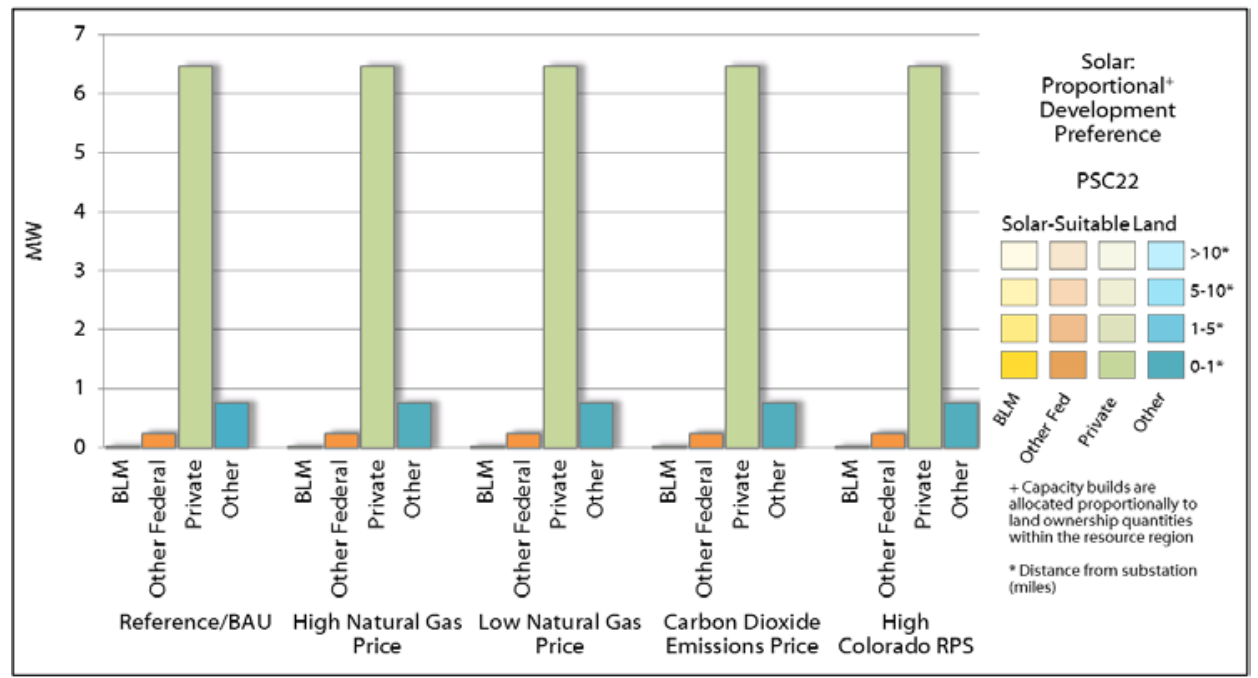

Figure 17. Solar: PSC22-proportional development preference 


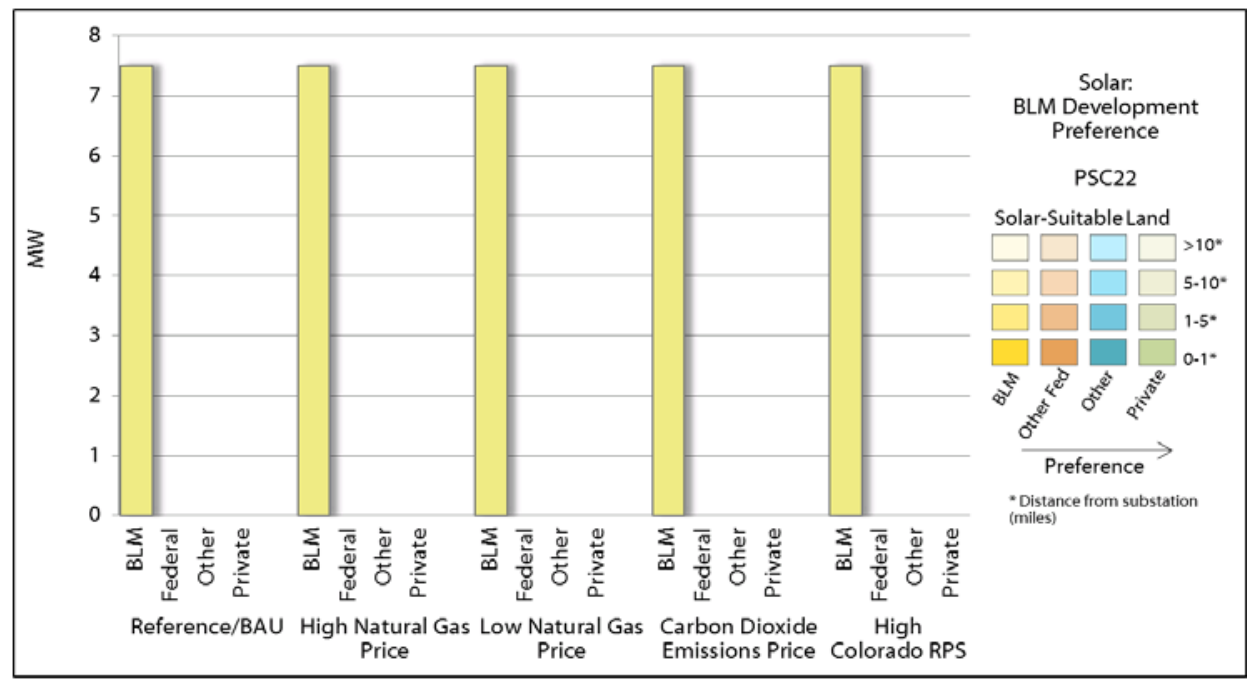

Figure 18. Solar: PSC22-BLM development preference

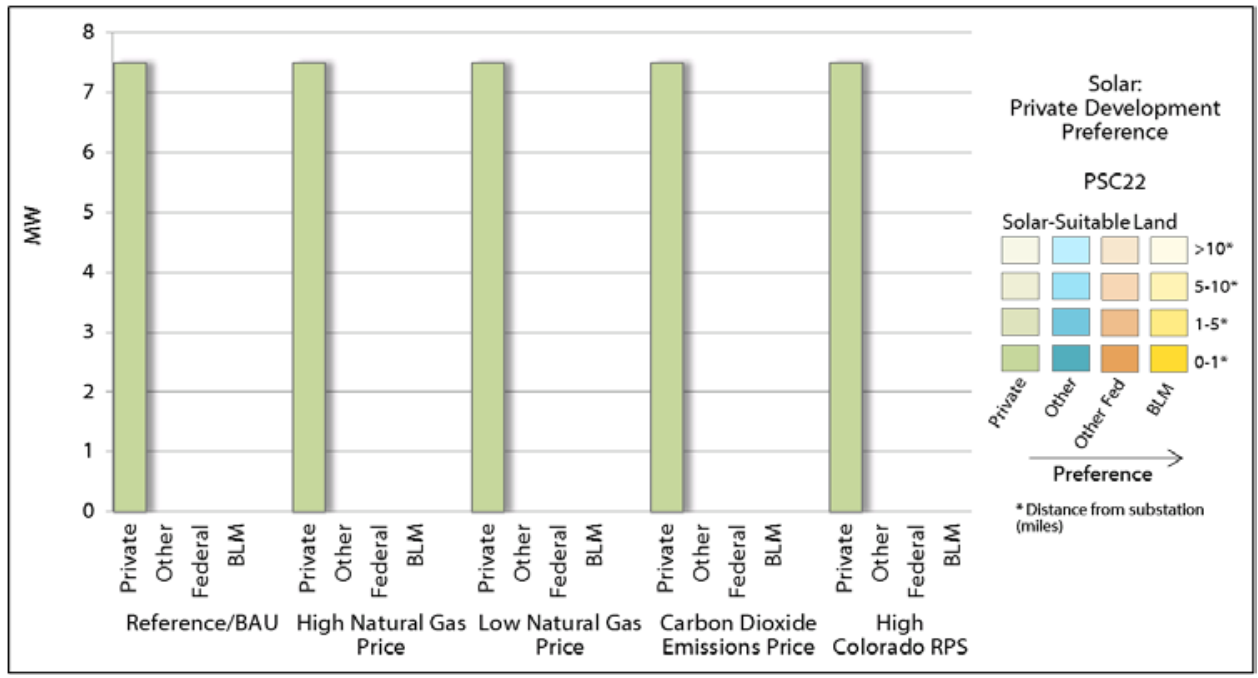

Figure 19. Solar: PSC22-private development preference

Figure 16 through Figure 19, and Table 12 and Table 13 present the same resource potential and GIS post-processing analysis on the PSC22 solar resource region. Table 12 shows that the majority of solar-suitable land is located at distances greater than $5 \mathrm{mi}$ from existing and planned transmission infrastructure. Table 13 shows that RPM simulates a relatively modest $8 \mathrm{MW}$ of solar capacity expansion in PSC22 in all scenarios. At this modest development level, both "Other" and private lands could accommodate the RPM simulated solar capacity additions on land within a mile of existing and planned transmission infrastructure. Due to the private ownership of the majority of solar-suitable lands, the proportional development preference chart in Figure 17 allocates most solar development in PSC22 to private lands. However, Figure 18 shows that if a BLM solar development preference existed, BLM-administered lands could accommodate the entire RPM simulated solar capacity expansion in PSC22.

The Appendix contains similar figures and tables for each resource region within Colorado where RPM results indicate wind or solar development is likely. 


\section{Implications for BLM Resource Management Planning in Colorado}

Overall, BLM-administered lands within 10 miles of the nearest transmission substation in Colorado total 47,000 wind-suitable acres, and 166,000 utility-scale solar-suitable acres. Within the ECRMP boundary BLM administers roughly 45,000 wind-suitable and 16,000 utility-scale solar-suitable acres. The RPM scenario simulation results highlight potential opportunities for BLM to allocate lands for renewable energy development in locations where BLM lands with high quality wind or solar resources are located near existing or planned transmission infrastructure. In particular, BLM-administered lands in Huerfano County have strong wind resource potential and are located close to transmission infrastructure. Additionally, new wind capacity is developed in regions PSC01 and PSC14 (see Appendix: Wind Resource Regions), which primarily represent lands in Huerfano County, across the full range of scenarios explored. This result suggests that wind development on BLM lands in the PSC01 and PSC14 wind resource regions, although modest, is particularly attractive.

The RPM simulation results suggest a limited amount of utility-scale solar PV development in Colorado. Furthermore, BLM-administered lands with solar resource potential tend to be located further from transmission infrastructure than other land ownerships. The resource potential of non-BLM-administered lands is more than sufficient to accommodate simulated solar capacity expansions in Colorado. Overall, attractive solar PV development opportunities on BLM lands are minimal, especially in the ECRMP region. The most attractive areas for solar PV development on BLM-administered lands exist along the Rocky Mountain Front Range in the PSC10 and PSC22 solar resource regions (see Appendix). These resource regions represent some of the most populated land area in Colorado along the I-25 corridor, stretching from Ft. Collins to Walsenburg. The heavily populated nature of these regions enhances the value of solar development since the need to transport energy long distances is alleviated, however lands available for development are fragmented and limited. 


\section{Conclusions}

The analysis presented here combines results obtained from RPM simulations and an additional GIS analysis applied to enhance the location specificity of RPM simulated capacity additions. The RPM scenarios were selected to give a range of likely future system development trajectories. GIS analysis has been applied to the wind and solar resource availability model inputs to generate the maps in the Appendix. The maps highlight suitable land for renewable development to provide a visual assessment of the proximity of various land ownerships to transmission infrastructure. Generally, larger generation developments will require access to higher voltage infrastructure to facilitate efficient long distance power transfer. For the purposes of this analysis, we provide a quantitative analysis of the total resource potential within various distances to transmission. Finally, within each wind and solar resource region, we analyze three potential development preferences. The development preference bar charts for each resource region in the Appendix describe the land usage allocations according a proportional, BLM, and private land development preferences. ${ }^{29}$ The analysis highlights the following broad trends for renewable development within Colorado:

- RPM scenario simulations find that new capacity additions are dominated by renewable technologies across the Western Interconnection and in Colorado.

- Across all modeled scenarios, the geographic distribution of new renewable capacity additions in Colorado is highly correlated to the resource quality and are limited to a relatively few resource regions within the state.

- Wind and solar-suitable land in Colorado far exceeds the land area needed to accommodate new renewable capacity additions through 2030 across all five modeled scenarios.

- This analysis suggests that the greatest opportunities for renewable energy development appear to exist on private lands, and BLM-administered lands are not necessarily needed to accommodate new renewable capacity additions across any of the scenarios in any of the regions.

- The limited need for BLM-administered lands to be used for RPM simulated renewable capacity additions can be explained through the relative difference in the amount and transmission proximity of renewable-suitable land areas that are BLM-administered and privately owned.

If the RPM results presented here are any indication of the trends of renewable energy development in the state of Colorado, there are likely many opportunities for partnerships between developers and various landowners. Opportunities for renewable energy development on lands managed by the BLM and other federal agencies will ultimately depend upon land management plans developed by these agencies in addition to the specific location, quality, and system interaction of available resources.

\footnotetext{
${ }^{29}$ For a more complete description of the three development preferences, refer to the text in the Appendix.
} 
The results presented in this report do not represent forecasts or predictions. The land development preferences and conclusions do not reflect any existing policy or other recommendation pertaining to the formation of BLM resource management plans. Instead, the results and conclusions presented here aim to capture a range of possible futures and the corresponding development opportunities on various lands, including BLM-administered lands. 


\section{References}

Barbose, Galen L., and Naïm R. Darghouth. 2015. Tracking the Sun VIII: The Installed Price of Residential and Non-Residential Photovoltaic Systems in the United States.

Blair, Nate, Karlynn Cory, Maureen Hand, Linda Parkhill, Bethany Speer, Tyler Stehly, David Feldman, et al. 2015. Annual Technology Baseline (Including Supporting Data). NREL (National Renewable Energy Laboratory).

Bolinger, Mark, and Joachim Seel. 2015. Utility-Scale Solar 2014: An Empirical Analysis of Project Cost, Performance, and Pricing Trends in the United States.

"Broomfield Firm to Build Colorado's Largest Solar Farm near Pueblo." 2016. Accessed January 29. http://www.denverpost.com/business/ci_28676186/broomfield-firm-build-stateslargest-solar-farm-near.

Dan Getman, Anthony Lopez, Trieu Mai, and Mark Dyson. 2015. "Methodology for Clustering High-Resolution Spatiotemporal Solar Resource Data.” TP-6A20-63148. NREL.

Denholm, Paul, Maureen Hand, Maddalena Jackson, and Sean Ong. 2009. Land-Use Requirements of Modern Wind Power Plants in the United States. National Renewable Energy Laboratory Golden, CO.

EIA. 2015. Annual Energy Outlook. Washington: Office of Energy Markets and End Use, U.S. Dept. of Energy : Supt. of Docs., U.S. GPO, [distributor]. Accessed August 5. http://www.eia.gov/forecasts/aeo/index.cfm.

Energy Information Administration (EIA). 2014. "Annual Energy Outlook 2014 with Projections to 2040”. DOE/EIA-0383(2014). Washington, D.C.: U.S. Energy Information Association.

Lew, D., G. Brinkman, E. Ibanez, A. Florita, M. Heaney, B. M. Hodge, M. Hummon, et al. 2013. Western Wind and Solar Integration Study Phase 2.

Lopez, A., B. Roberts, D. Heimiller, N. Blair, and G. Porro. 2012. U.S. Renewable Energy Technical Potentials: A GIS-Based Analysis. http://www.osti.gov/scitech/servlets/purl/1047328.

Mai, T., C. Barrows, A. Lopez, E. Hale, M. Dyson, and K. Eurek. 2015. Implications of Model Structure and Detail for Utility Planning: Scenario Case Studies Using the Resource Planning Model.

Mai, T., E. Drury, K. Eurek, N. Bodington, A. Lopez, and A. Perry. 2013. Resource Planning Model: An Integrated Resource Planning and Dispatch Tool for Regional Electric Systems.

Mai, T., D. Sandor, R. Wiser, and T. Schneider. 2012. "Renewable Electricity Futures Study. Executive Summary."

Margolis, R, C Coggeshall, and J Zuboy. 2012. "SunShot Vision Study." US Dept. of Energy.

NERC. 2013. "2013 Summer Reliability Assessment." http://www.nerc.com/pa/RAPA/ra/Reliability\%20Assessments\%20DL/2013SRA_Final.p df.

"RPP." 2015. Accessed October 15. http://resourceplanning.lbl.gov/login.php.

Sigrin, Ben, Michael Gleason, Robert Preus, Ian Baring-Gould, and Robert Margolis. 2016. "The Distributed Generation Market Demand Model (dGen): Documentation”. Technical Report. NREL.

Sullivan, Patrick, Wesley Cole, Nate Blair, Eric Lantz, Venkat Krishnan, Trieu Mai, David Mulcahy, and Gian Porro. 2015. "2015 Standard Scenarios Annual Report: U.S. Electric Sector Scenario Exploration." 
US EPA, OAR. 2015. “Clean Power Plan Final Rule”. Policies and Guidance. Accessed October 15. http://www2.epa.gov/cleanpowerplan/clean-power-plan-final-rule.

WECC. 2011a. "WREGIS Annual Report 2011." https://www.wecc.biz/Administrative/2011\%20WREGIS\%20Annual\%20Report.pdf.

—. 2011b. "2020 Study Report”. 10-Year Regional Transmission Plan. Western Electricity Coordinating Council.

https://www.wecc.biz/_layouts/15/WopiFrame.aspx?sourcedoc=/Reliability/2011Plan_20 20\%20Study\%20Report.pdf\&action=default.

_. 2013. "2022 Study Report”. 10-Year Regional Transmission Plan. Western Electricity Coordinating Council. https://www.wecc.biz/Reliability/2022PC1_Common_Case_StudyReport_2011SP.docx. "Xcel Energy Flips the Switch on Colorado Solar Power Plant." 2016. Denver Business Journal. Accessed January 29.

http://www.bizjournals.com/denver/blog/earth_to_power/2015/12/colorado-gets-massiveboost-in-solar-power.html. 


\section{Appendix}

The following figures and tables show the renewable resource regions within Colorado in which any RPM simulation scenario results in wind or utility-scale solar photovoltaic capacity expansions. Each resource region section contains several figures and tables of information designed to communicate the resource availability, land ownership, transmission proximity, and RPM simulation results. Each section is structured with the following information:

\section{- Resource region maps:}

- The thumbnail map in the bottom right shows the location of the highlighted resource region with the red outline. The map displays the Reference scenario simulated wind or solar capacity expansion as shaded resource regions. The map also contains the yellow border outlining the area covered by the ECRMP.

- The main "Colorado RPM Clusters" map featured in the figure focuses in on an individual resource region. Land area shaded in dark grey is unsuitable for resource development, while the land area highlighted in color is suitable for resource development following the exclusion rules outlined in (Lopez et al. 2012). The different colors of the shaded land area represent the different land ownerships (BLM, Other Federal ${ }^{30}$, Private, and Other ${ }^{31}$ ). In service and proposed transmission lines and substations are displayed in shades of purple and brown, respectively. The voltage rating of transmission infrastructure follows the legend in the bottom left of the figure. Finally, geographic information such as town names and road networks are displayed in light grey.

\section{- Suitable land area and MW potential tables:}

- Tables display the available land in acres and the corresponding resource potential in MW for lands of each ownership type within distances of 0-1 mi, 1-5 mi, 5-10 $\mathrm{mi}$, and $>10 \mathrm{mi}$ from the nearest in-service or proposed substation.

\section{- Modeled capacity tables:}

- The modeled capacity tables display the MW capacity expansion of each resource by 2030 in each RPM simulation scenario.

\section{- Proportional development preference grouped bar chart:}

- The proportional preference grouped bar chart describes a possible distribution of capacity sighting across land ownership types for each RPM simulation scenario. The distribution assumes that capacity expansion simulated in RPM scenarios is

\footnotetext{
${ }^{30}$ Other Federal: Bureau of Reclamation (BOR), Department of Defense (DOD), Department of Energy (DOE), Fish and Wildlife Service (FWS), National Parks Service (NPS), US Forest Service (USFS), Other/Unknown Federal

${ }^{31}$ Other: Jointly Owned, Non-Governmental Organization, Regional/Local, State, Tribal, Unknown
} 
built on each category of land ownership proportional to the distribution of suitable land area of each ownership type within the resource region. Each capacity bar is also shaded by the amount of suitable land within the various distances to transmission substations.

\section{- BLM development preference grouped bar chart:}

- The BLM preference grouped bar chart describes a possible distribution of capacity sighting across land ownership types assuming development takes place with the following priority order: BLM-administered land gets developed first, and other federal, "other", and private lands get developed second, third, and last. For example, consider a situation where RPM simulates a 30MW capacity expansion within a particular resource region. If BLM only administers enough land to accommodate $20 \mathrm{MW}$ of capacity within the resource region, the $20 \mathrm{MW}$ of capacity is allocated to BLM lands, and the remainder of the simulated capacity expansion is allocated first to other federal, then "other", and finally to private lands if necessary.

\section{- Private development preference grouped bar chart:}

- The private preference grouped bar chart describes a possible distribution of capacity sighting across land ownership types assuming development takes place with the following priority order: private land gets developed first, and "other", other federal, and BLM lands get developed second, third, and last. For example, consider a situation where RPM simulates a 30MW capacity expansion within a particular resource region. If private lands only account for enough land to accommodate 20MW of capacity within the resource region, the 20MW of capacity is allocated to private lands, and the remainder of the simulated capacity expansion is allocated first to "other", then other federal, and finally to BLM lands if necessary. 


\section{Wind Resource Regions}

\section{Colorado Wind Resource Regions}

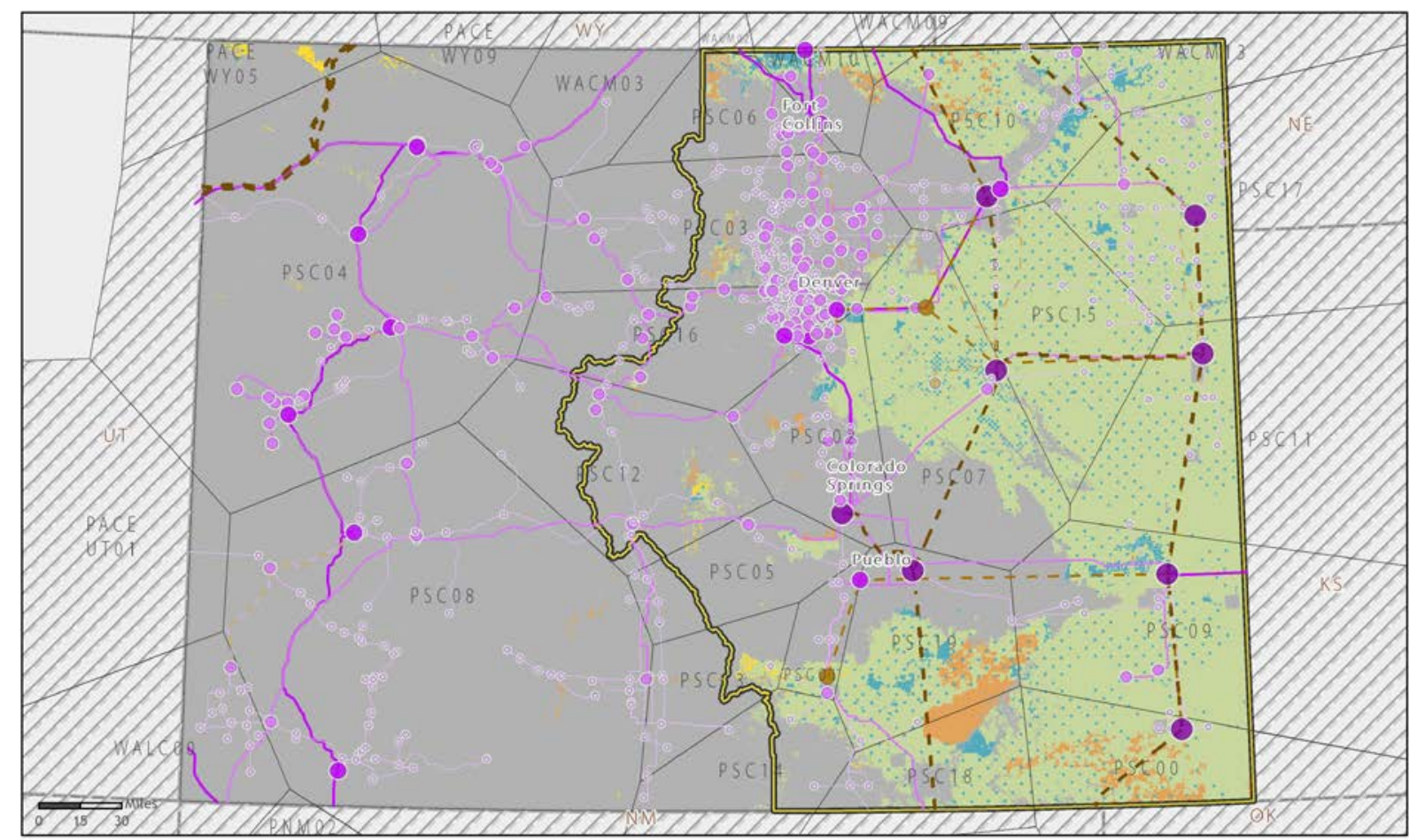

Substations and Transmission Lines
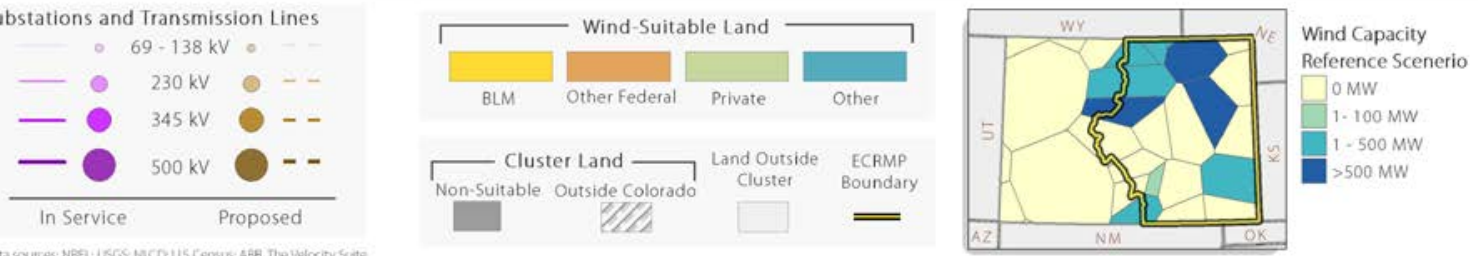

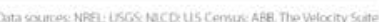

\begin{tabular}{c|cc|cc|cc|cc}
\hline \hline \multicolumn{8}{c}{ Colorado-Wind-Suitable Land: Area and MW Potential } \\
\hline Distance to & \multicolumn{2}{|c|}{$\mathbf{0 - 1}$ Miles } & \multicolumn{2}{c}{$\mathbf{1 - 5}$ Miles } & \multicolumn{2}{c}{$\mathbf{5 - 1 0}$ Miles } & \multicolumn{2}{c}{$>$ 10 Miles } \\
Transmission & Acres & MW & Acres & MW & Acres & MW & Acres & MW \\
\hline BLM & 676 & 8 & 10,742 & 130 & 35,485 & 431 & 85,689 & 1,040 \\
Federal & 286 & 3 & 35,028 & 425 & 152,692 & 1,854 & 747,768 & 9,078 \\
Other & 14,855 & 180 & 286,770 & 3,482 & 403,691 & 4,901 & 630,510 & 7,655 \\
Private & 170,090 & 2,065 & $3,482,771$ & 42,283 & $5,609,683$ & 68,105 & $8,660,317$ & 105,141 \\
\hline \hline
\end{tabular}

\begin{tabular}{ccccc}
\hline \hline \multicolumn{5}{c}{ Colorado-Modeled Wind Capacity } \\
\hline Ref & HI-NG & LO-NG & C02 & HI-RPS \\
4,428 & 6,395 & 4,080 & 10,002 & 5,758 \\
\hline \hline
\end{tabular}




\section{ECRMP Wind Resource Regions}

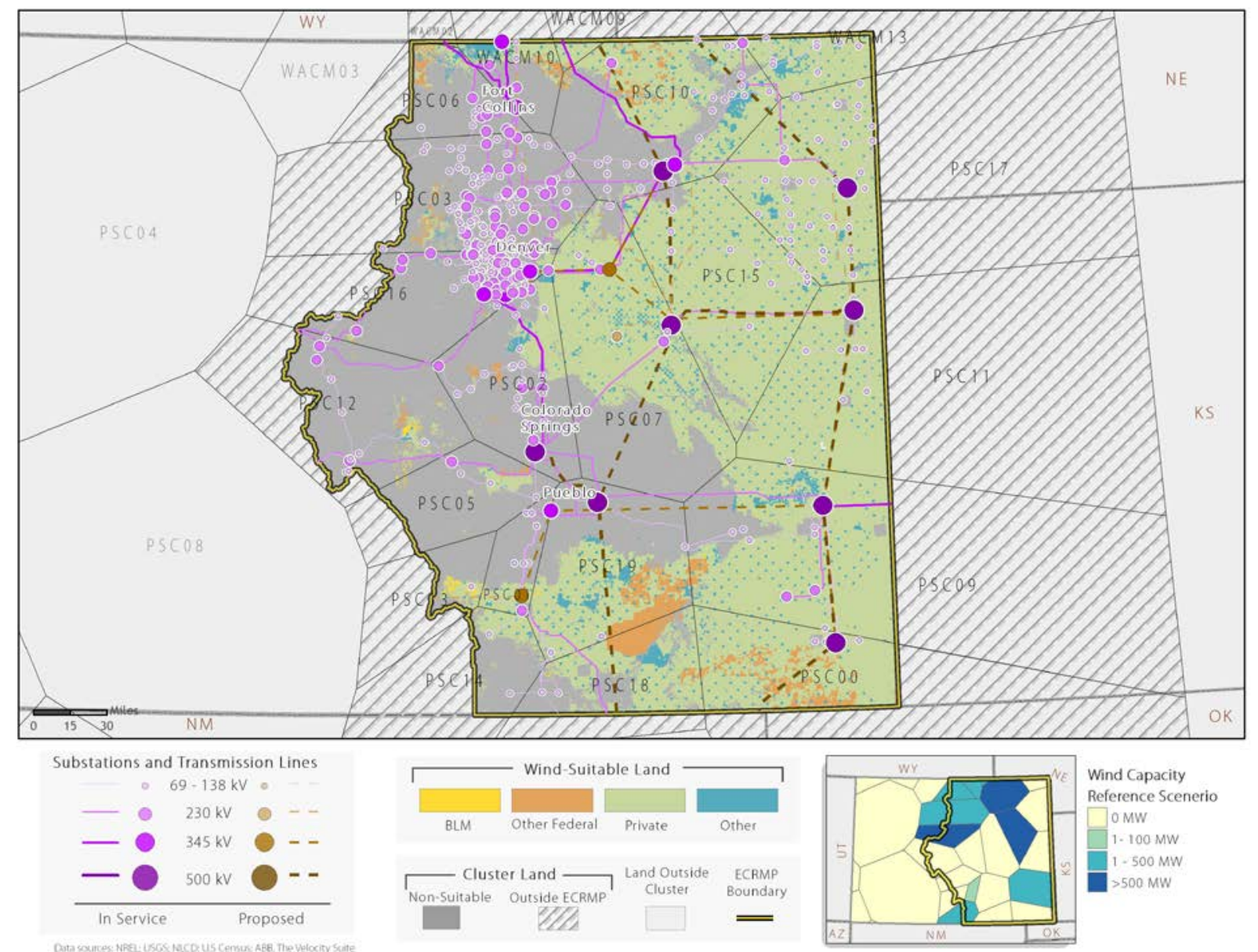

\begin{tabular}{c|cc|cc|cc|cc}
\hline \hline \multicolumn{10}{c}{ ECRMP-Wind-Suitable Land: Area and MW Potential } \\
\hline $\begin{array}{c}\text { Distance to } \\
\text { Transmission }\end{array}$ & \multicolumn{2}{c|}{$\mathbf{0 - 1}$ Miles } & \multicolumn{2}{c}{$\mathbf{1 - 5}$ Miles } & \multicolumn{2}{c}{$\mathbf{5 - 1 0}$ Miles } & \multicolumn{2}{c}{$>$ 10 Miles } \\
\hline BLM & 660 & 8 & 10,262 & 125 & 33,696 & 409 & 22,132 & 269 \\
Federal & 276 & 3 & 33,679 & 409 & 148,468 & 1,802 & 732,313 & 8,891 \\
Other & 14,855 & 180 & 286,284 & 3,476 & 403,365 & 4,897 & 624,398 & 7,581 \\
Private & 169,934 & 2,063 & $3,479,603$ & 42,244 & $5,595,939$ & 67,938 & $8,625,066$ & 104,713 \\
\hline \hline
\end{tabular}

\begin{tabular}{ccccc}
\hline \hline \multicolumn{5}{c}{ ECRMP-Modeled Wind Capacity } \\
\hline Ref & HI-NG & LO-NG & C02 & HI-RPS \\
4,428 & 6,395 & 4,080 & 9,986 & 5,758 \\
\hline \hline
\end{tabular}




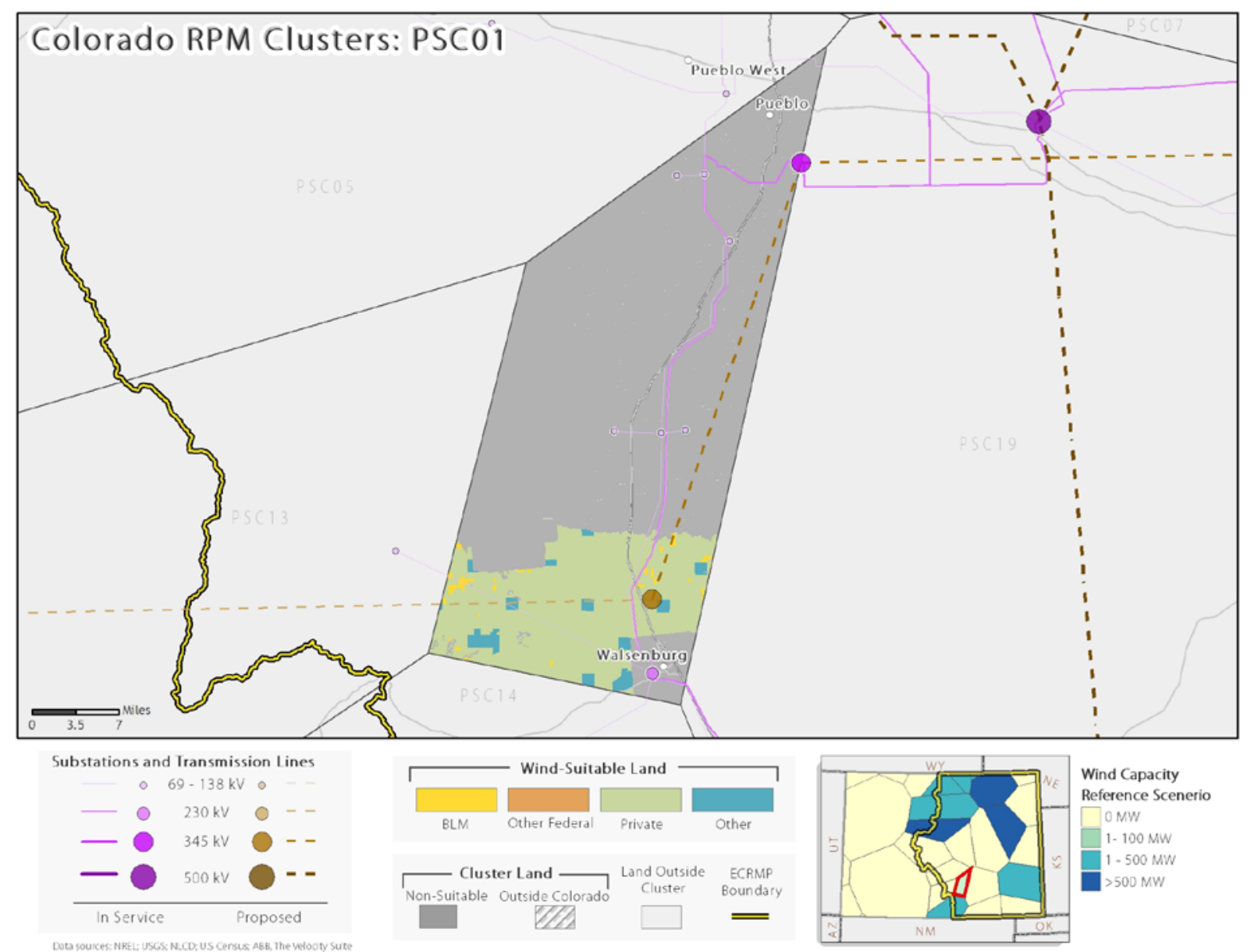

\begin{tabular}{c|cc|cc|cc|cc}
\hline \hline \multicolumn{8}{c}{ PSC1-Wind-Suitable Land: Area and MW Potential } \\
\hline $\begin{array}{c}\text { Distance to } \\
\text { Transmission }\end{array}$ & \multicolumn{2}{c|}{$\mathbf{0 - 1}$ Miles } & \multicolumn{2}{c}{$\mathbf{1 - 5}$ Miles } & \multicolumn{2}{c}{$\mathbf{5 - 1 0}$ Miles } & \multicolumn{2}{c}{$>$ 10 Miles } \\
\hline Acres & MW & Acres & MW & Acres & MW & Acres & MW \\
\hline Federal & 0 & 0 & 926 & 11 & 1,626 & 20 & 160 & 2 \\
Other & 0 & 0 & 0 & 0 & 0 & 0 & 0 & 0 \\
Private & 228 & 3 & 3,311 & 40 & 2,947 & 36 & 1,764 & 21 \\
\hline \hline
\end{tabular}

\begin{tabular}{ccccc}
\hline \hline \multicolumn{5}{c}{ PSC01-Modeled Wind Capacity } \\
\hline Ref & HI-NG & LO-NG & C02 & HI-RPS \\
29 & 29 & 29 & 1,145 & 29 \\
\hline \hline
\end{tabular}




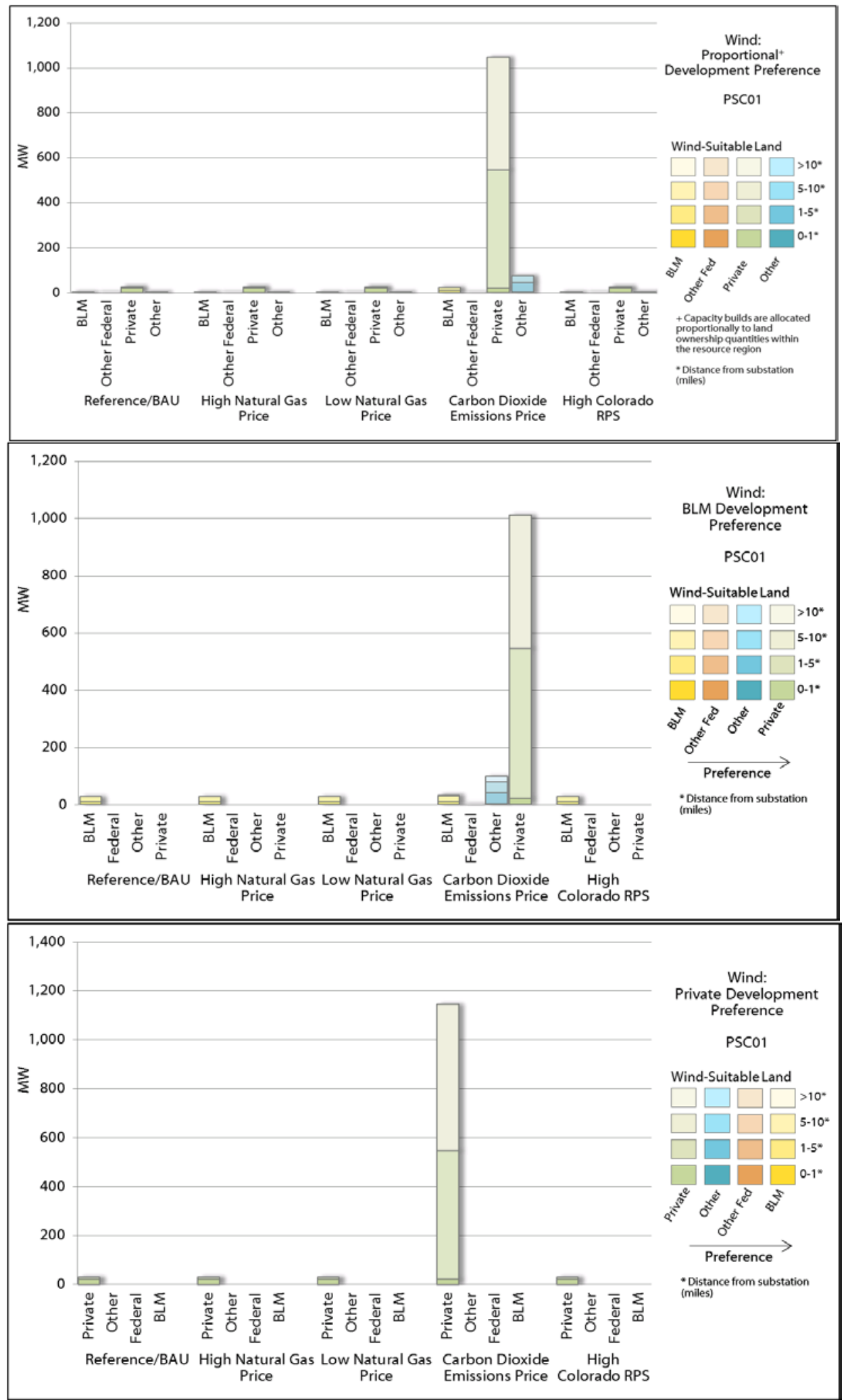

This report is available at no cost from the National Renewable Energy Laboratory (NREL at www.nrel.gov/publications. 


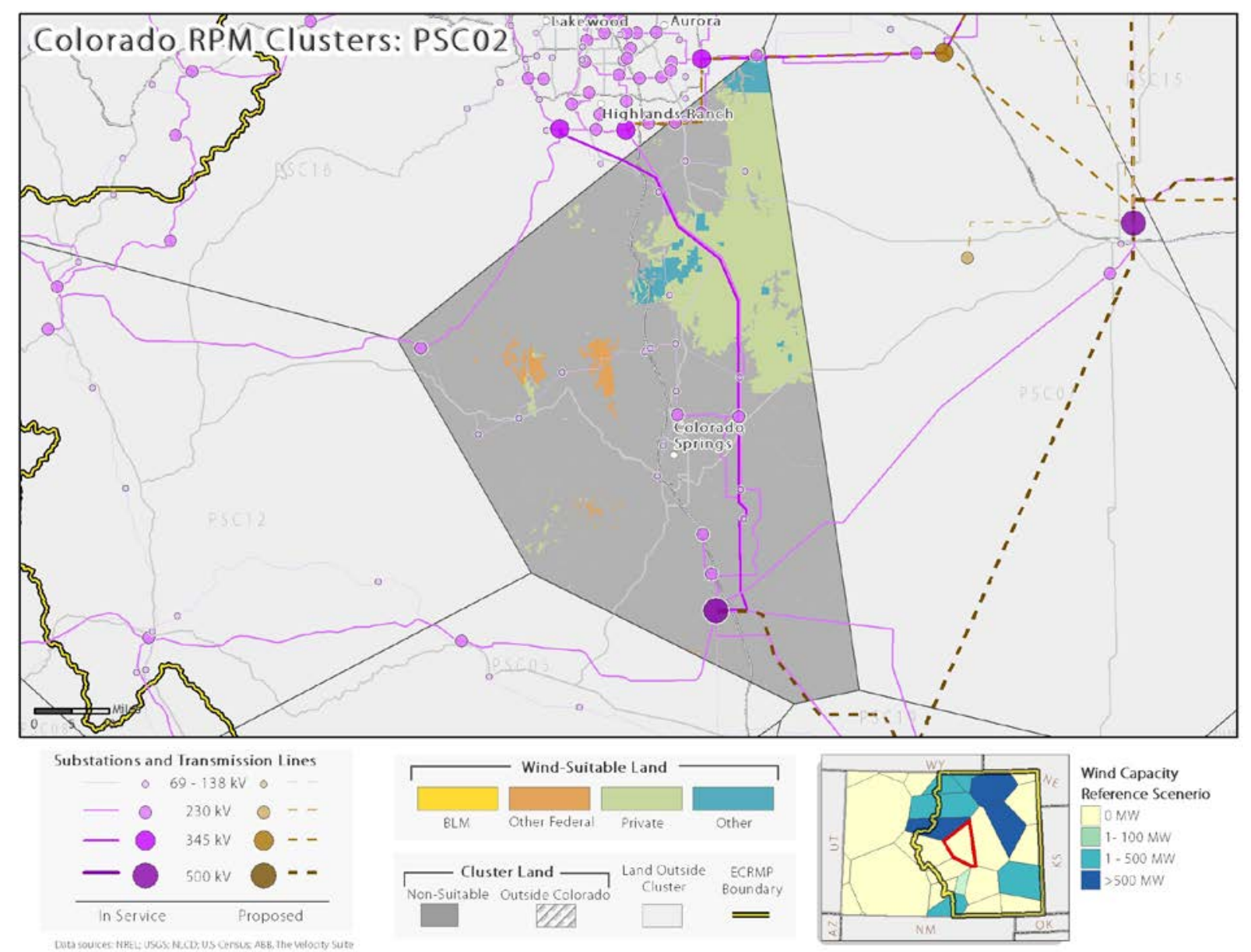

\begin{tabular}{|c|c|c|c|c|c|c|c|c|}
\hline \multicolumn{9}{|c|}{ PSC02_Wind-Suitable Land: Area and MW Potential } \\
\hline \multirow{2}{*}{$\begin{array}{l}\text { Distance to } \\
\text { Transmission }\end{array}$} & \multicolumn{2}{|c|}{ 0-1 Miles } & \multicolumn{2}{|c|}{ 1-5 Miles } & \multicolumn{2}{|c|}{ 5-10 Miles } & \multicolumn{2}{|c|}{$>10$ Miles } \\
\hline & Acres & MW & Acres & MW & Acres & MW & Acres & MW \\
\hline BLM & 0 & 0 & 27 & 0 & 10 & 0 & 197 & 2 \\
\hline Federal & 0 & 0 & 7,562 & 91 & 14,777 & 179 & 867 & 10 \\
\hline Other & 1,103 & 13 & 26,424 & 321 & 8,264 & 100 & 684 & 8 \\
\hline Private & 4,274 & 51 & 87,237 & 1,060 & 153,080 & 1,860 & 45,535 & 553 \\
\hline
\end{tabular}

\begin{tabular}{ccccc}
\hline \hline \multicolumn{5}{c}{ PSC02-Modeled Wind Capacity } \\
\hline Ref & HI-NG & LO-NG & C02 & HI-RPS \\
0 & 0 & 0 & 628 & 0 \\
\hline \hline
\end{tabular}



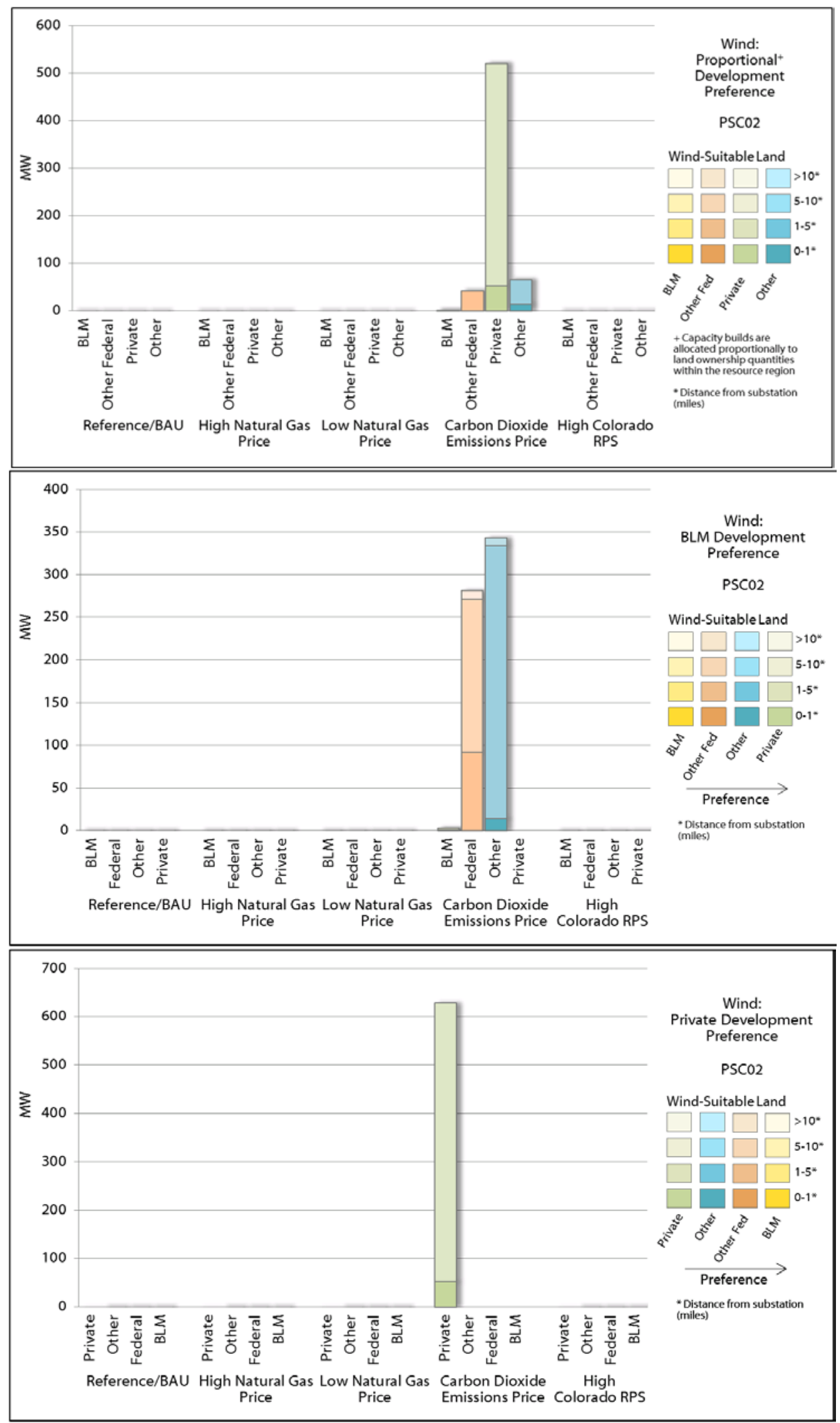

This report is available at no cost from the National Renewable Energy Laboratory (NREL at www.nrel.gov/publications. 


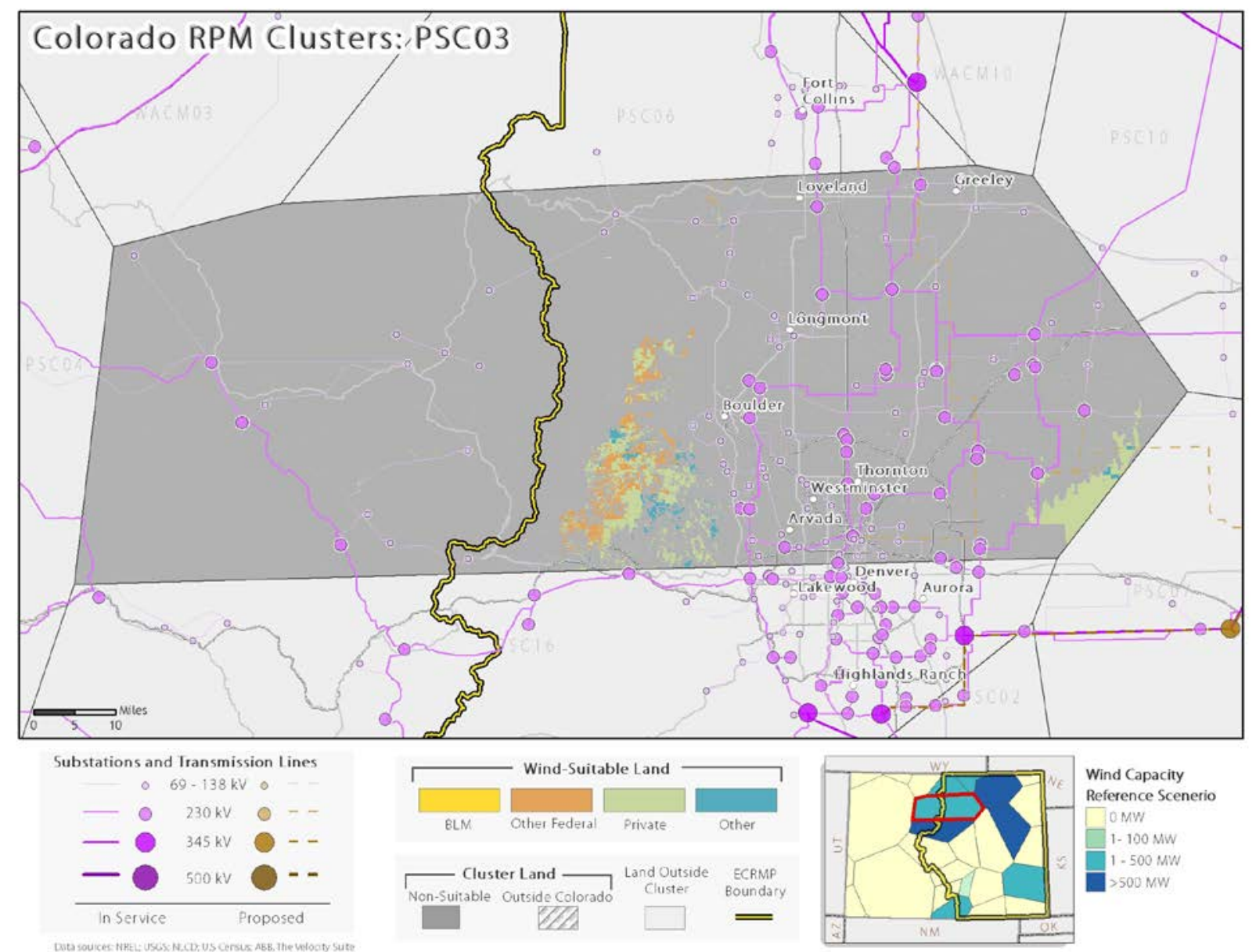

\begin{tabular}{c|cc|cc|cc|cc}
\hline \hline \multicolumn{8}{c}{ PSC3-Wind-Suitable Land: Area and MW Potential } \\
\hline $\begin{array}{c}\text { Distance to } \\
\text { Transmission }\end{array}$ & \multicolumn{2}{c|}{$\mathbf{0 - 1}$ Miles } & \multicolumn{2}{c|}{$\mathbf{1 - 5}$ Miles } & \multicolumn{2}{c}{5 -10 Miles } & \multicolumn{2}{c}{$>$ 10 Miles } \\
Acres & MW & Acres & MW & Acres & MW & Acres & MW \\
\hline BLM & 0 & 0 & 90 & 1 & 238 & 2 & 0 & 0 \\
Federal & 0 & 0 & 1,960 & 23 & 21,570 & 262 & 5,964 & 72 \\
Other & 0 & 0 & 2,579 & 31 & 6,627 & 80 & 216 & 2 \\
Private & 499 & 6 & 9,675 & 117 & 58,891 & 715 & 6,394 & 77 \\
\hline \hline
\end{tabular}

\begin{tabular}{ccccc}
\hline \hline \multicolumn{5}{c}{ PSC03-Modeled Wind Capacity } \\
\hline Ref & HI-NG & LO-NG & C02 & HI-RPS \\
275 & 607 & 275 & $1,821^{32}$ & 275 \\
\hline \hline
\end{tabular}

\footnotetext{
32 The total MW potential for wind-suitable lands in PSC03 is $1,388 \mathrm{MW}$ while RPM capacity expansion in the $\mathrm{CO}_{2}$ scenario exceeds this number by $433 \mathrm{MW}$. Excess capacity expansion results in certain regions are due to noncoterminous resource availability and prescribed capacity expansion data sets.
} 


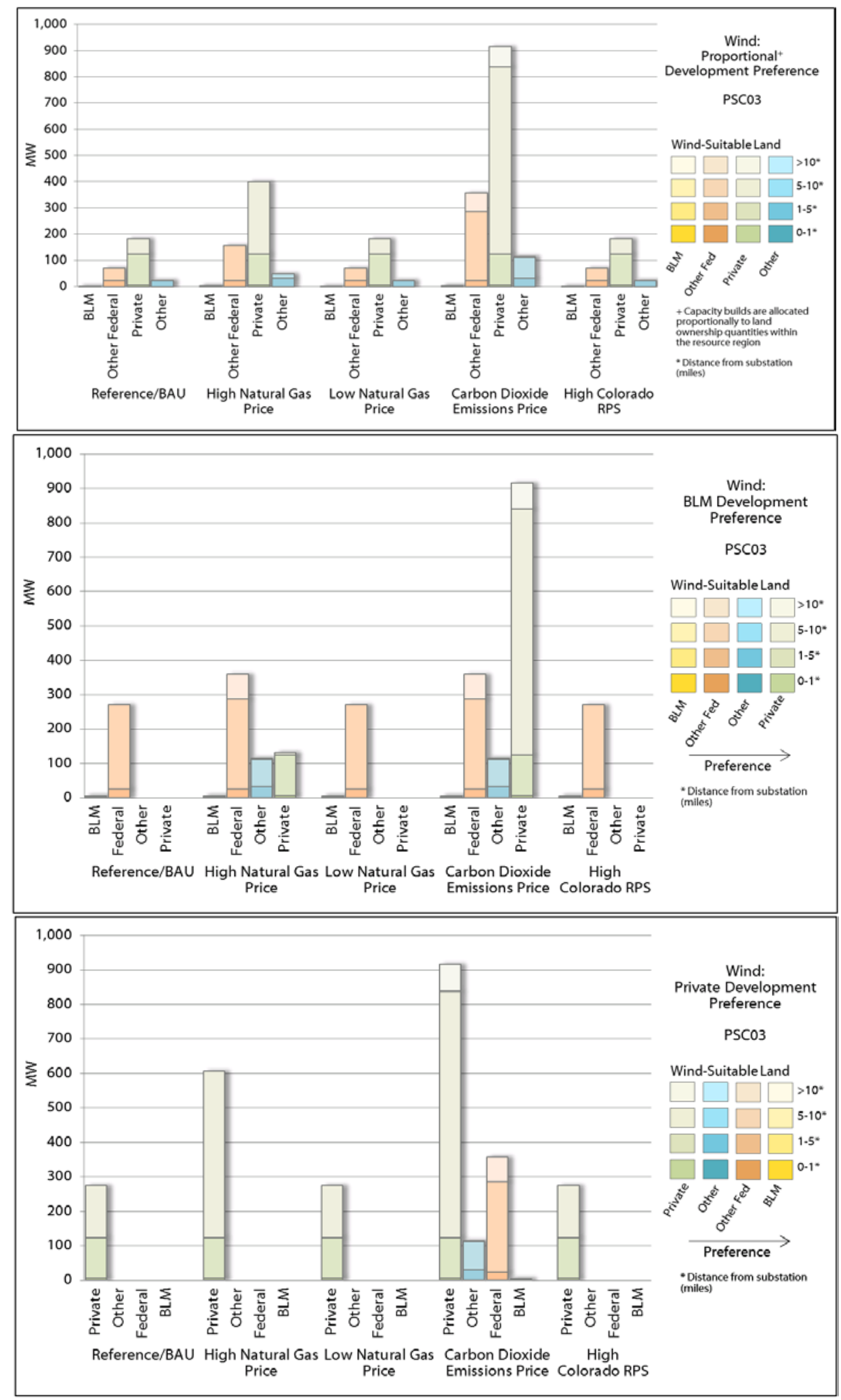

This report is available at no cost from the National Renewable Energy Laboratory (NREL at www.nrel.gov/publications. 


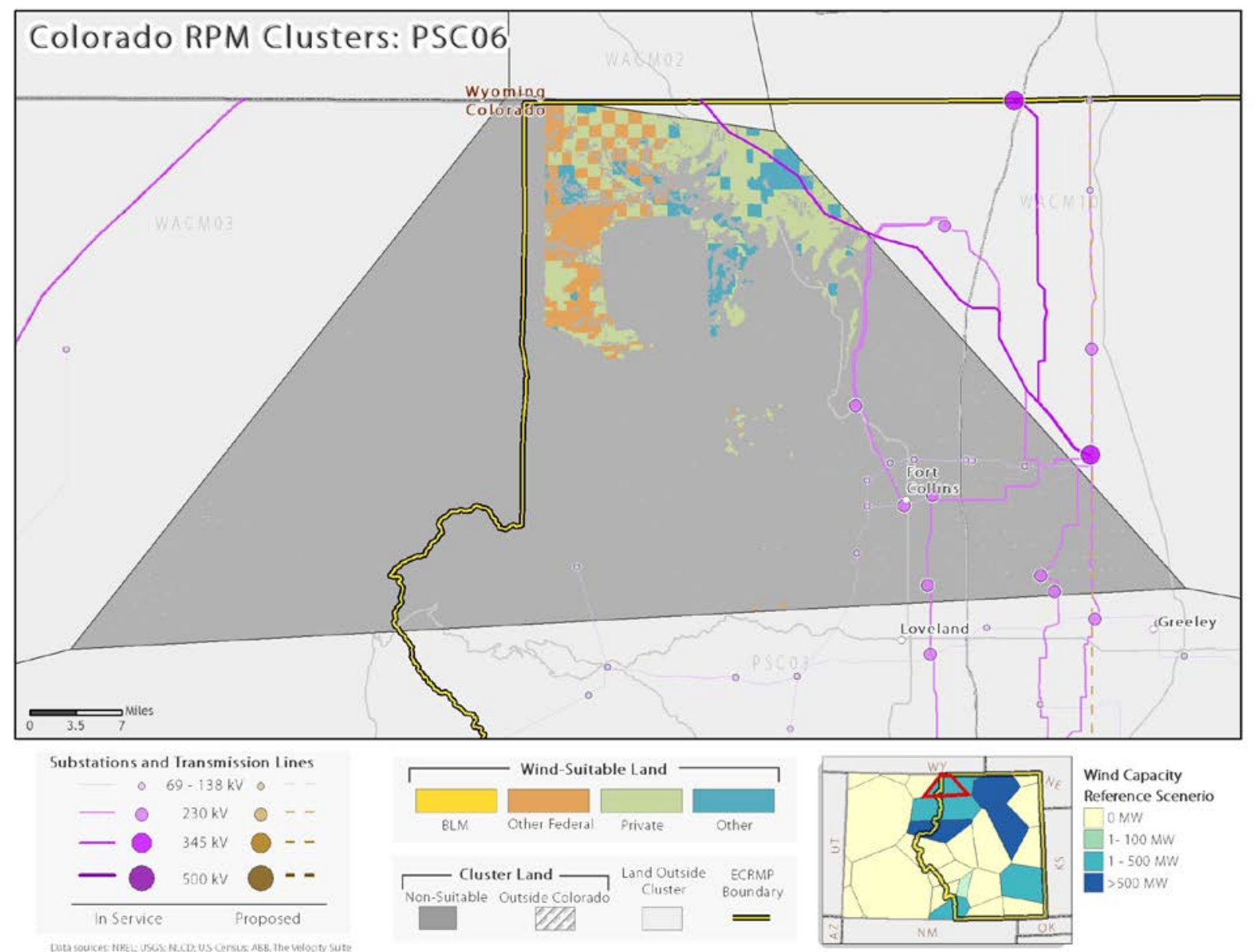

\begin{tabular}{c|cc|cc|cc|cc}
\hline \hline \multicolumn{8}{c}{ PSC06 - Wind-Suitable Land: Area and MW Potential } \\
\hline $\begin{array}{c}\text { Distance to } \\
\text { Transmission }\end{array}$ & \multicolumn{2}{c|}{-1 Miles } & \multicolumn{2}{c}{$\mathbf{1 - 5}$ Miles } & \multicolumn{2}{c}{$\mathbf{5 - 1 0}$ Miles } & \multicolumn{2}{c}{$>$ >10 Miles } \\
\hline Acres & MW & Acres & MW & Acres & MW & Acres & MW \\
\hline BLM & 0 & 0 & 0 & 0 & 16 & 0 & 0 & 0 \\
Federal & 0 & 0 & 0 & 0 & 283 & 3 & 34,608 & 420 \\
Other & 0 & 0 & 0 & 0 & 1,184 & 14 & 19,870 & 241 \\
Private & 0 & 0 & 183 & 2 & 8,824 & 107 & 58,789 & 714 \\
\hline \hline
\end{tabular}

\begin{tabular}{ccccc}
\hline \hline \multicolumn{5}{c}{ PSC06- } \\
\hline Ref & HI-NG & LO-NG & C02 & HI-RPS \\
277 & 965 & 224 & 1,171 & 670 \\
\hline \hline
\end{tabular}




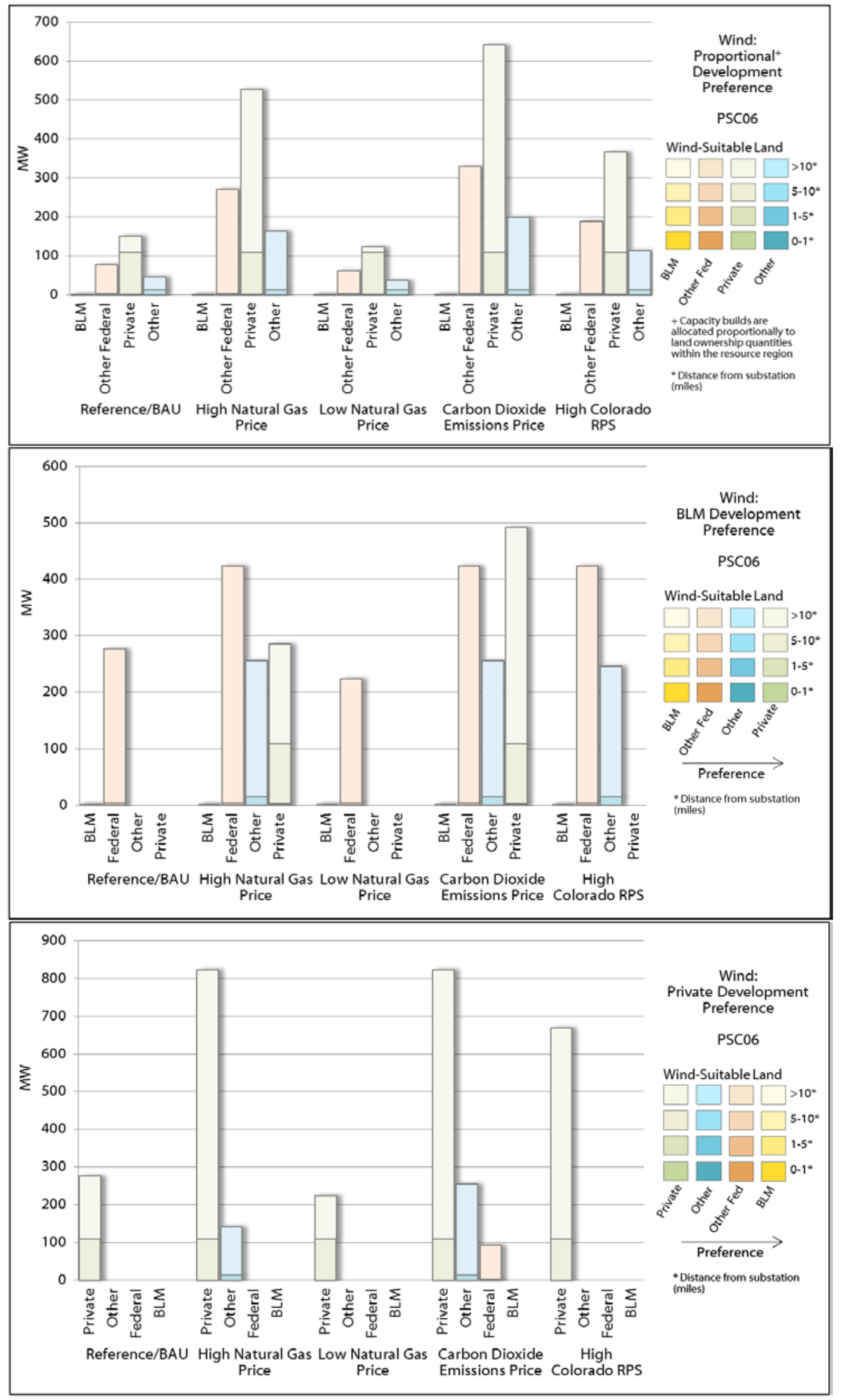




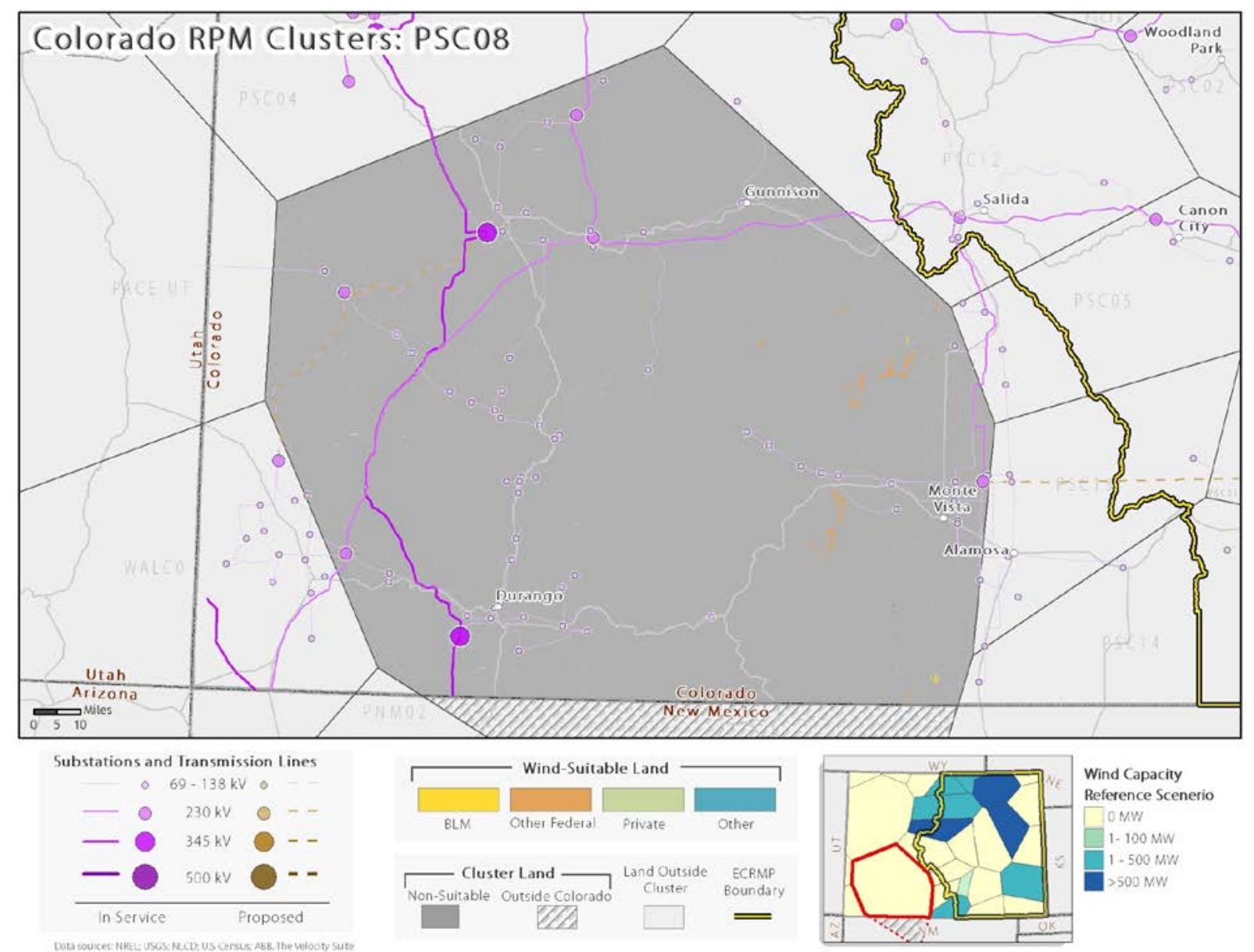

\begin{tabular}{c|cc|cc|cc|cc}
\hline \hline \multicolumn{8}{c}{ PSC08-Wind-Suitable Land: Area and MW Potential } \\
\hline $\begin{array}{c}\text { Distance to } \\
\text { Transmission }\end{array}$ & \multicolumn{2}{c|}{$\mathbf{0 - 1}$ Miles } & \multicolumn{2}{c}{$\mathbf{1 - 5}$ Miles } & \multicolumn{2}{c}{$\mathbf{5 - 1 0}$ Miles } & \multicolumn{2}{c}{$>$ 10 Miles } \\
Acres & MW & Acres & MW & Acres & MW & Acres & MW \\
\hline BLM & 0 & 0 & 25 & 0 & 741 & 9 & 514 & 6 \\
Federal & 10 & 0 & 1,278 & 15 & 3,487 & 42 & 13,518 & 164 \\
Other & 0 & 0 & 65 & 0 & 0 & 0 & 287 & 3 \\
Private & 0 & 0 & 107 & 1 & 52 & 0 & 109 & 1 \\
\hline \hline
\end{tabular}

\begin{tabular}{ccccc}
\hline \hline \multicolumn{5}{c}{ PSC08-Modeled Wind Capacity } \\
\hline Ref & HI-NG & LO-NG & C02 & HI-RPS \\
0 & 0 & 0 & 16 & 0 \\
\hline \hline
\end{tabular}




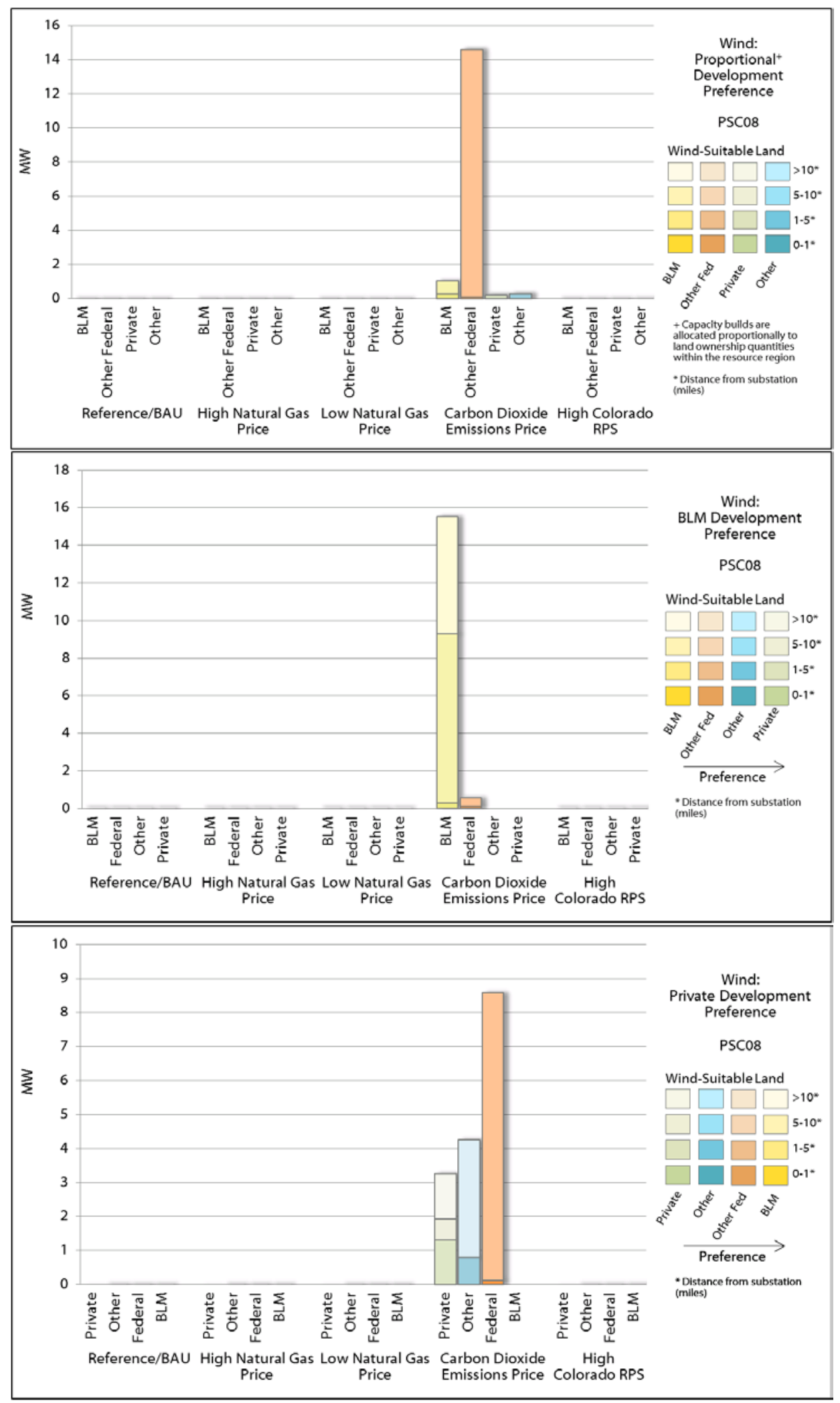

This report is available at no cost from the National Renewable Energy Laboratory (NREL at www.nrel.gov/publications. 


\section{PSC09 Wind Resource Region}

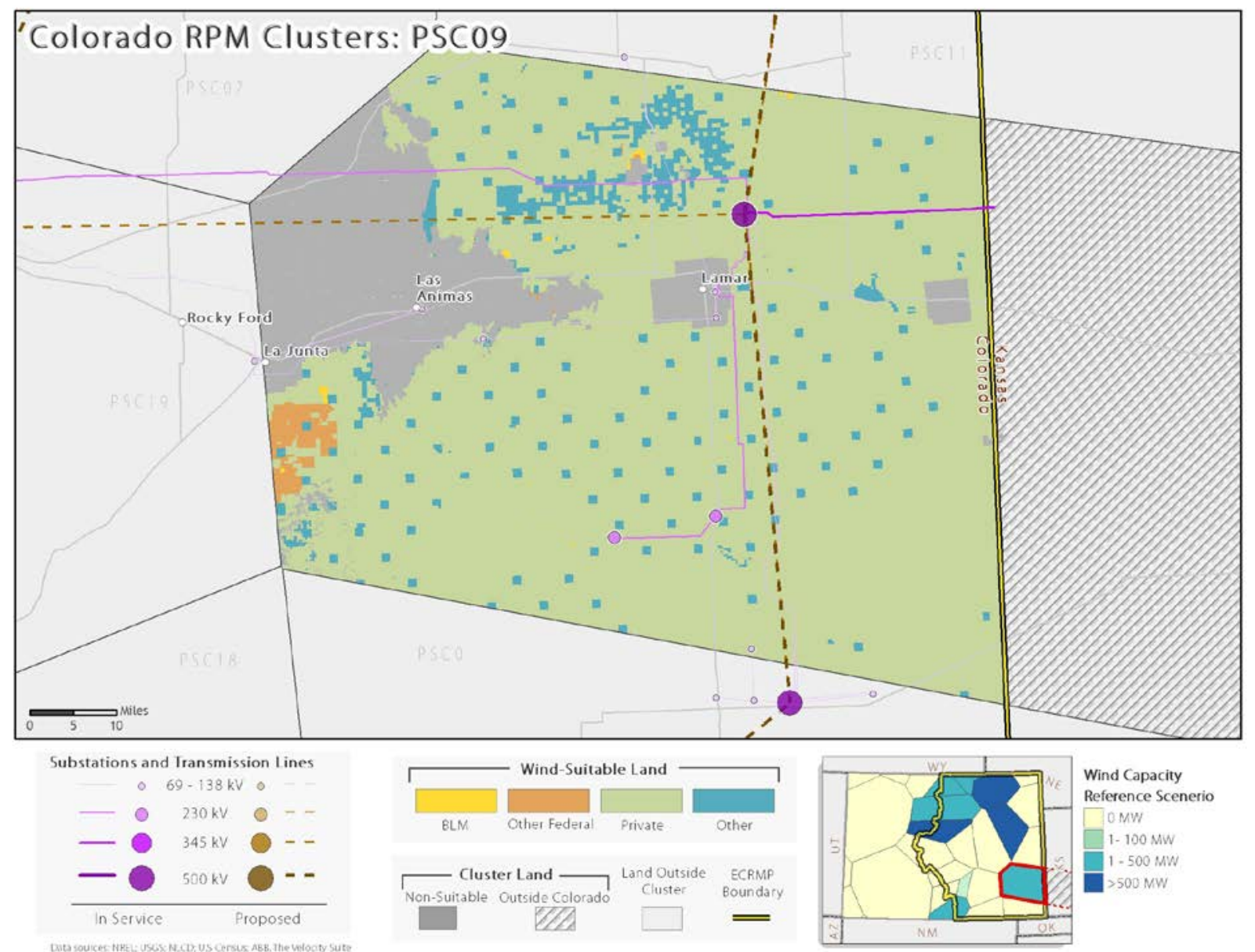

\begin{tabular}{c|cc|cc|cc|cc}
\hline \hline \multicolumn{8}{c}{ PSC09-Wind-Suitable Land: Area and MW Potential } \\
\hline $\begin{array}{c}\text { Distance to } \\
\text { Transmission }\end{array}$ & $\mathbf{0 - 1}$ Miles & \multicolumn{2}{c}{ 1-5 Miles } & \multicolumn{2}{c}{$\mathbf{5 - 1 0}$ Miles } & \multicolumn{2}{c}{$>$ 10 Miles } \\
\hline Acres & MW & Acres & MW & Acres & MW & Acres & MW \\
\hline Federal & 0 & 0 & 90 & 1 & 1,809 & 21 & 1,882 & 22 \\
Other & 0 & 0 & 33 & 0 & 13,469 & 163 & 18,803 & 228 \\
Private & 533 & 6 & 12,491 & 151 & 57,470 & 698 & 106,279 & 1,291 \\
\hline \hline
\end{tabular}

\begin{tabular}{ccccc}
\hline \hline \multicolumn{5}{c}{ PSC09_Modeled Wind Capacity } \\
\hline Ref & HI-NG & LO-NG & C02 & HI-RPS \\
237 & 237 & 237 & 237 & 237 \\
\hline \hline
\end{tabular}



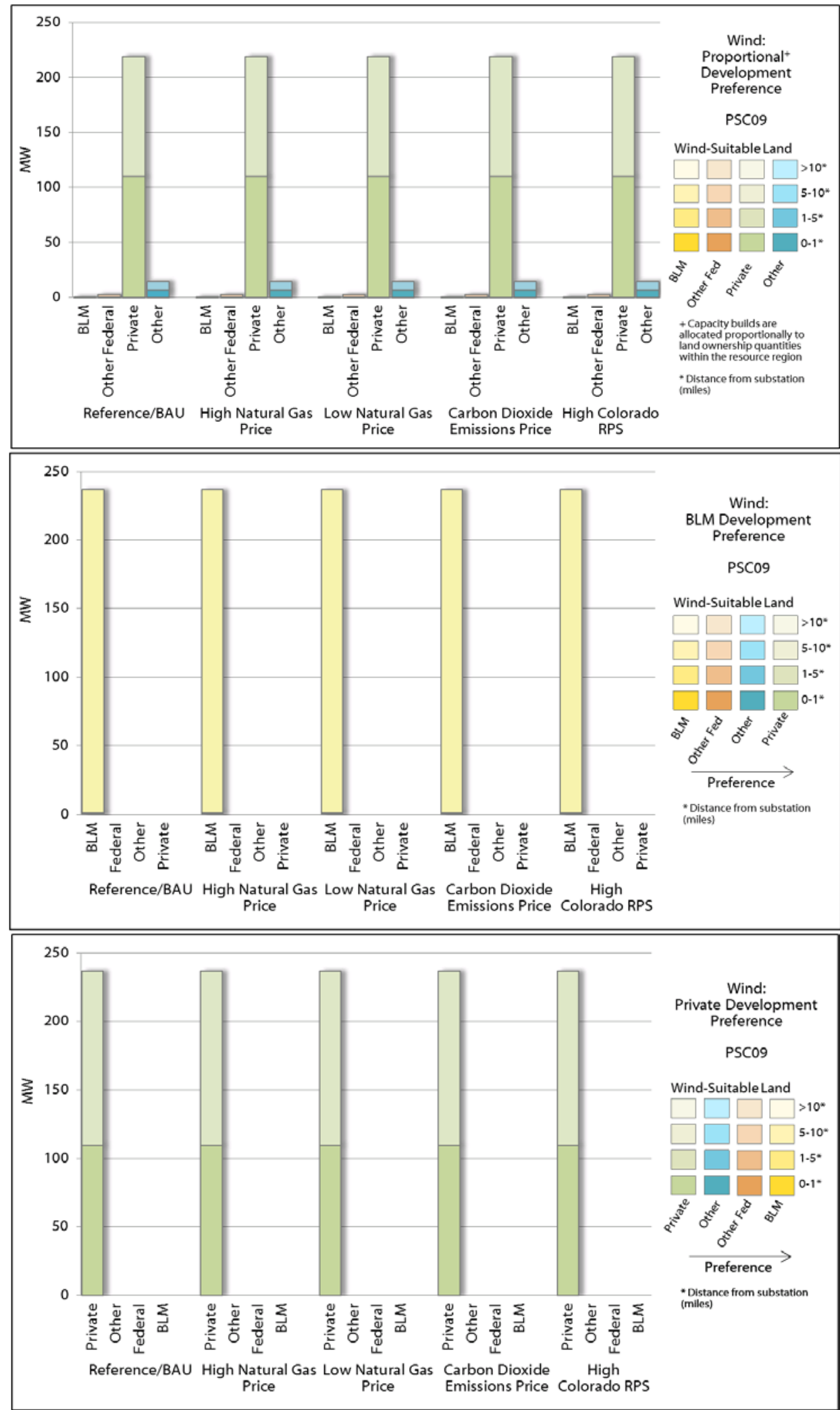


\section{PSC10 Wind Resource Region}

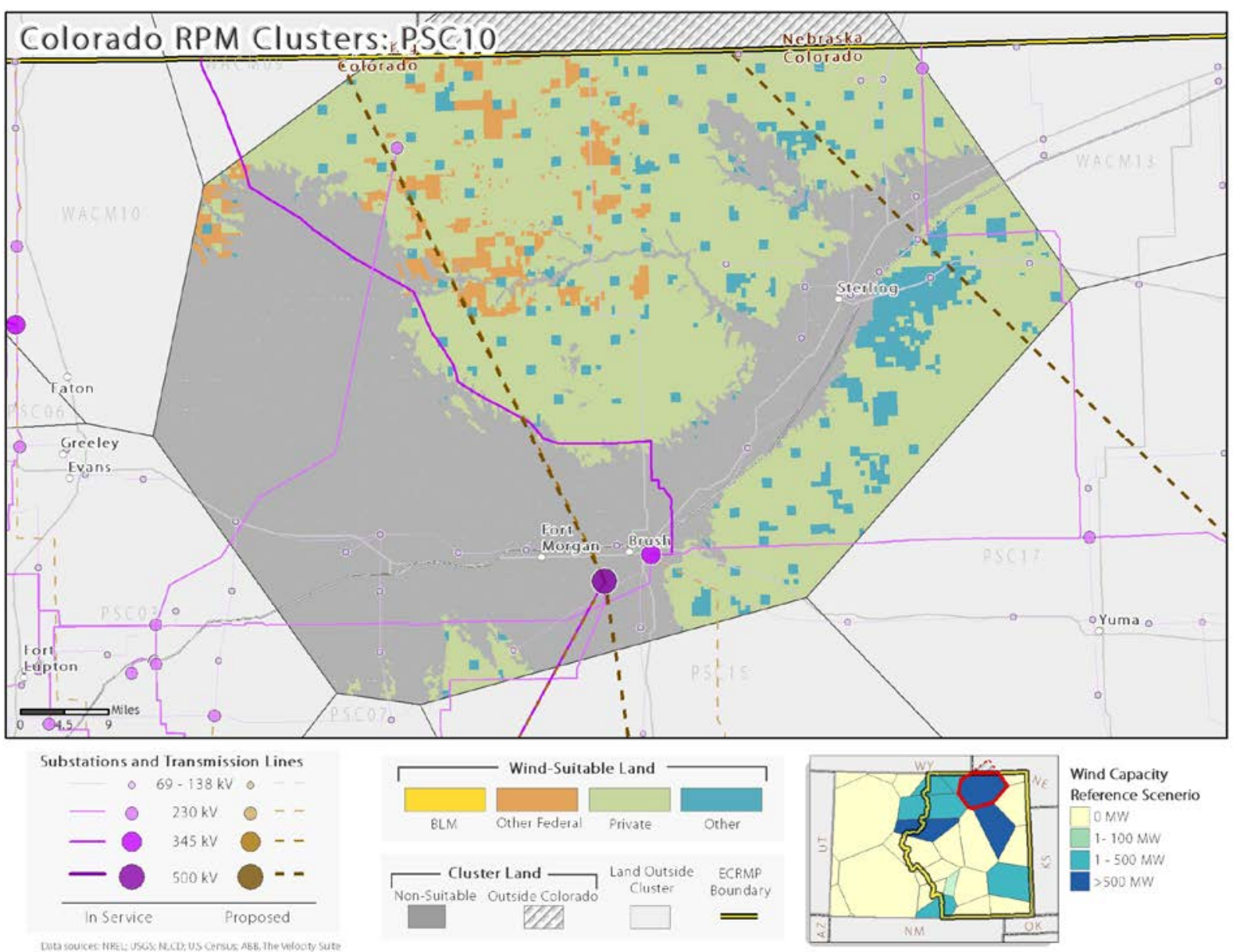

\begin{tabular}{c|cc|cc|cc|cc}
\hline \hline \multicolumn{8}{c}{ PSC10-Wind-Suitable Land: Area and MW Potential } \\
\hline $\begin{array}{c}\text { Distance to } \\
\text { Transmission }\end{array}$ & A-1 Miles & \multicolumn{2}{|c|}{$\mathbf{1 - 5}$ Miles } & \multicolumn{2}{c}{$\mathbf{5 - 1 0}$ Miles } & \multicolumn{2}{c}{$>$ >10 Miles } \\
\hline BLM & 0 & 0 & 0 & 0 & 105 & 1 & 56 & 0 \\
Federal & 0 & 0 & 4,289 & 52 & 16,839 & 204 & 70,446 & 856 \\
Other & 2,283 & 27 & 54,102 & 657 & 58,238 & 707 & 43,326 & 526 \\
Private & 15,575 & 189 & 275,559 & 3,348 & 524,775 & 6,377 & 537,298 & 6,529 \\
\hline \hline
\end{tabular}

\begin{tabular}{ccccc}
\hline \hline \multicolumn{5}{c}{ PSC10-Modeled Wind Capacity } \\
\hline Ref & HI-NG & LO-NG & C02 & HI-RPS \\
1,131 & 1,001 & 1,001 & 1,131 & 1,131 \\
\hline \hline
\end{tabular}



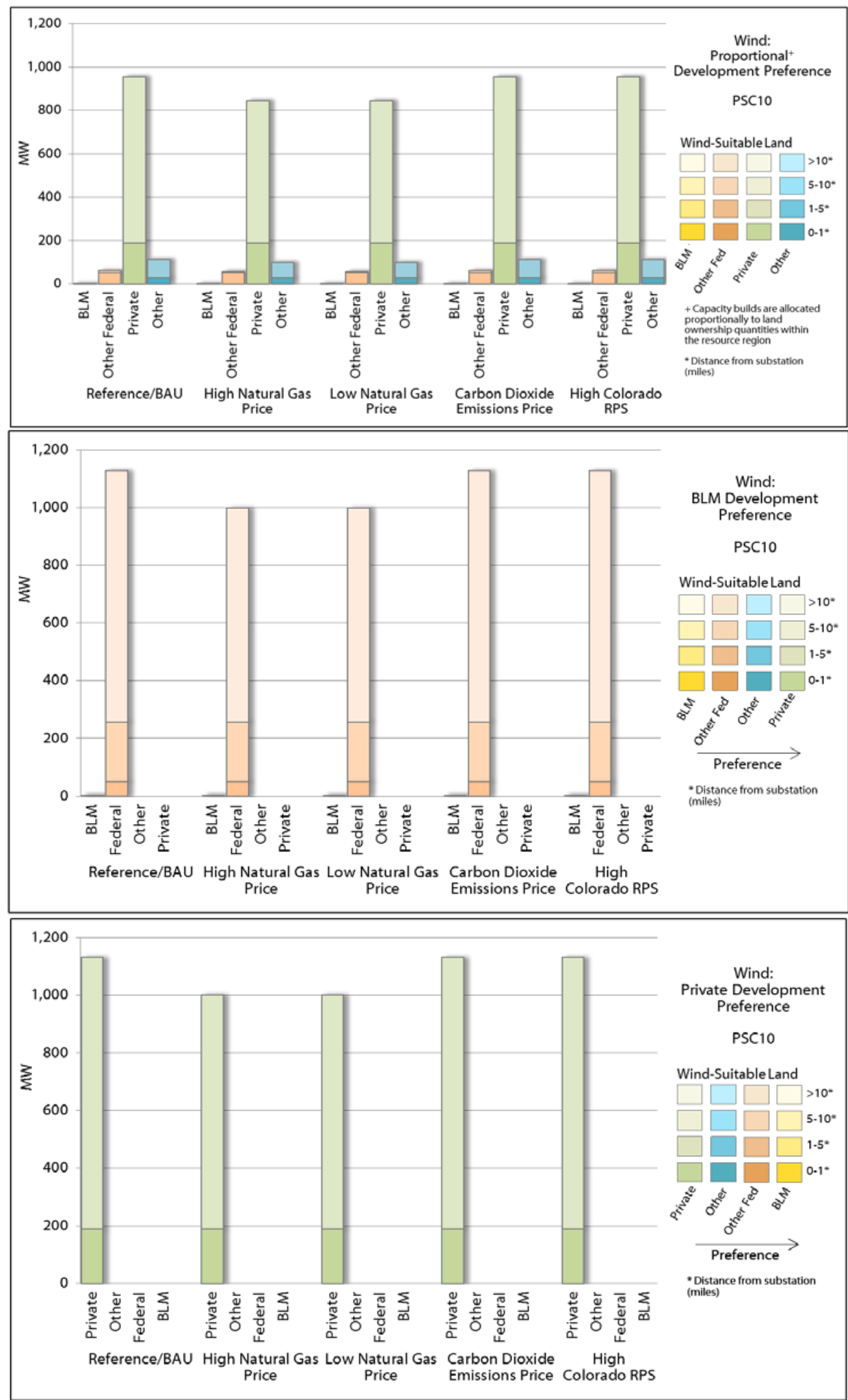


\section{PSC12 Wind Resource Region}

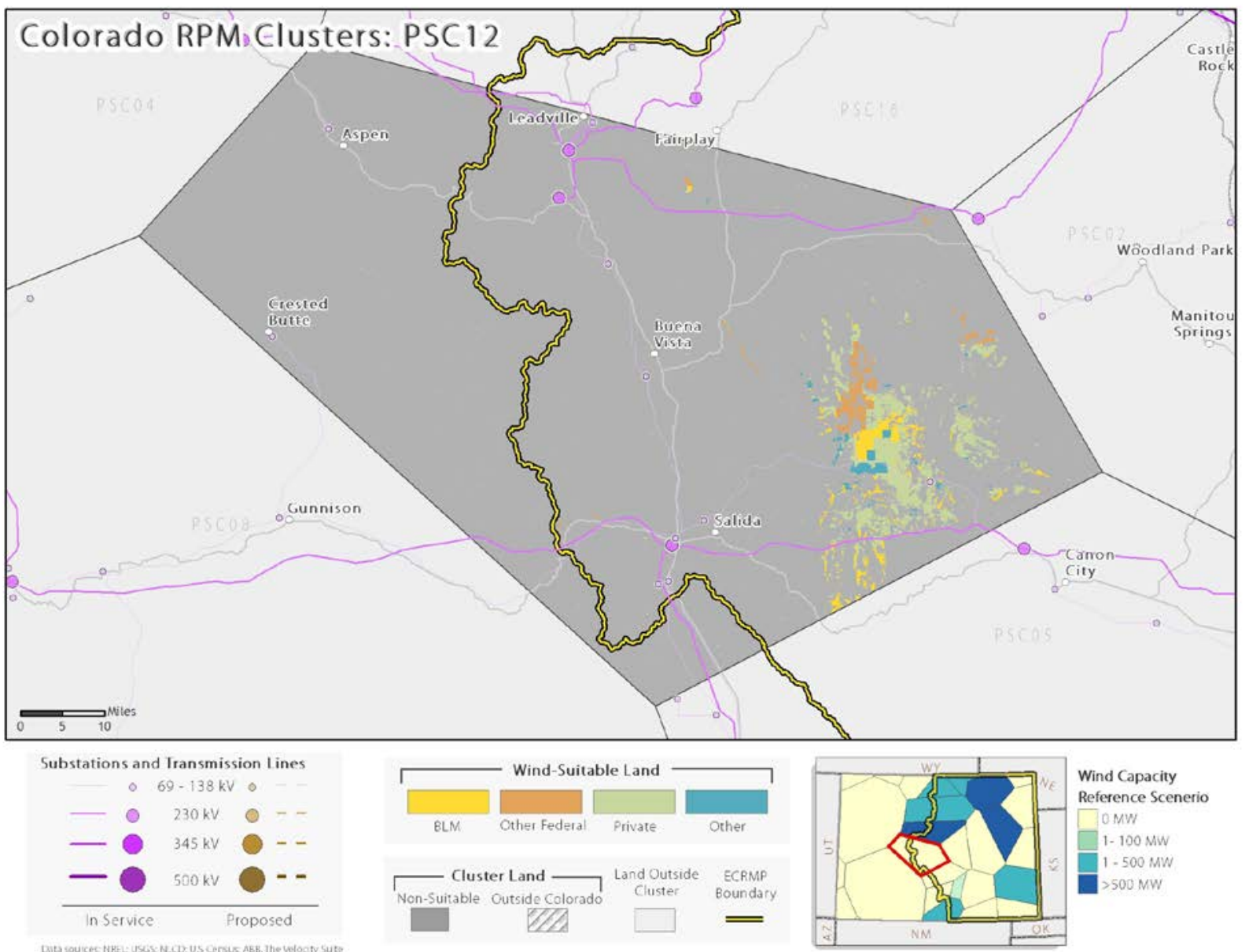

\begin{tabular}{c|cc|cc|cc|cc}
\hline \hline \multicolumn{8}{c}{ PSC12-Wind-Suitable Land: Area and MW Potential } \\
\hline Distance to & \multicolumn{2}{c|}{$\mathbf{0 - 1}$ Miles } & \multicolumn{2}{c|}{$\mathbf{1 - 5}$ Miles } & \multicolumn{2}{c}{$\mathbf{5 - 1 0}$ Miles } & \multicolumn{2}{c}{$>$ 10 Miles } \\
Transmission & Acres & MW & Acres & MW & Acres & MW & Acres & MW \\
\hline BLM & 230 & 2 & 1,506 & 18 & 11,751 & 142 & 7,706 & 93 \\
Federal & 0 & 0 & 1 & 0 & 2,946 & 35 & 12,587 & 152 \\
Other & 91 & 1 & 608 & 7 & 5,288 & 64 & 2,227 & 27 \\
Private & 414 & 5 & 14,534 & 176 & 31,796 & 386 & 17,677 & 214 \\
\hline \hline
\end{tabular}

\begin{tabular}{ccccc}
\hline \hline \multicolumn{5}{c}{ PSC12-Modeled Wind Capacity } \\
\hline Ref & HI-NG & LO-NG & C02 & HI-RPS \\
0 & 0 & 0 & 388 & 0 \\
\hline \hline
\end{tabular}



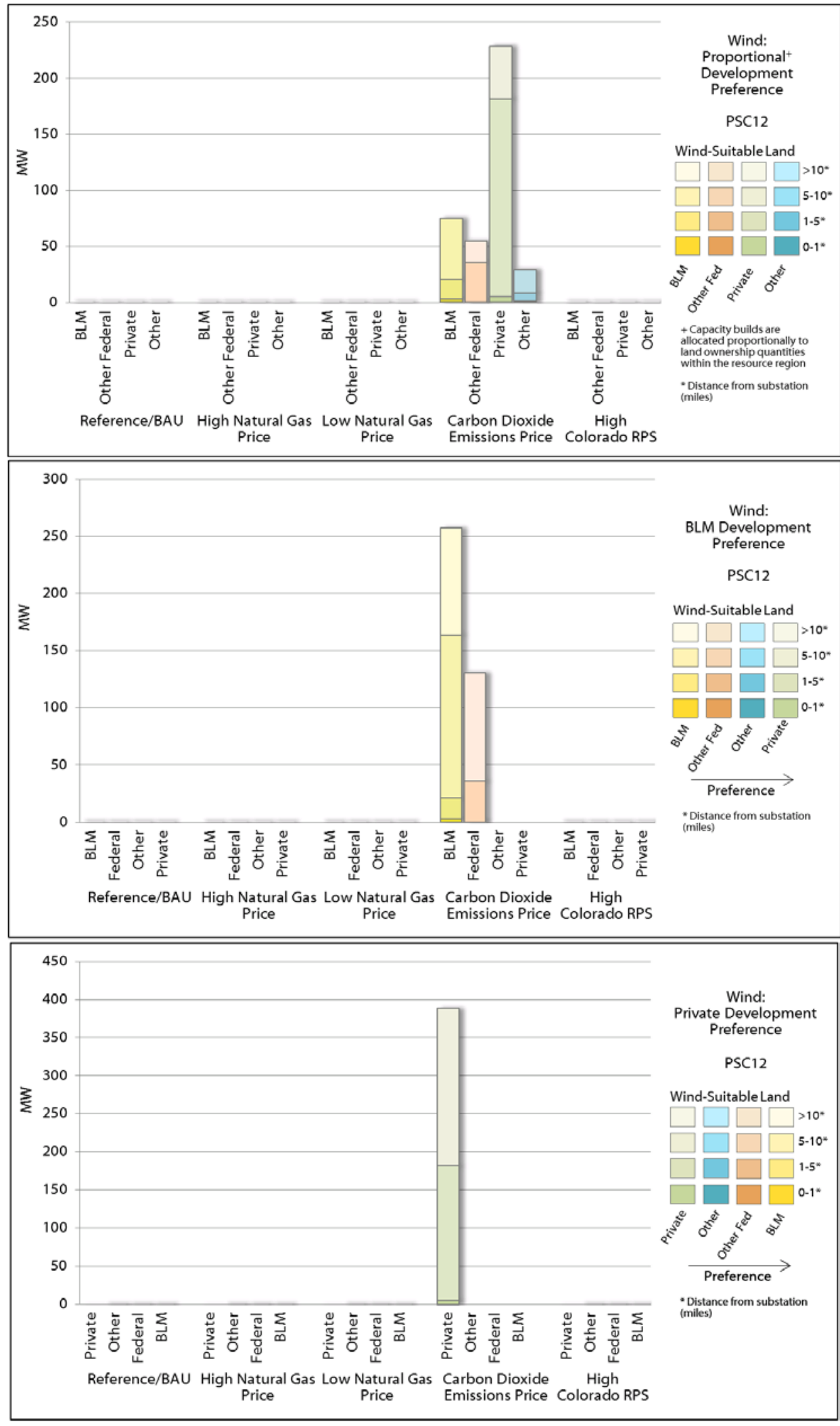


\section{PSC13 Wind Resource Region}

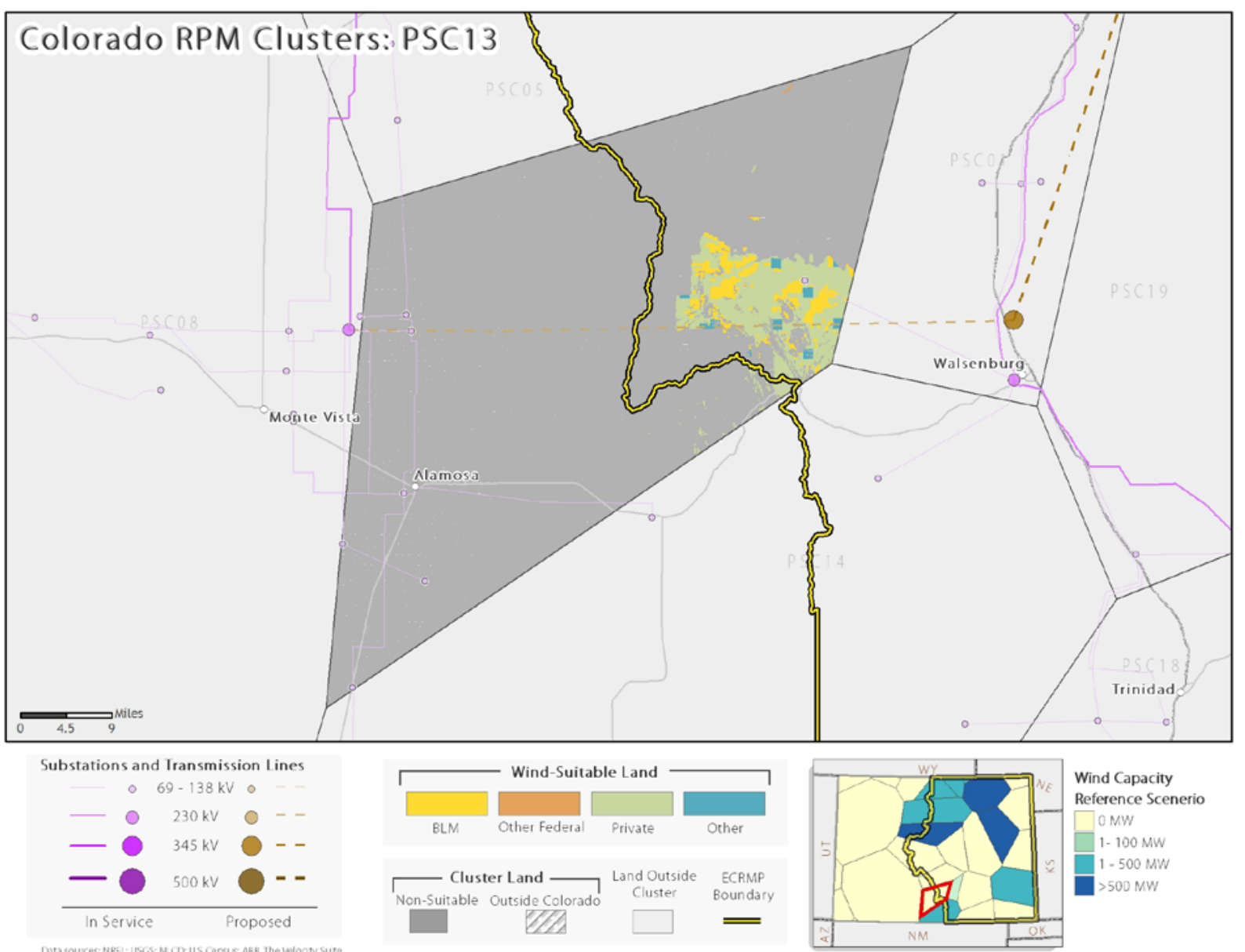

\begin{tabular}{c|cc|cc|cc|cc}
\hline \hline \multicolumn{8}{c}{ PSC13-Wind-Suitable Land: Area and MW Potential } \\
\hline $\begin{array}{c}\text { Distance to } \\
\text { Transmission }\end{array}$ & A-1 Miles & \multicolumn{2}{c}{$\mathbf{1 - 5}$ Miles } & \multicolumn{2}{c}{5 -10 Miles } & \multicolumn{2}{c}{$>$ 10 Miles } \\
\hline BLM & 430 & 5 & 6,933 & 84 & 10,654 & 129 & 2,168 & 26 \\
Federal & 0 & 0 & 0 & 0 & 92 & 1 & 165 & 2 \\
Other & 148 & 1 & 1,517 & 18 & 2,027 & 24 & 696 & 8 \\
Private & 1,432 & 17 & 23,758 & 288 & 27,619 & 335 & 10,253 & 124 \\
\hline \hline
\end{tabular}

\begin{tabular}{ccccc}
\hline \hline \multicolumn{5}{c}{ PSC13-Modeled Wind Capacity } \\
\hline Ref & HI-NG & LO-NG & C02 & HI-RPS \\
0 & 540 & 0 & 540 & 540 \\
\hline \hline
\end{tabular}




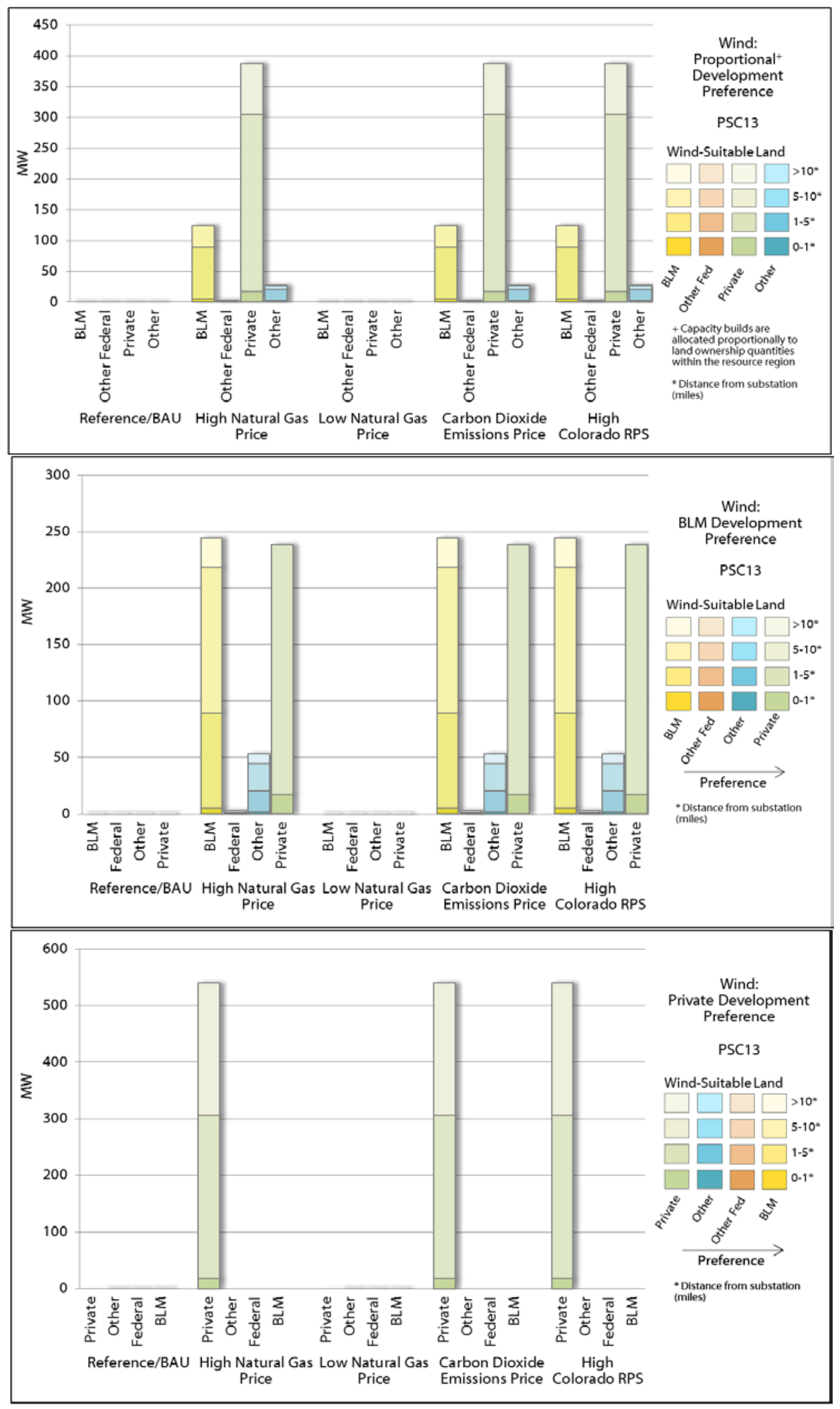




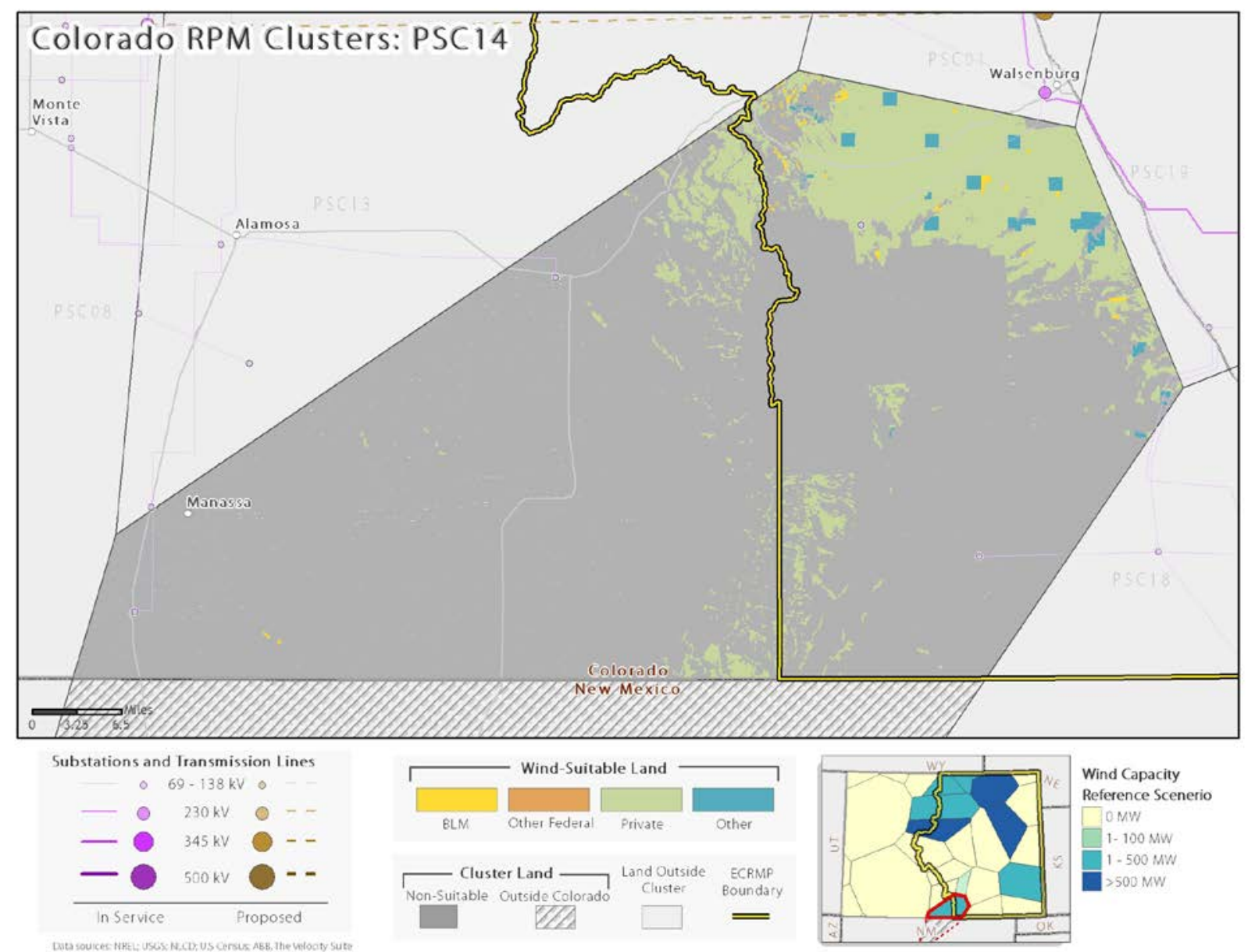

\begin{tabular}{c|cc|cc|cc|cc}
\hline \hline \multicolumn{8}{c}{ PSC14-Wind-Suitable Land: Area and MW Potential } \\
\hline Distance to & \multicolumn{2}{c|}{$\mathbf{0 - 1}$ Miles } & \multicolumn{2}{c|}{$\mathbf{1 - 5}$ Miles } & \multicolumn{2}{c}{5 -10 Miles } & \multicolumn{2}{c}{$>$ 10 Miles } \\
Transmission & Acres & MW & Acres & MW & Acres & MW & Acres & MW \\
\hline BLM & 0 & 0 & 174 & 2 & 2,331 & 28 & 534 & 6 \\
Federal & 0 & 0 & 0 & 0 & 0 & 0 & 0 & 0 \\
Other & 0 & 0 & 811 & 9 & 6,825 & 82 & 1,585 & 19 \\
Private & 1,789 & 21 & 37,196 & 452 & 103,813 & 1,261 & 51,224 & 622 \\
\hline \hline
\end{tabular}

\begin{tabular}{ccccc}
\hline \hline \multicolumn{5}{c}{ PSC14-Modeled Wind Capacity } \\
\hline Ref & HI-NG & LO-NG & C02 & HI-RPS \\
225 & 540 & 0 & 540 & 540 \\
\hline \hline
\end{tabular}



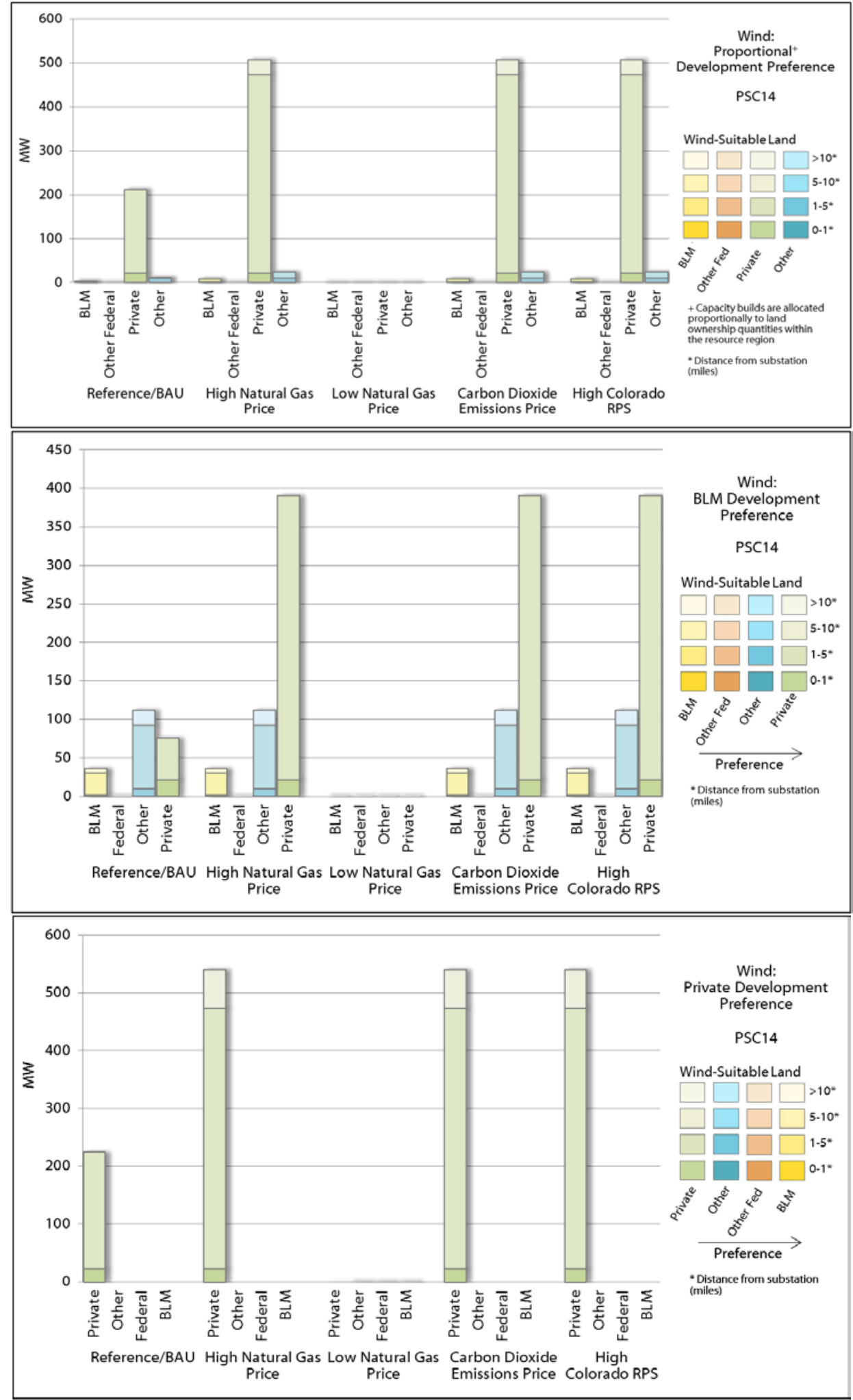


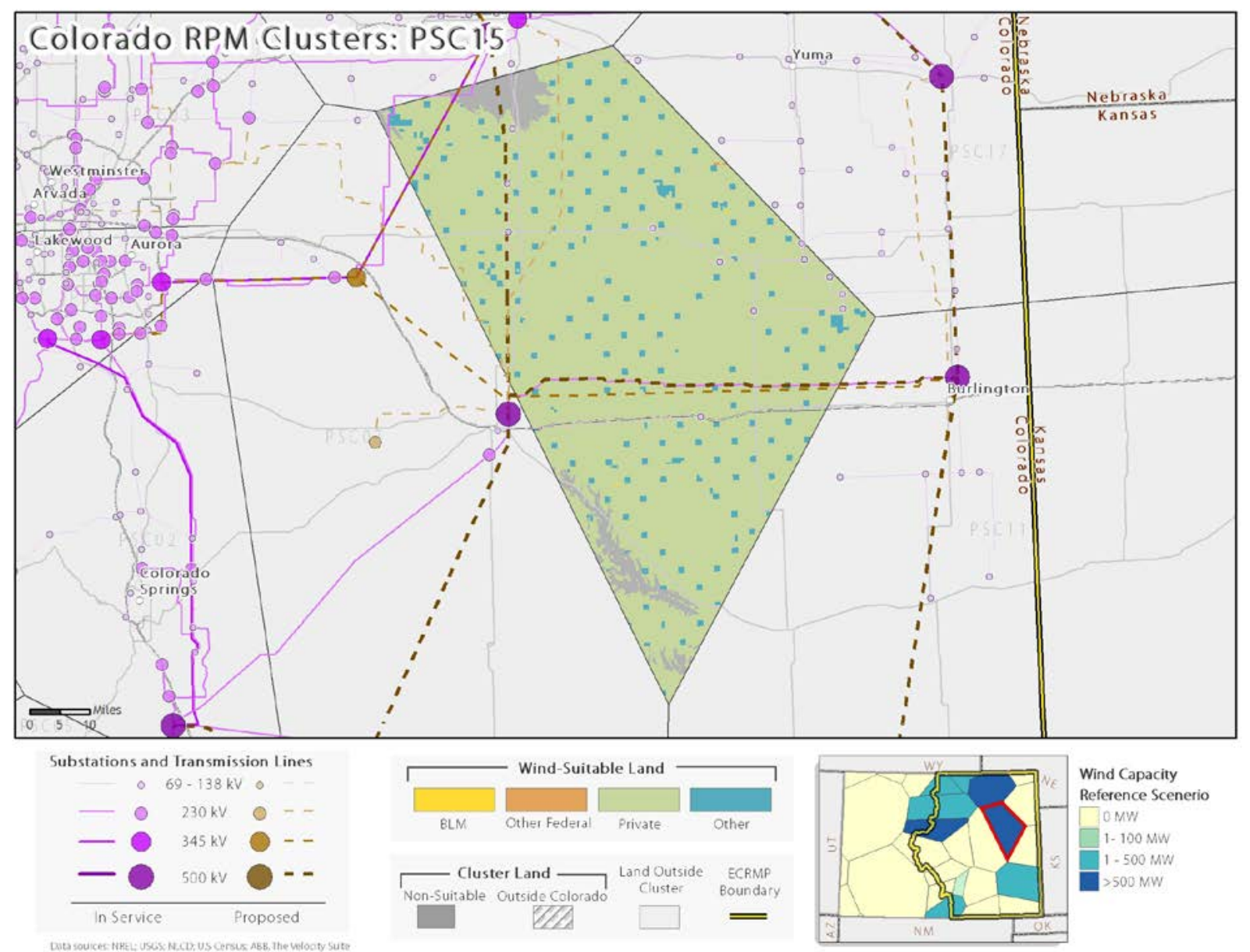

\begin{tabular}{c|cc|cc|cc|cc}
\hline \hline \multicolumn{10}{c}{ PSC15-Wind-Suitable Land: Area and MW Potential } \\
\hline Distance to & \multicolumn{2}{|c|}{$\mathbf{0 - 1}$ Miles } & \multicolumn{2}{c|}{$\mathbf{1 - 5}$ Miles } & \multicolumn{2}{c}{5 -10 Miles } & \multicolumn{2}{c}{$>$ 10 Miles } \\
Transmission & Acres & MW & Acres & MW & Acres & MW & Acres & MW \\
\hline BLM & 0 & 0 & 0 & 0 & 157 & 1 & 240 & 2 \\
Federal & 0 & 0 & 613 & 7 & 0 & 0 & 0 & 0 \\
Other & 135 & 1 & 22,795 & 277 & 45,961 & 558 & 52,738 & 640 \\
Private & 23,295 & 283 & 434,978 & 5,286 & 908,865 & 11,045 & $1,205,957$ & 14,655 \\
\hline \hline
\end{tabular}

\begin{tabular}{ccccc}
\hline \hline \multicolumn{5}{c}{ PSC15-Modeled Wind Capacity } \\
\hline Ref & HI-NG & LO-NG & C02 & HI-RPS \\
643 & 643 & 643 & 643 & 643 \\
\hline \hline
\end{tabular}



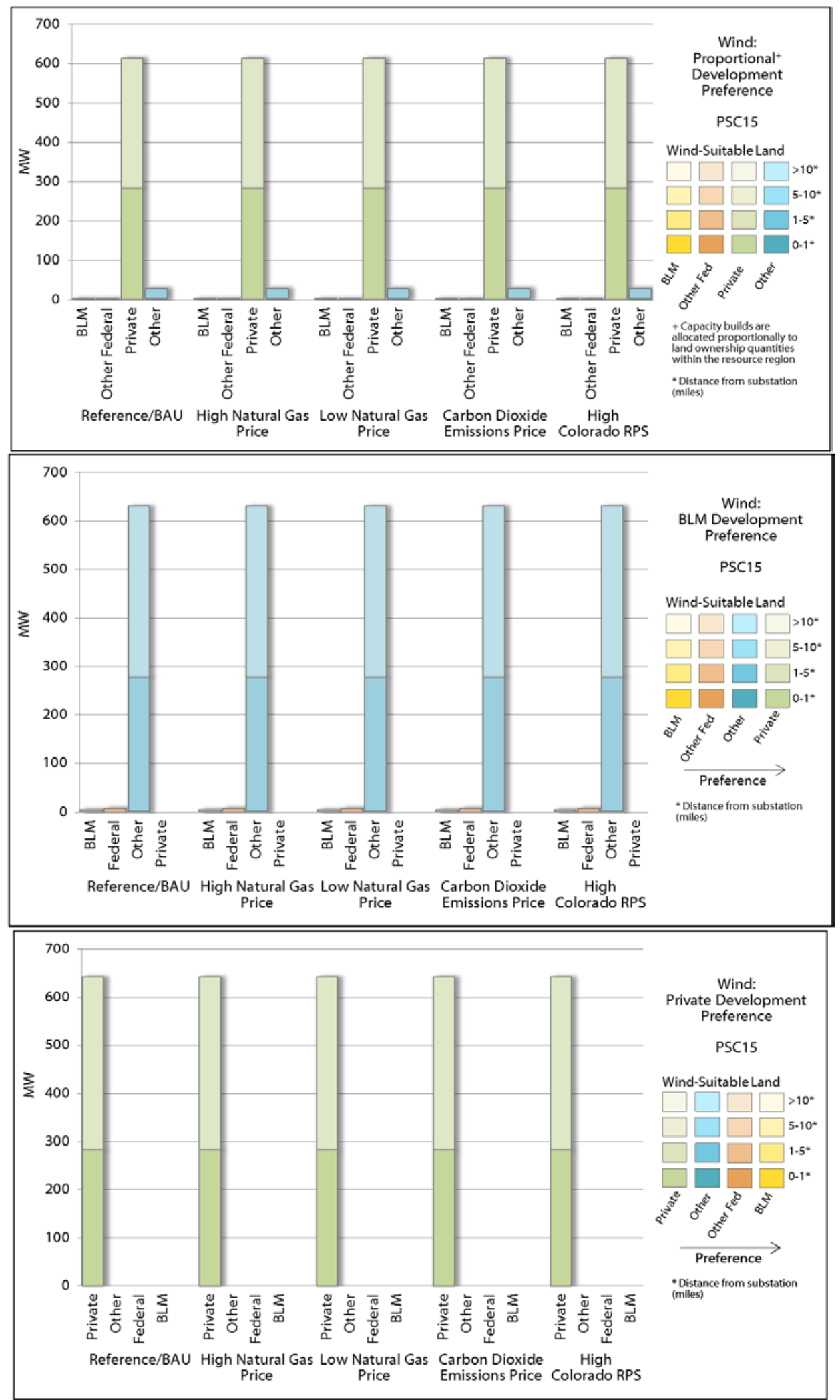


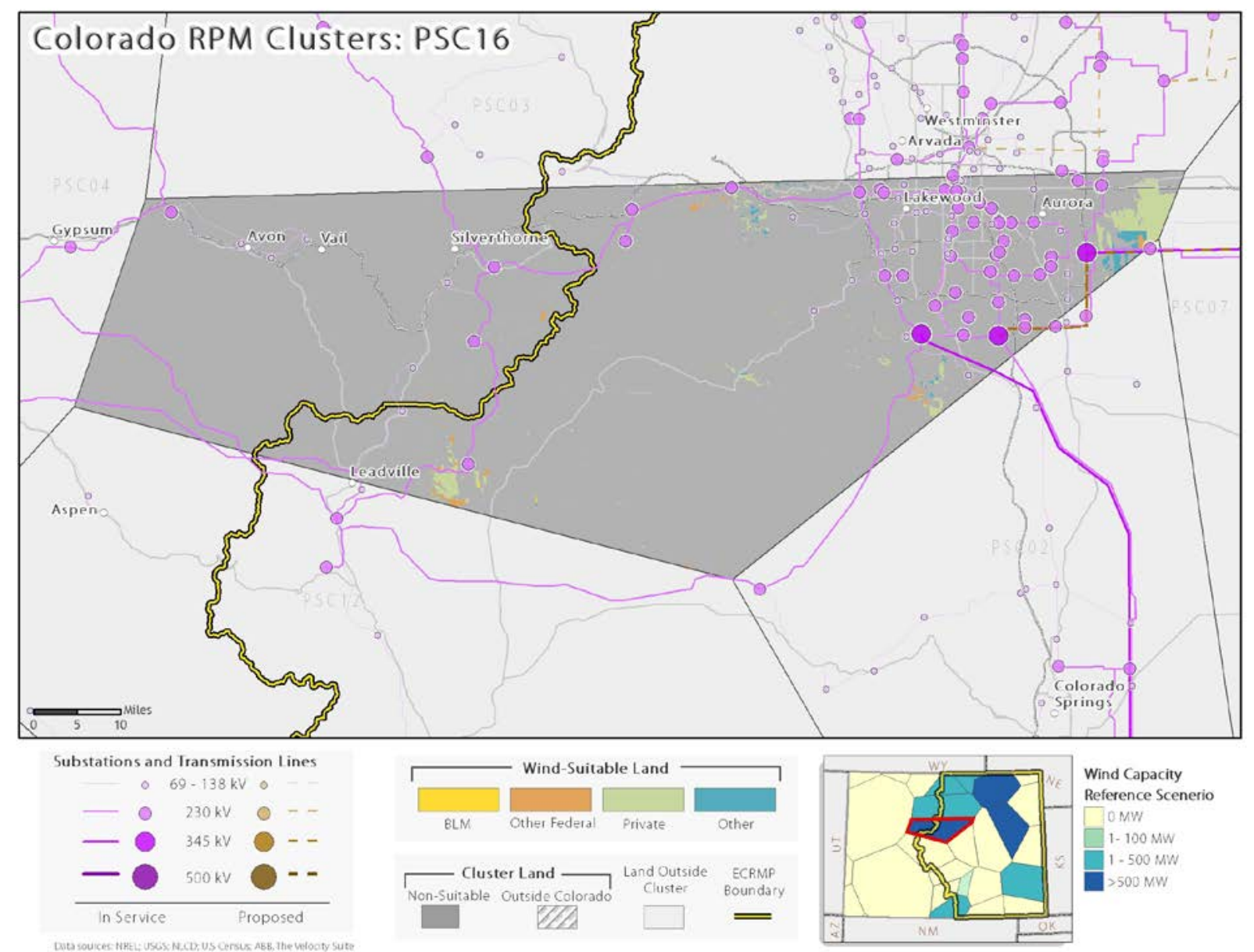

\begin{tabular}{c|cc|cc|cc|cc}
\hline \hline \multicolumn{1}{c}{ PSC16-Wind-Suitable Land: Area and MW Potential } \\
\hline $\begin{array}{c}\text { Distance to } \\
\text { Transmission }\end{array}$ & \multicolumn{2}{c|}{$\mathbf{0 - 1}$ Miles } & \multicolumn{2}{c|}{$\mathbf{1 - 5}$ Miles } & \multicolumn{2}{c}{5 -10 Miles } & \multicolumn{2}{c}{$>$ 10 Miles } \\
Acres & MW & Acres & MW & Acres & MW & Acres & MW \\
\hline BLM & 0 & 0 & 80 & 0 & 72 & 0 & 0 & 0 \\
Federal & 274 & 3 & 3,220 & 39 & 2,199 & 26 & 128 & 1 \\
Other & 135 & 1 & 7,082 & 86 & 264 & 3 & 66 & 0 \\
Private & 464 & 5 & 25,160 & 305 & 6,473 & 78 & 862 & 10 \\
\hline \hline
\end{tabular}

\begin{tabular}{ccccc}
\hline \hline \multicolumn{5}{c}{ PSC16-Modeled Wind Capacity ${ }^{33}$} \\
\hline Ref & HI-NG & LO-NG & C02 & HI-RPS \\
1,368 & 1,459 & 1,297 & 1,498 & 1,450 \\
\hline \hline
\end{tabular}

\footnotetext{
${ }^{33}$ The total MW potential for wind-suitable lands in PSC16 is 557 MW. RPM capacity expansion consistently exceeds this number. Excess capacity expansion results in certain regions are due to non-coterminous resource availability and prescribed capacity expansion data sets.
} 

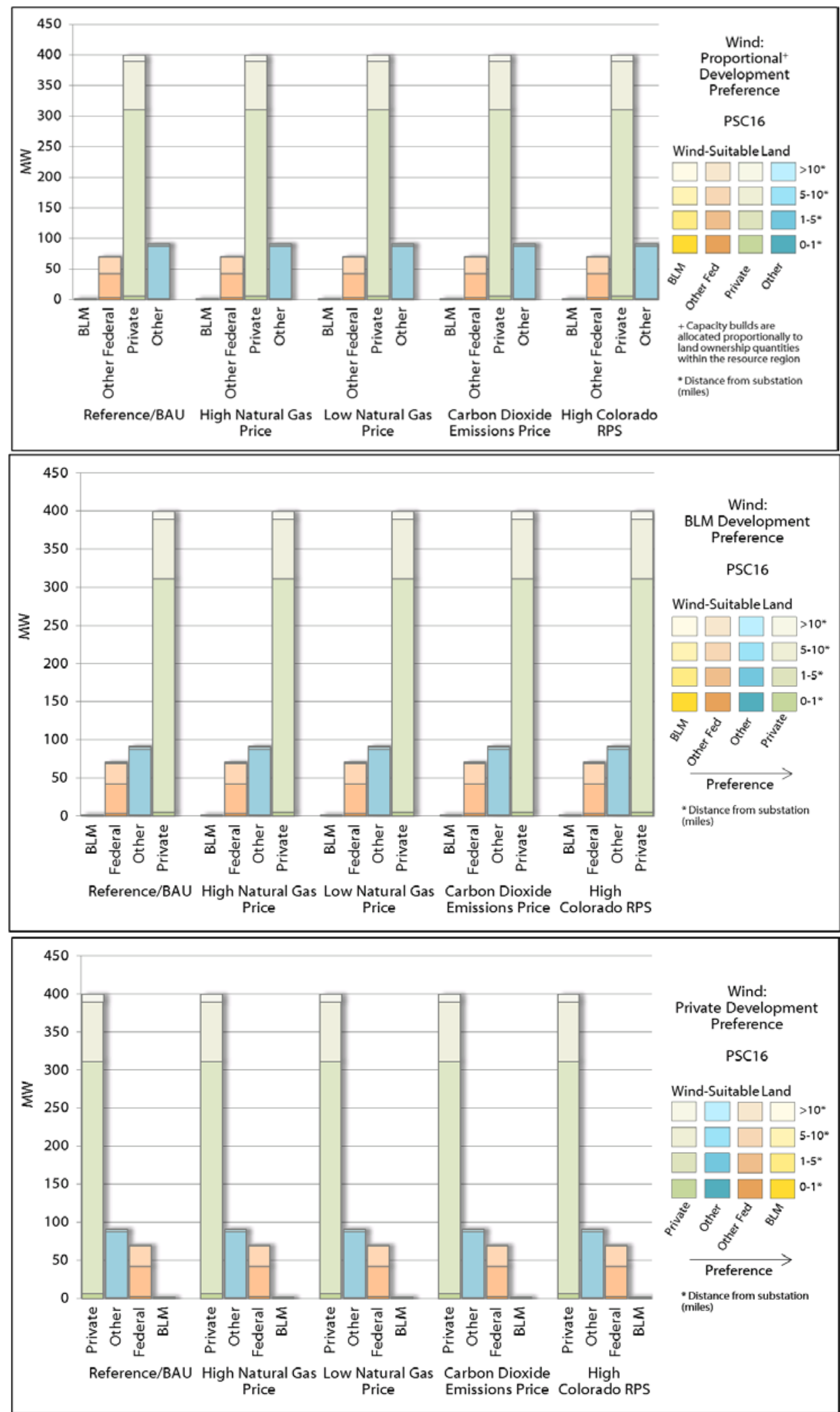


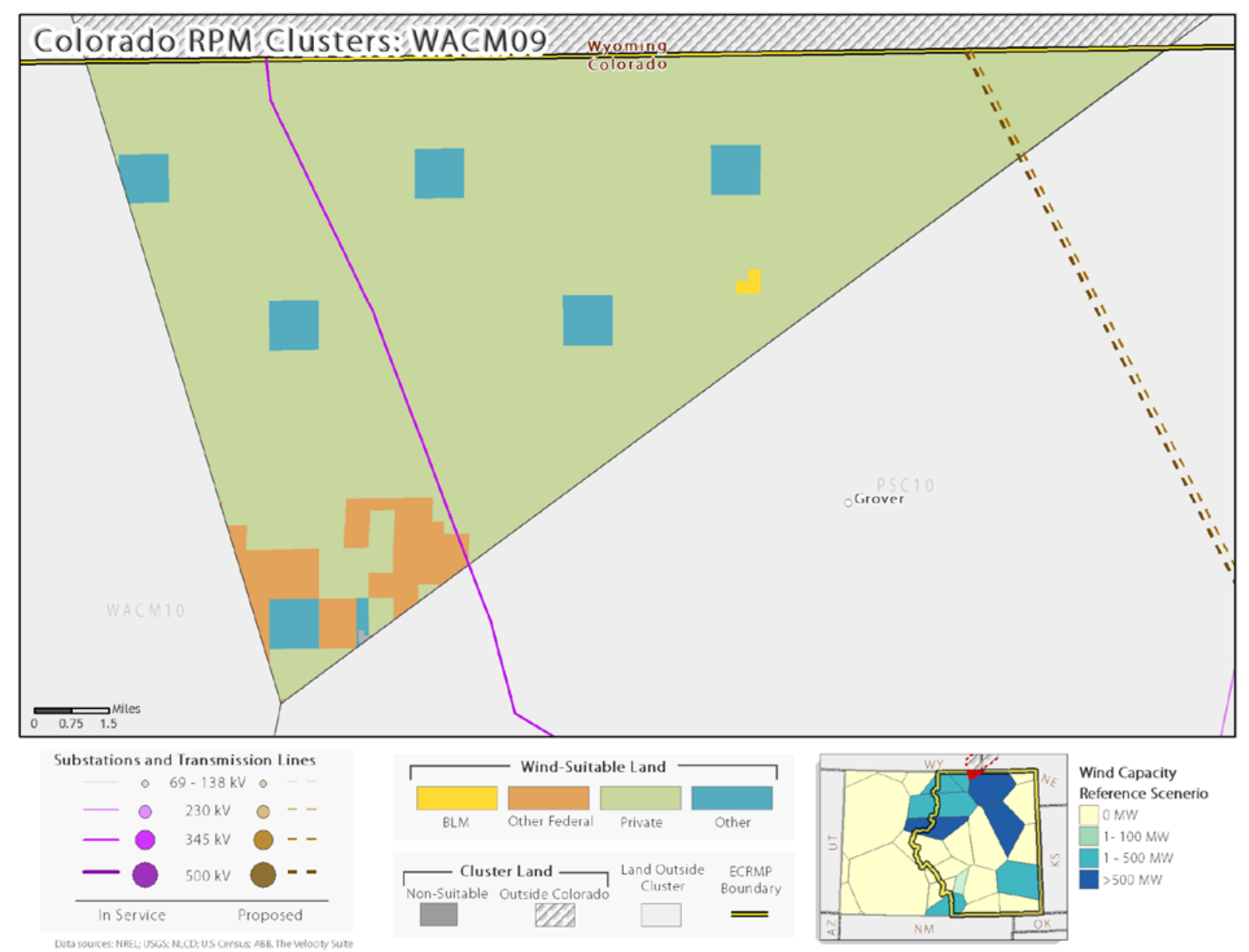

\begin{tabular}{c|cc|cc|cc|cc}
\hline \hline \multicolumn{8}{c}{ WACM09-Wind-Suitable Land: Area and MW Potential } \\
\hline Distance to & \multicolumn{2}{c|}{$\mathbf{0 - 1}$ Miles } & \multicolumn{2}{c|}{$\mathbf{1 - 5}$ Miles } & \multicolumn{2}{c}{$\mathbf{5 - 1 0}$ Miles } & \multicolumn{2}{c}{$>$ >10 Miles } \\
Transmission & Acres & MW & Acres & MW & Acres & MW & Acres & MW \\
\hline BLM & 0 & 0 & 0 & 0 & 0 & 0 & 122 & 1 \\
Federal & 0 & 0 & 0 & 0 & 0 & 0 & 3,806 & 46 \\
Other & 0 & 0 & 0 & 0 & 0 & 0 & 3,909 & 47 \\
Private & 0 & 0 & 0 & 0 & 5,180 & 62 & 77,048 & 936 \\
\hline \hline
\end{tabular}

\begin{tabular}{ccccc}
\hline \hline \multicolumn{5}{c}{ WACM09-Modeled Wind Capacity } \\
\hline Ref & HI-NG & LO-NG & C02 & HI-RPS \\
121 & 251 & 251 & 121 & 121 \\
\hline \hline
\end{tabular}



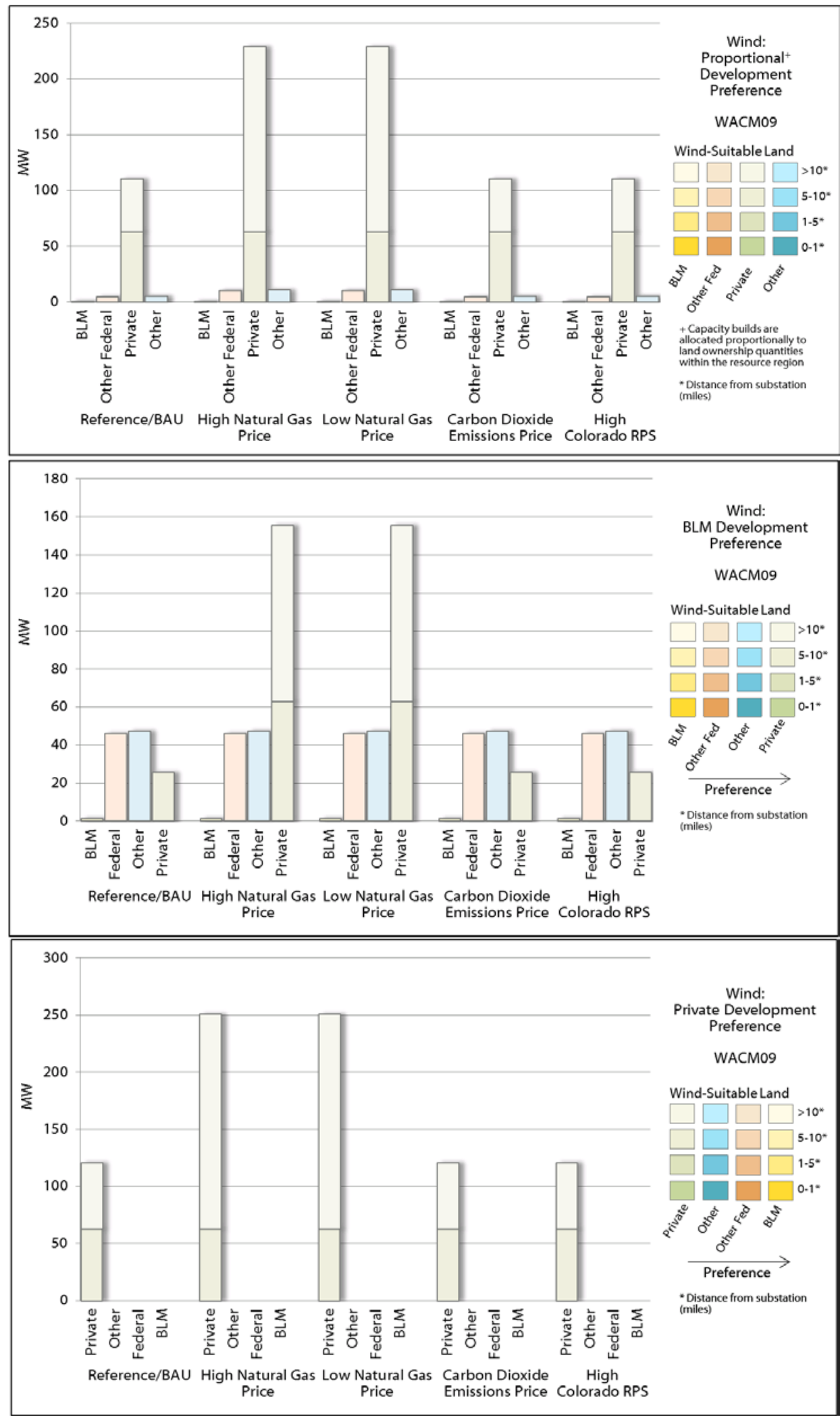


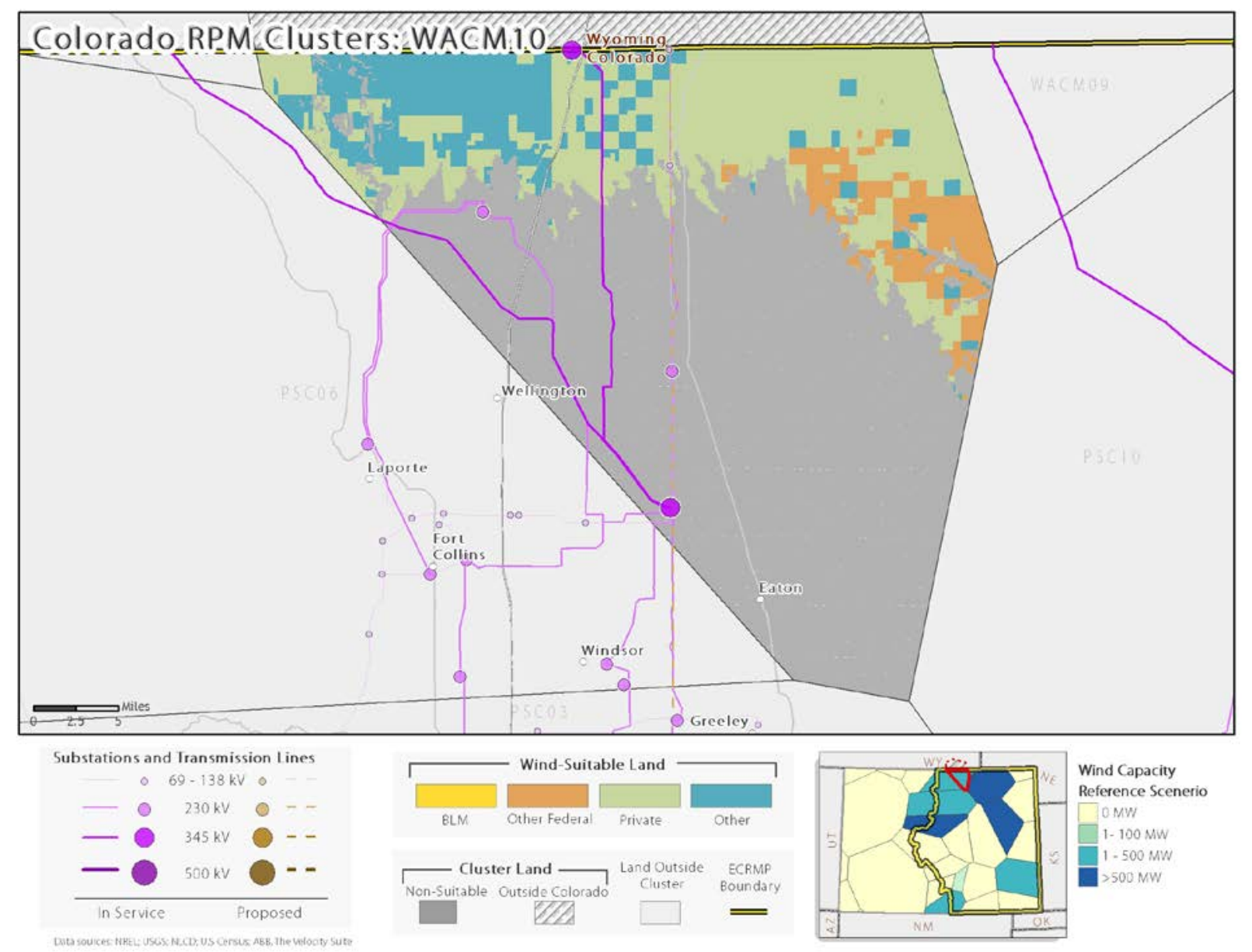

\begin{tabular}{c|cc|cc|cc|cc}
\hline \hline \multicolumn{8}{c}{ WACM10-Wind-Suitable Land: Area and MW Potential } \\
\hline Distance to & \multicolumn{2}{c|}{$\mathbf{0 - 1}$ Miles } & \multicolumn{2}{|c|}{$\mathbf{1 - 5}$ Miles } & \multicolumn{2}{c}{$\mathbf{5 - 1 0}$ Miles } & \multicolumn{2}{c}{$>$ 10 Miles } \\
Transmission & Acres & MW & Acres & MW & Acres & MW & Acres & MW \\
\hline BLM & 0 & 0 & 0 & 0 & 0 & 0 & 0 & 0 \\
Federal & 0 & 0 & 503 & 6 & 4,675 & 56 & 25,570 & 310 \\
Other & 1,022 & 12 & 23,833 & 289 & 26,700 & 324 & 13,622 & 165 \\
Private & 2,718 & 33 & 51,209 & 622 & 35,043 & 425 & 51,276 & 623 \\
\hline \hline
\end{tabular}

\begin{tabular}{ccccc}
\hline \hline \multicolumn{5}{c}{ WACM10-Modeled Wind Capacity } \\
\hline Ref & HI-NG & LO-NG & C02 & HI-RPS \\
123 & 123 & 123 & 123 & 123 \\
\hline \hline
\end{tabular}



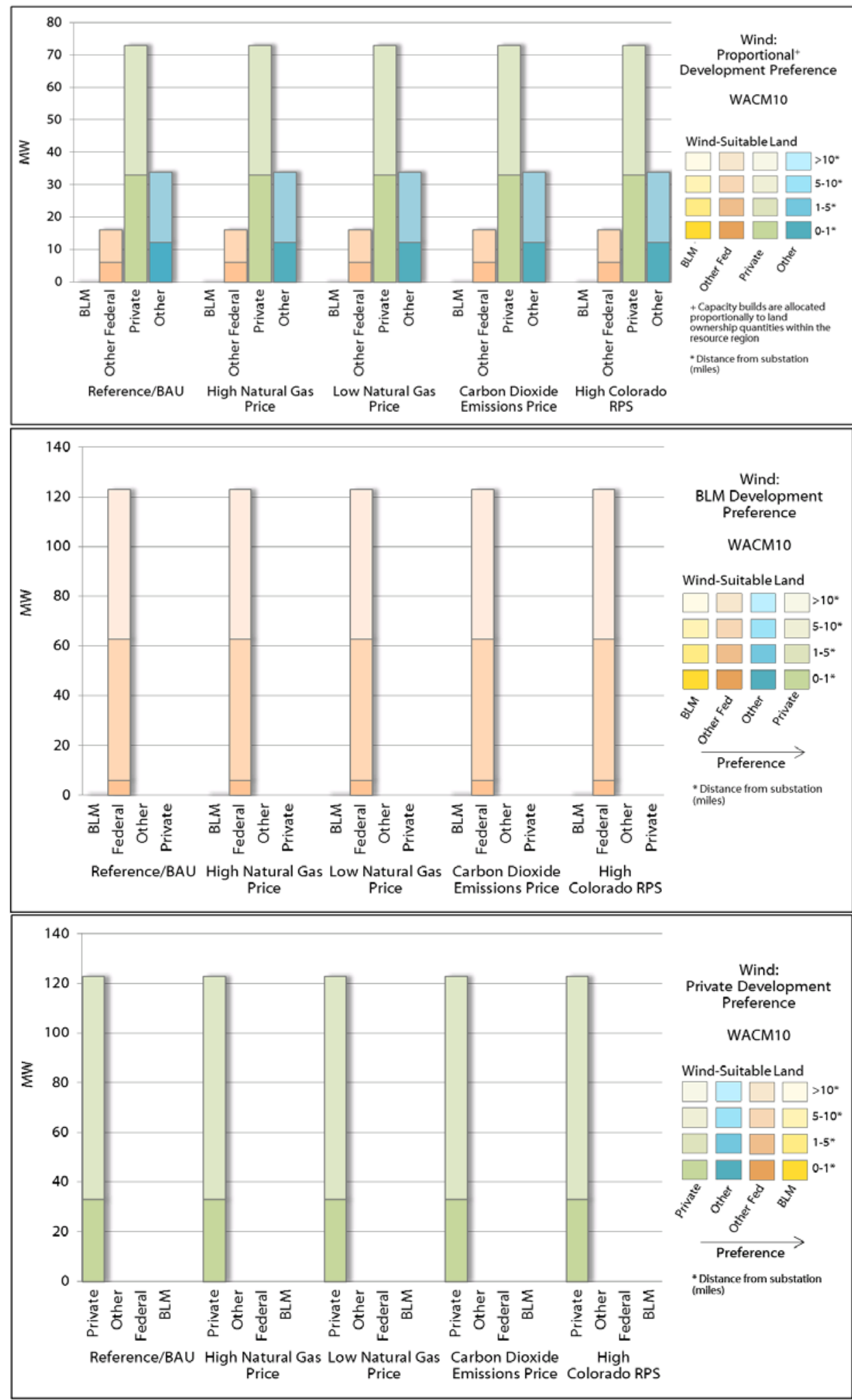


\section{Solar Resource Regions}

\section{Colorado Solar Resource Regions}

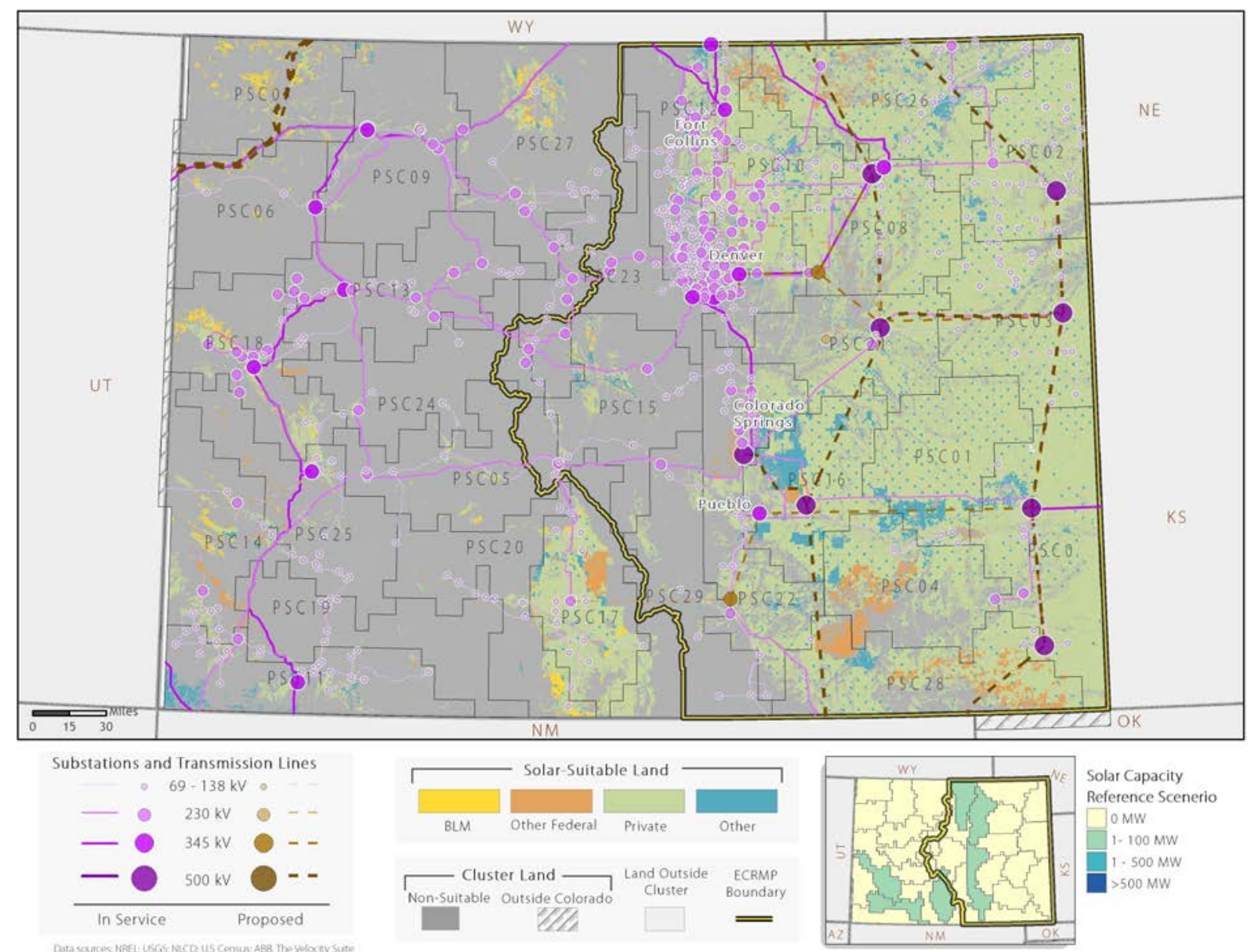

\begin{tabular}{c|cc|cc|cc|cc}
\hline \hline \multicolumn{8}{c}{ Colorado-Solar-Suitable Land: Area and MW Potential } \\
\hline Distance to & \multicolumn{2}{|c|}{$\mathbf{0 - 1}$ Miles } & \multicolumn{2}{c}{$\mathbf{1 - 5}$ Miles } & \multicolumn{2}{c}{$\mathbf{5 - 1 0}$ Miles } & \multicolumn{2}{c}{$>$ 10 Miles } \\
Transmission & Acres & MW & Acres & MW & Acres & MW & Acres & MW \\
\hline BLM & 542 & 155 & 53,225 & 15,251 & 111,854 & 32,050 & 259,125 & 74,248 \\
Federal & 936 & 268 & 65,781 & 18,848 & 212,993 & 61,030 & 605,166 & 173,400 \\
Other & 18,784 & 5,382 & 321,219 & 92,040 & 489,051 & 140,129 & $1,050,674$ & 301,053 \\
Private & 311,631 & 89,293 & $5,025,581$ & $1,439,995$ & $5,892,545$ & $1,688,408$ & $9,035,090$ & $2,588,851$ \\
\hline \hline
\end{tabular}

\begin{tabular}{ccccc}
\hline \hline \multicolumn{5}{c}{ Colorado-Modeled Solar Capacity } \\
\hline Ref & HI-NG & LO-NG & C02 & HI-RPS \\
118 & 1,198 & 112 & 195 & 132 \\
\hline \hline
\end{tabular}




\section{ECRMP Solar Resource Regions}

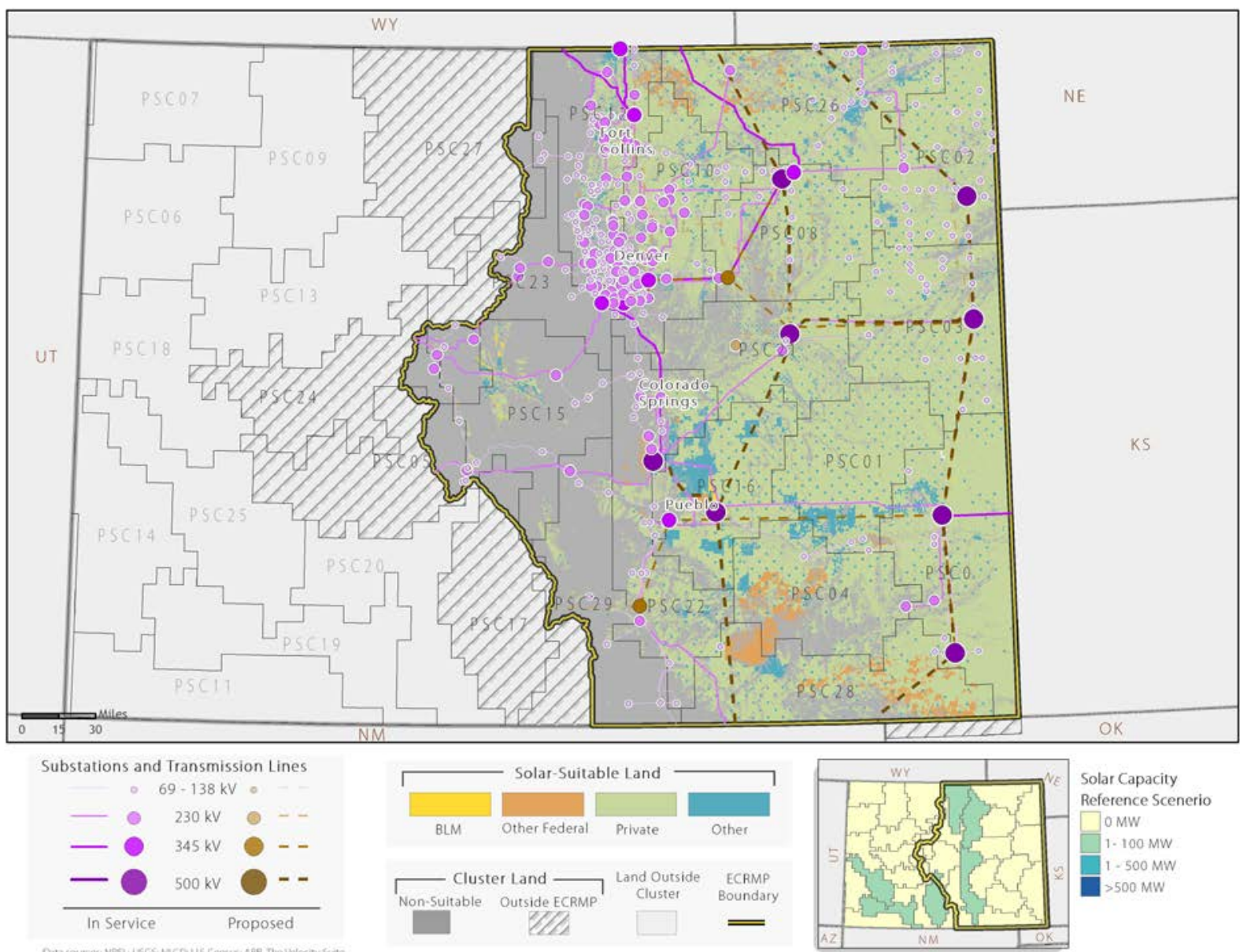

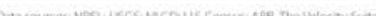

\begin{tabular}{c|cc|cc|cc|cc}
\hline \hline \multicolumn{8}{c}{ ECRMP-Solar-Suitable Land: Area and MW Potential } \\
\hline $\begin{array}{c}\text { Distance to } \\
\text { Transmission }\end{array}$ & \multicolumn{2}{c|}{$\mathbf{0 - 1}$ Miles } & \multicolumn{2}{c|}{$\mathbf{1 - 5}$ Miles } & \multicolumn{2}{c}{$\mathbf{5 - 1 0}$ Miles } & \multicolumn{2}{c}{$>$ 10 Miles } \\
\hline BLM & 43 & 12 & 3,296 & 945 & 12,376 & 3,546 & 24,173 & 6,926 \\
Federal & 731 & 209 & 47,607 & 13,641 & 117,043 & 33,537 & 549,218 & 157,369 \\
Other & 17,180 & 4,923 & 289,844 & 83,050 & 425,478 & 121,914 & 877,034 & 251,299 \\
Private & 264,183 & 75,697 & $4,292,574$ & $1,229,964$ & $5,237,288$ & $1,500,655$ & $8,428,131$ & $2,414,937$ \\
\hline \hline
\end{tabular}

\begin{tabular}{ccccc}
\hline \hline \multicolumn{5}{c}{ ECRMP-Modeled Solar Capacity } \\
\hline Ref & HI-NG & LO-NG & C02 & HI-RPS \\
17 & 107 & 17 & 29 & 28 \\
\hline \hline
\end{tabular}




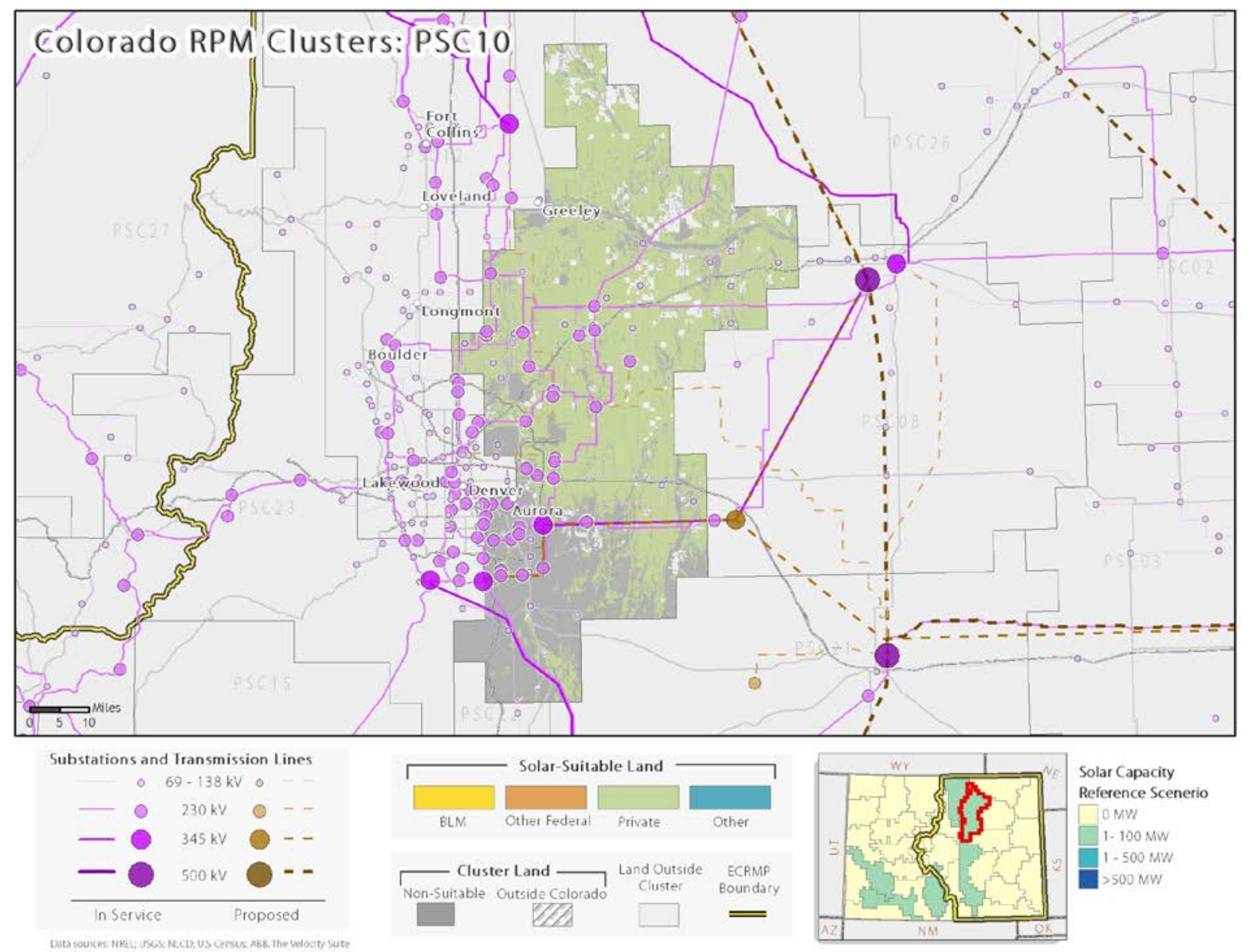

\begin{tabular}{c|cc|cc|cc|cc}
\hline \hline \multicolumn{8}{c|}{ PSC10-Solar-Suitable Land: Area and MW Potential } \\
\hline Distance to & \multicolumn{2}{|c|}{$\mathbf{0 - 1}$ Miles } & \multicolumn{2}{c|}{$\mathbf{1 - 5}$ Miles } & \multicolumn{2}{c}{5 5-10 Miles } & \multicolumn{2}{c}{$>$ >10 Miles } \\
Transmission & Acres & MW & Acres & MW & Acres & MW & Acres & MW \\
\hline BLM & 13 & 4 & 80 & 23 & 226 & 65 & 0 & 0 \\
Federal & 84 & 24 & 2,264 & 649 & 5,716 & 1,638 & 18,386 & 5,268 \\
Other & 2,021 & 579 & 41,812 & 11,981 & 41,398 & 11,862 & 10,240 & 2,934 \\
Private & 57,509 & 16,478 & 701,083 & 200,883 & 397,722 & 113,960 & 172,623 & 49,462 \\
\hline \hline
\end{tabular}

\begin{tabular}{ccccc}
\hline \hline \multicolumn{5}{c}{ PSC10-Modeled Solar Capacity } \\
\hline Ref & HI-NG & LO-NG & C02 & HI-RPS \\
3 & 3 & 3 & 3 & 3 \\
\hline \hline
\end{tabular}




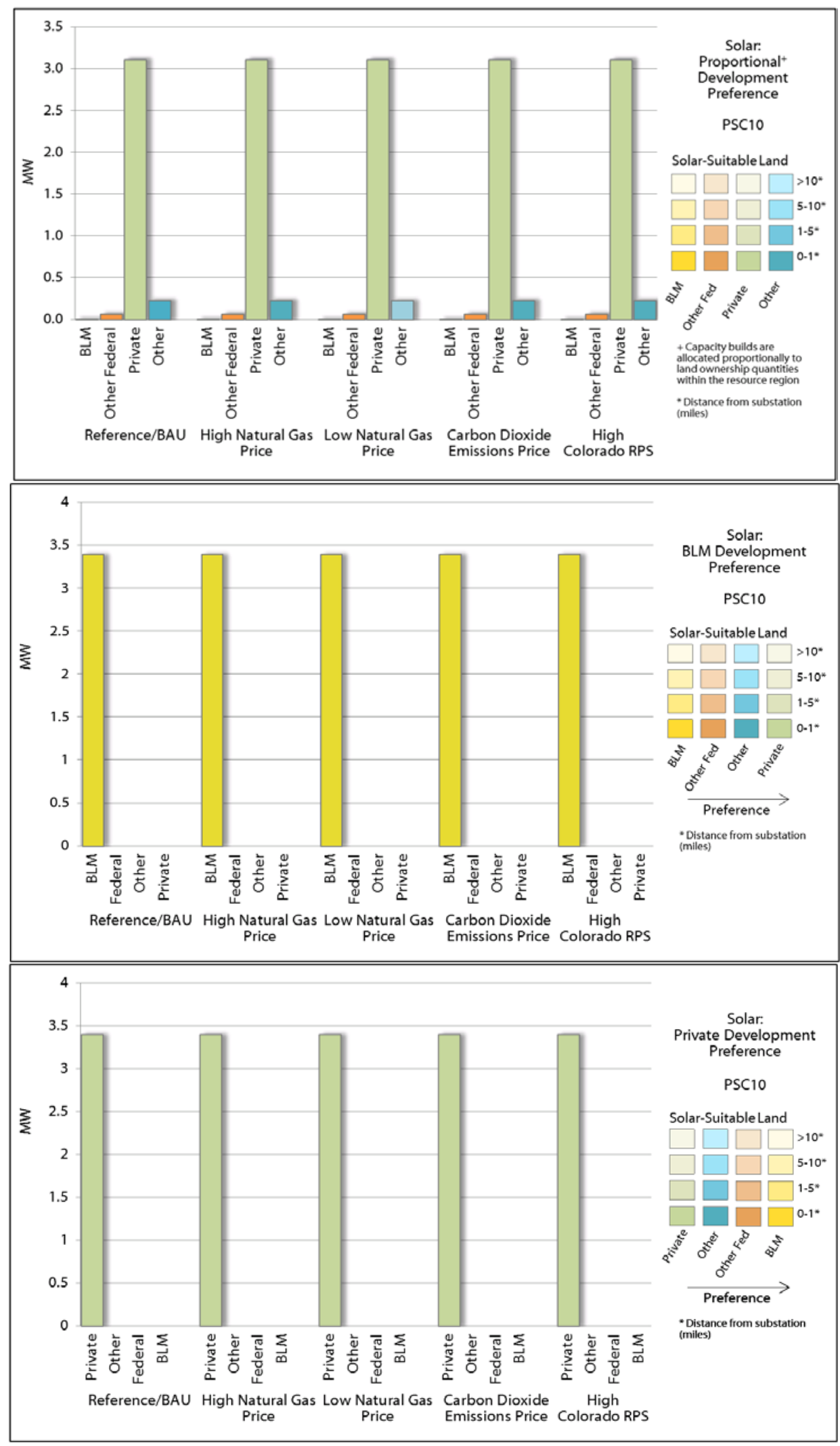

This report is available at no cost from the National Renewable Energy Laboratory (NREL at www.nrel.gov/publications. 


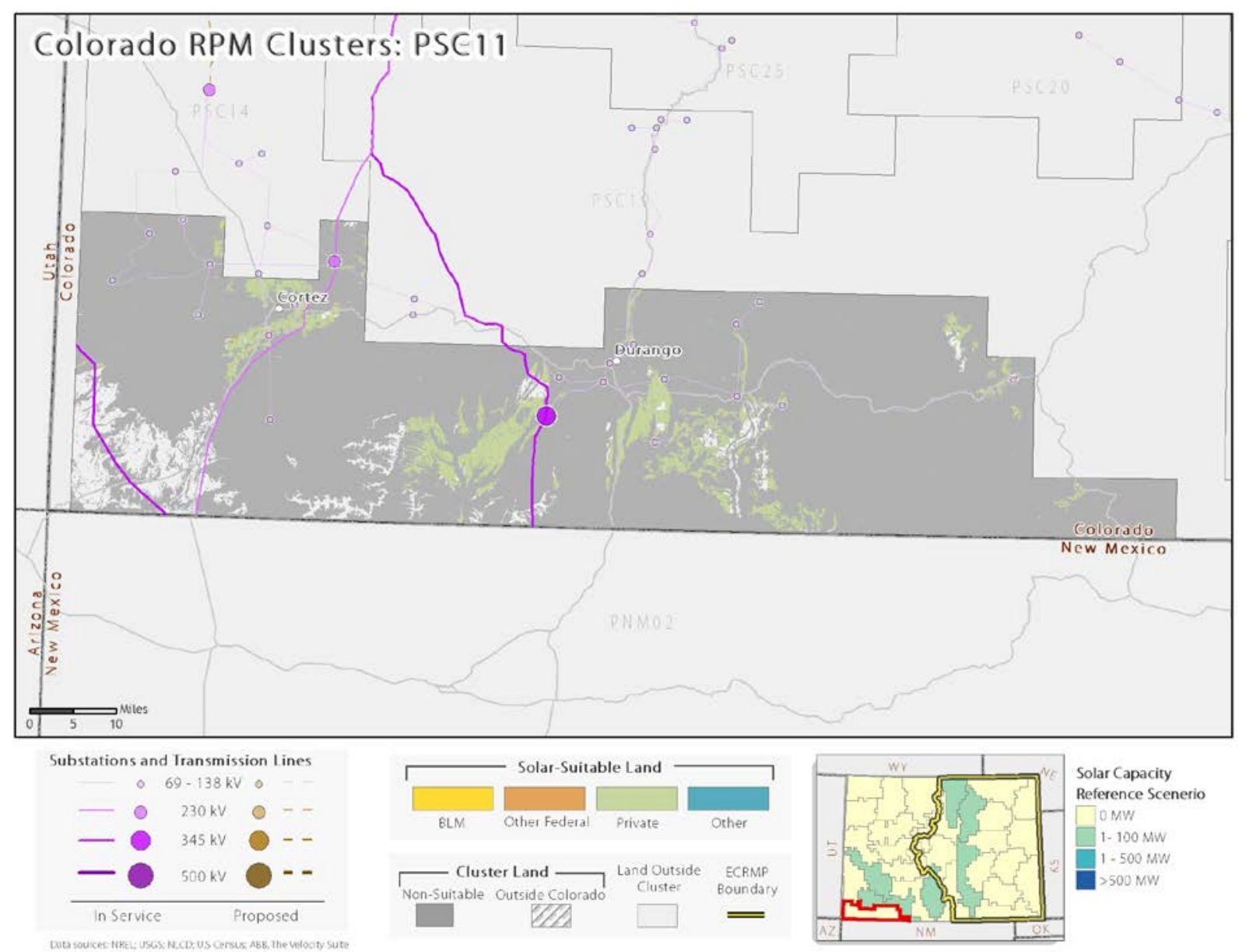

\begin{tabular}{c|cc|cc|cc|cc}
\hline \hline \multicolumn{10}{c}{ PSC11-Solar-Suitable Land: Area and MW Potential } \\
\hline $\begin{array}{c}\text { Distance to } \\
\text { Transmission }\end{array}$ & \multicolumn{2}{|c|}{ Acres Miles } & \multicolumn{2}{|c|}{$\mathbf{1 - 5}$ Miles } & \multicolumn{2}{c}{$\mathbf{5 - 1 0}$ Miles } & \multicolumn{2}{c}{$>$ 10 Miles } \\
\hline BLM & 0 & 0 & 323 & 93 & 3 & 1 & 0 & 0 \\
Federal & 0 & 0 & 335 & 96 & 1,788 & 512 & 424 & 121 \\
Other & 16 & 5 & 8,020 & 2,298 & 14,720 & 4,218 & 88,186 & 25,268 \\
Private & 3,783 & 1,084 & 60,999 & 17,478 & 26,232 & 7,516 & 24,787 & 7,102 \\
\hline \hline
\end{tabular}

\begin{tabular}{ccccc}
\hline \hline \multicolumn{5}{c}{ PSC11-Modeled Solar Capacity } \\
\hline Ref & HI-NG & LO-NG & C02 & HI-RPS \\
0 & 347 & 0 & 48 & 0 \\
\hline \hline
\end{tabular}




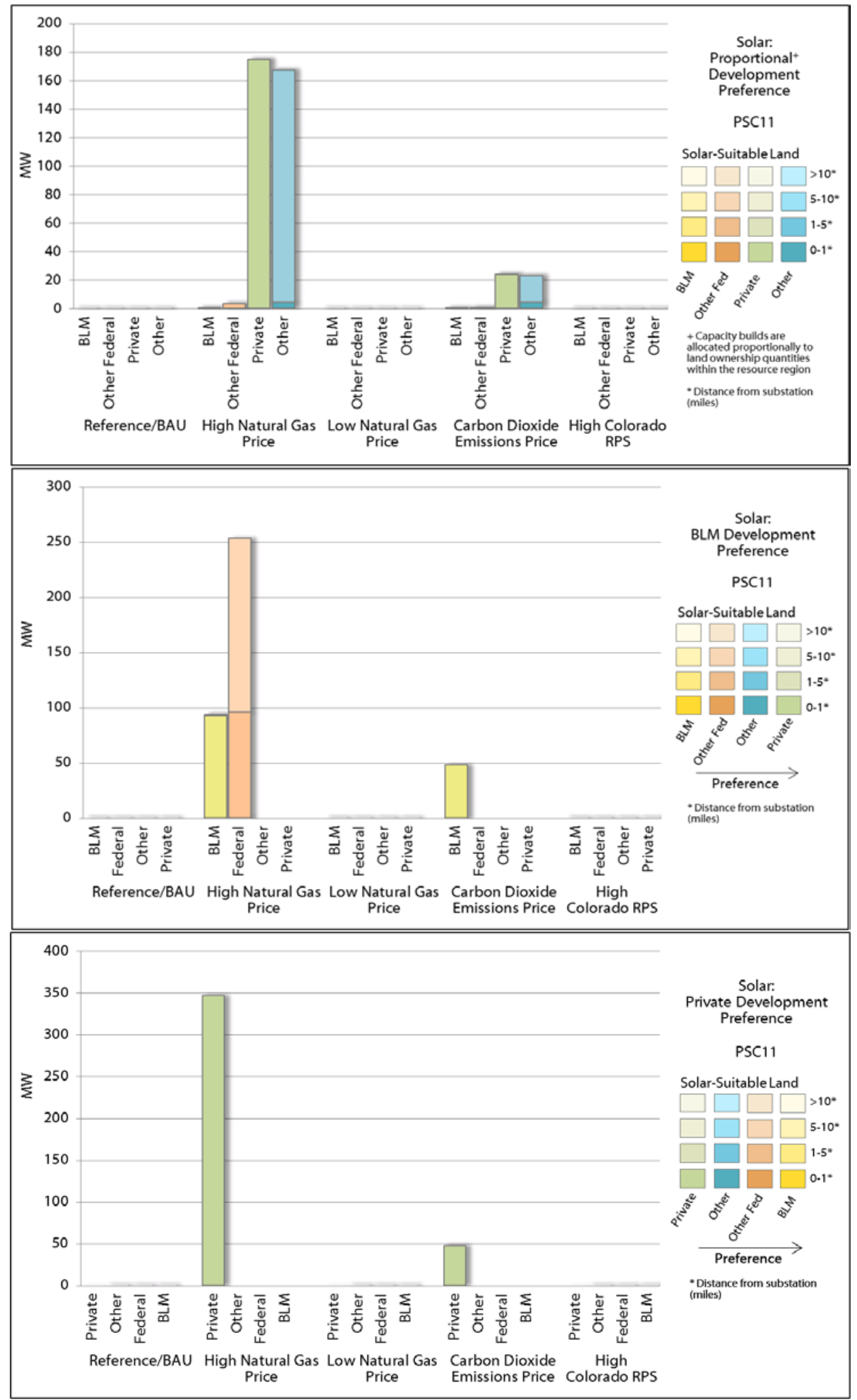

This report is available at no cost from the National Renewable Energy Laboratory (NREL at www.nrel.gov/publications. 


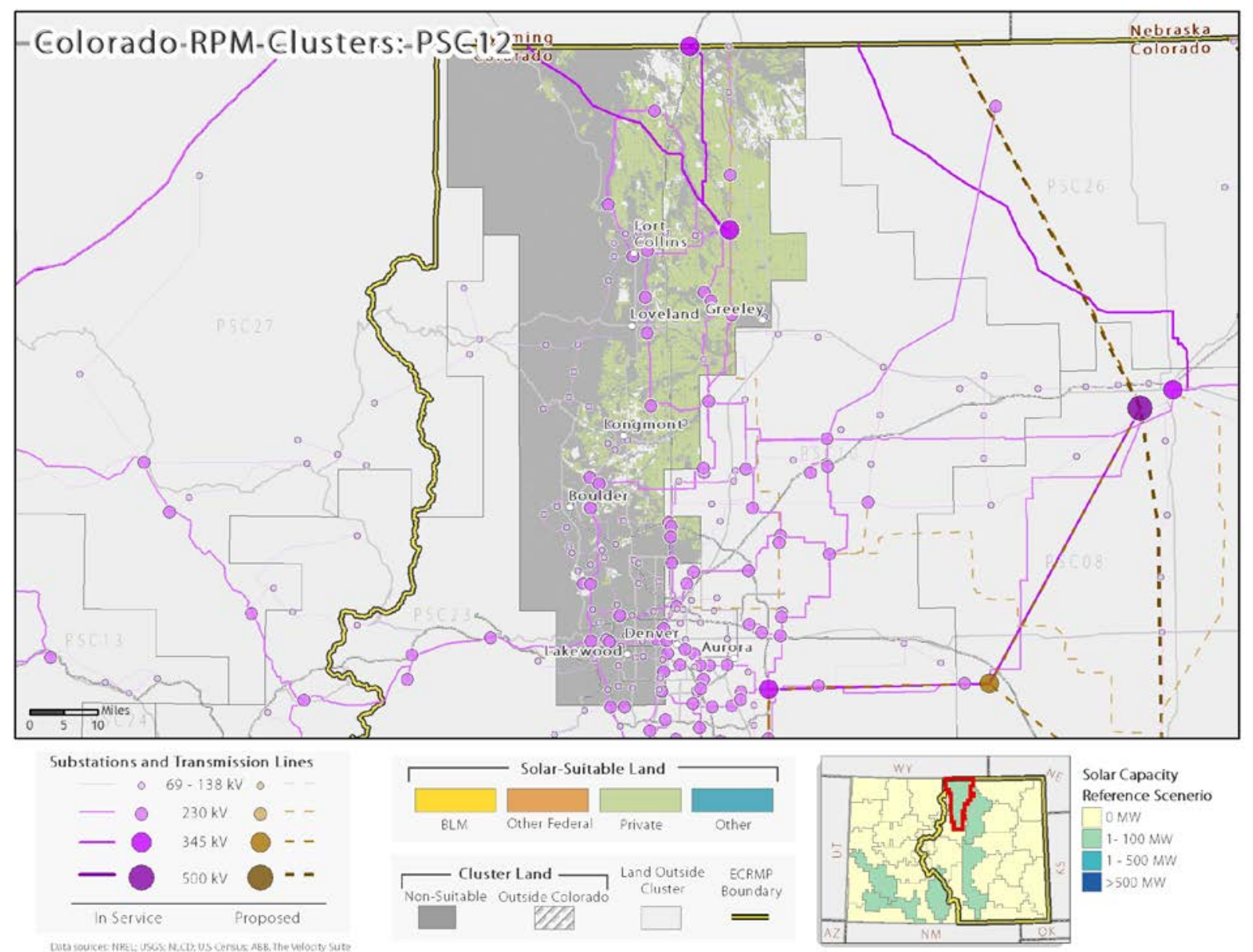

\begin{tabular}{c|cc|cc|cc|cc}
\hline \hline \multicolumn{10}{c}{ PSC12-Solar-Suitable Land: Area and MW Potential } \\
\hline Distance to & \multicolumn{2}{|c|}{$\mathbf{0 - 1}$ Miles } & \multicolumn{2}{c|}{$\mathbf{1 - 5}$ Miles } & \multicolumn{2}{c}{$\mathbf{5 - 1 0}$ Miles } & \multicolumn{2}{c}{$>$ 10 Miles } \\
Transmission & Acres & MW & Acres & MW & Acres & MW & Acres & MW \\
\hline BLM & 0 & 0 & 1 & 0 & 43 & 12 & 0 & 0 \\
Federal & 4 & 1 & 2,313 & 663 & 15,170 & 4,347 & 3,212 & 920 \\
Other & 3,128 & 896 & 53,761 & 15,404 & 12,438 & 3,564 & 1,782 & 511 \\
Private & 28,706 & 8,225 & 346,056 & 99,156 & 124,534 & 35,683 & 13,002 & 3,725 \\
\hline \hline
\end{tabular}

\begin{tabular}{ccccc}
\hline \hline \multicolumn{5}{c}{ PSC12-Modeled Solar Capacity } \\
\hline Ref & HI-NG & LO-NG & C02 & HI-RPS \\
6 & 82 & 6 & 6 & 6 \\
\hline \hline
\end{tabular}




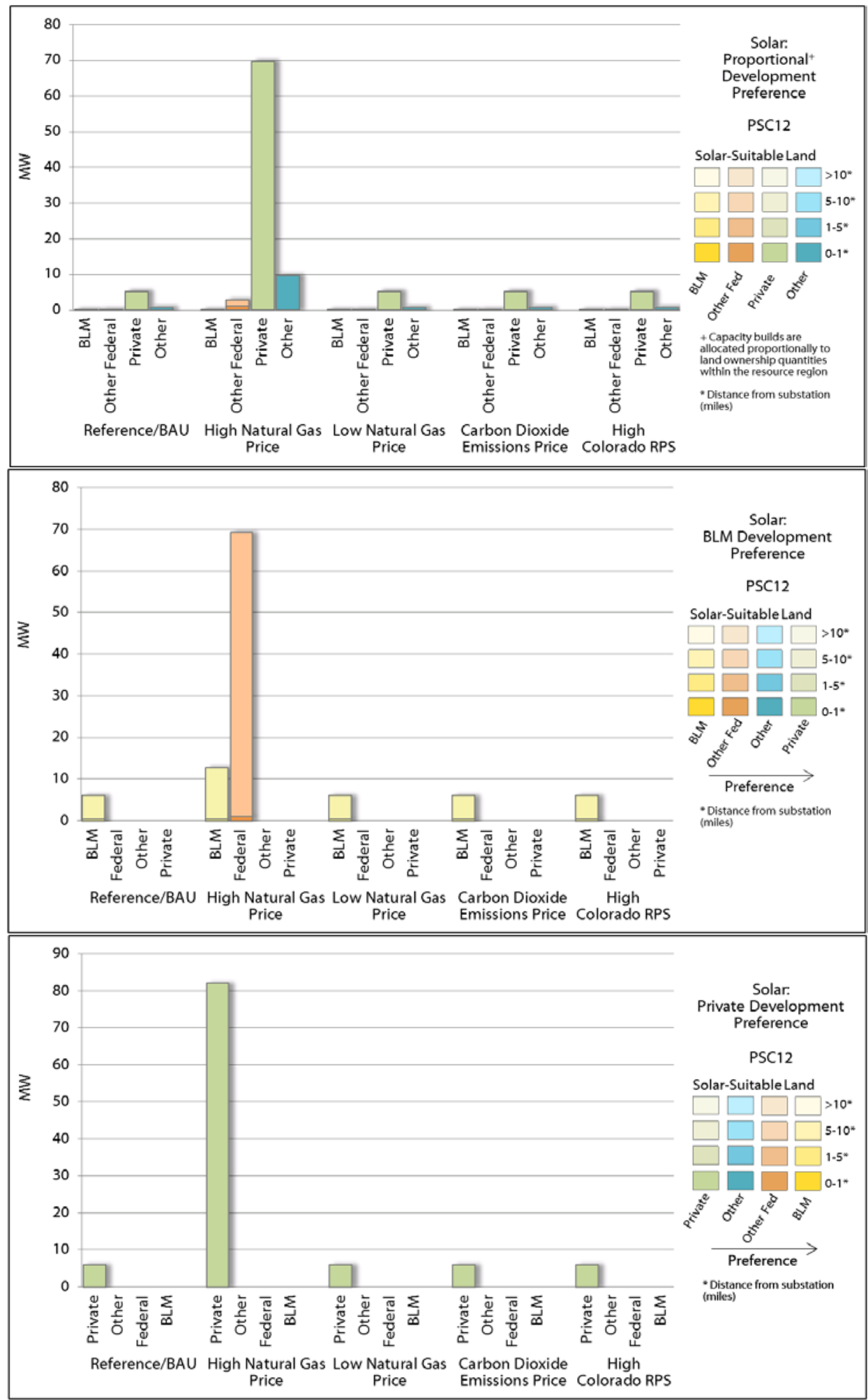

This report is available at no cost from the National Renewable Energy Laboratory (NREL at www.nrel.gov/publications. 


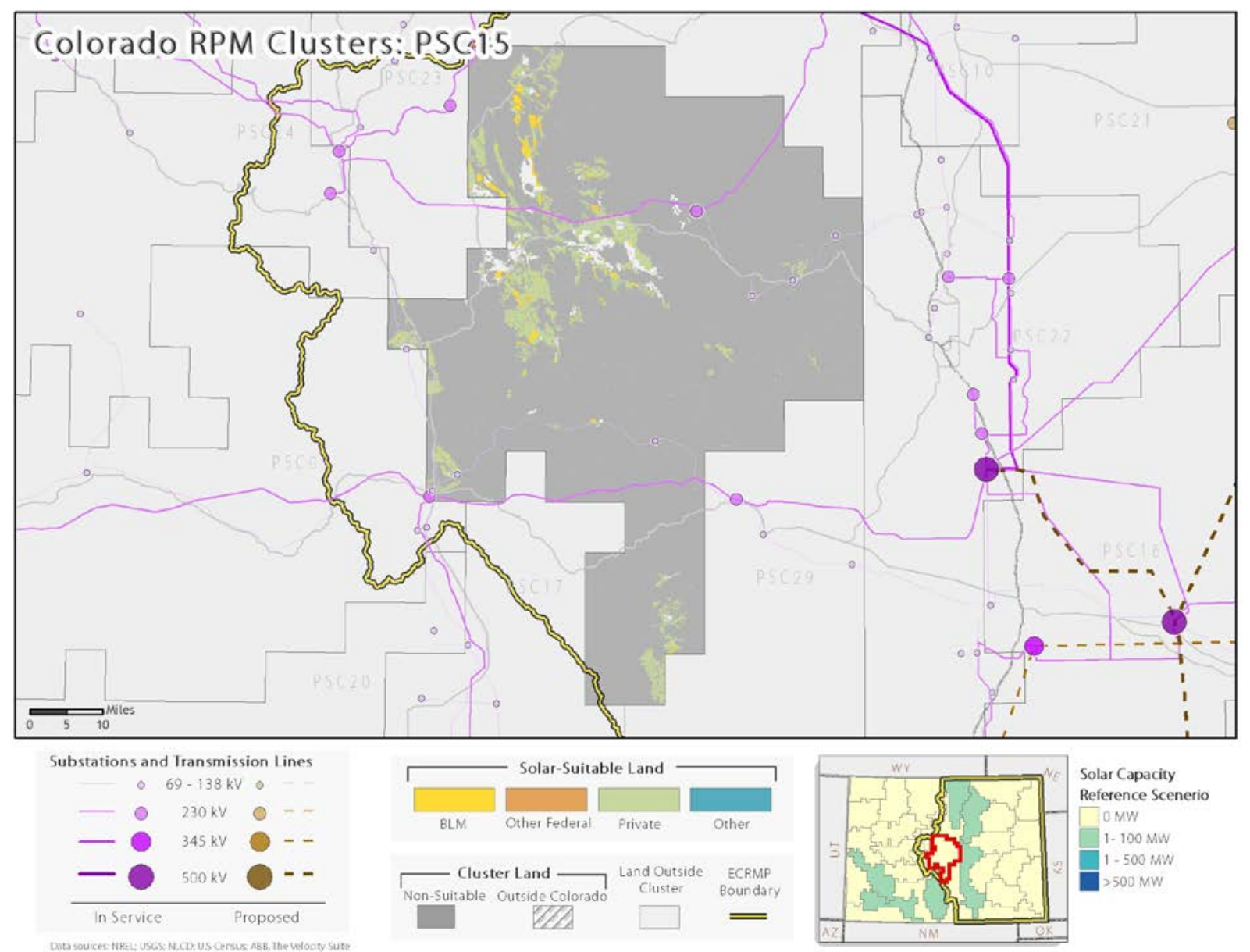

\begin{tabular}{|c|c|c|c|c|c|c|c|c|}
\hline \multicolumn{9}{|c|}{ PSC15-Solar-Suitable Land: Area and MW Potential } \\
\hline \multirow{2}{*}{$\begin{array}{l}\text { Distance to } \\
\text { Transmission }\end{array}$} & \multicolumn{2}{|c|}{ 0-1 Miles } & \multicolumn{2}{|c|}{ 1-5 Miles } & \multicolumn{2}{|c|}{ 5-10 Miles } & \multicolumn{2}{|c|}{ >10 Miles } \\
\hline & Acres & MW & Acres & MW & Acres & MW & Acres & MW \\
\hline BLM & 0 & 0 & 242 & 69 & 2,971 & 851 & 11,350 & 3,252 \\
\hline Federal & 0 & 0 & 1,100 & 315 & 2 & 1 & 24 & 7 \\
\hline Other & 673 & 193 & 298 & 85 & 515 & 148 & 28,035 & 8,033 \\
\hline Private & 1,309 & 375 & 10,887 & 3,119 & 16,523 & 4,735 & 93,418 & 26,767 \\
\hline
\end{tabular}

\begin{tabular}{ccccc}
\hline \hline \multicolumn{5}{c}{ PSC15-Modeled Solar Capacity } \\
\hline Ref & HI-NG & LO-NG & C02 & HI-RPS \\
0 & 14 & 0 & 12 & 11 \\
\hline \hline
\end{tabular}




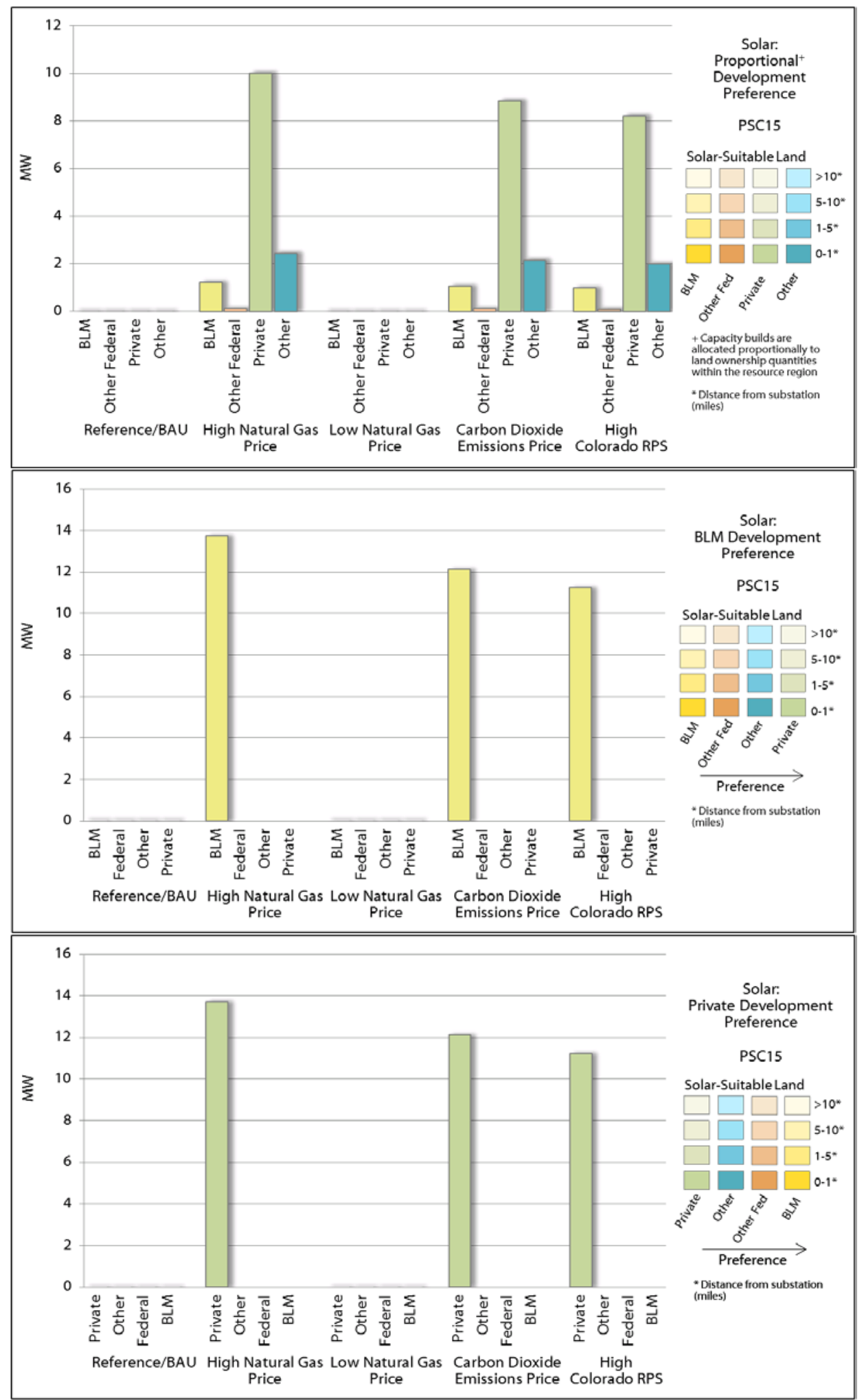

This report is available at no cost from the National Renewable Energy Laboratory (NREL at www.nrel.gov/publications. 

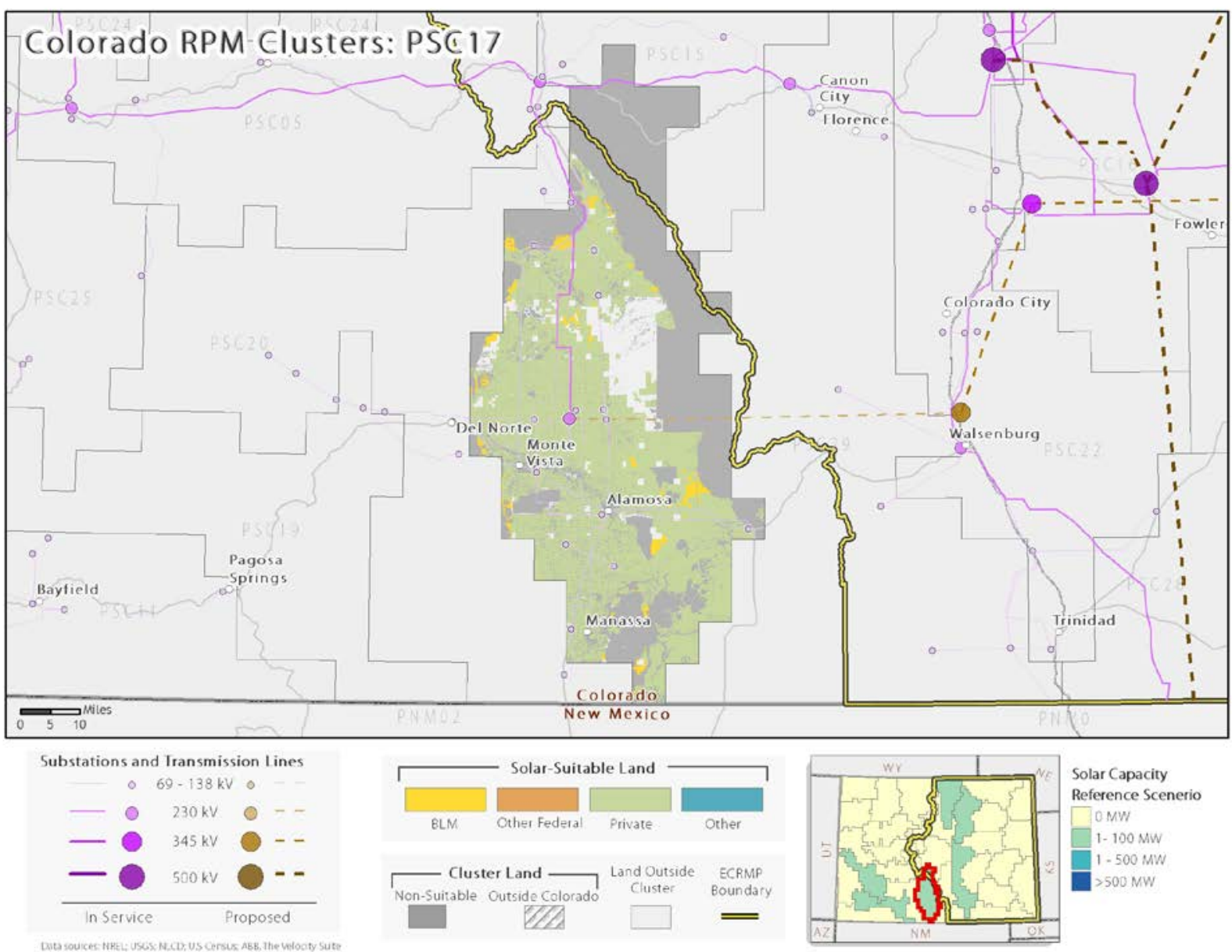

\begin{tabular}{c|cc|cc|cc|cc}
\hline \hline \multicolumn{10}{c}{ PSC17-Solar-Suitable Land: Area and MW Potential } \\
\hline Distance to & \multicolumn{2}{|c|}{$\mathbf{0 - 1}$ Miles } & \multicolumn{2}{|c|}{$\mathbf{1 - 5}$ Miles } & \multicolumn{2}{c}{$\mathbf{5 - 1 0}$ Miles } & \multicolumn{2}{c}{$>$ >10 Miles } \\
Transmission & Acres & MW & Acres & MW & Acres & MW & Acres & MW \\
\hline BLM & 86 & 25 & 9,934 & 2,846 & 16,833 & 4,823 & 10,998 & 3,151 \\
Federal & 151 & 43 & 9,417 & 2,698 & 56,086 & 16,070 & 19,218 & 5,507 \\
Other & 684 & 196 & 16,657 & 4,773 & 36,869 & 10,564 & 37,076 & 10,623 \\
Private & 23,994 & 6,875 & 376,762 & 107,955 & 370,048 & 106,031 & 185,197 & 53,065 \\
\hline \hline
\end{tabular}

\begin{tabular}{ccccc}
\hline \hline \multicolumn{5}{c}{ PSC17-Modeled Solar Capacity } \\
\hline Ref & HI-NG & LO-NG & C02 & HI-RPS \\
93 & 301 & 93 & 93 & 93 \\
\hline \hline
\end{tabular}




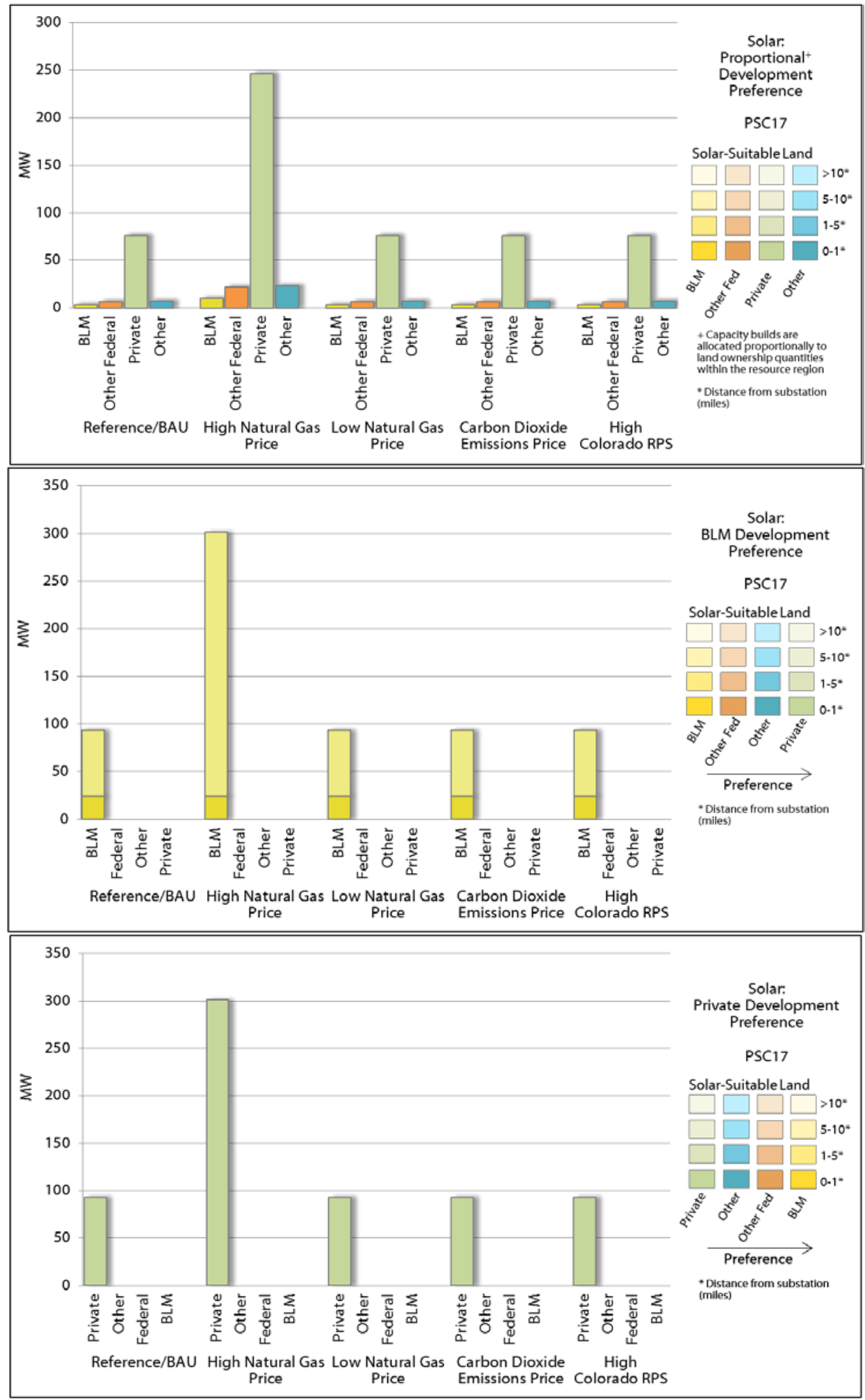

This report is available at no cost from the National Renewable Energy Laboratory (NREL at www.nrel.gov/publications. 
PSC19 Solar Resource Region

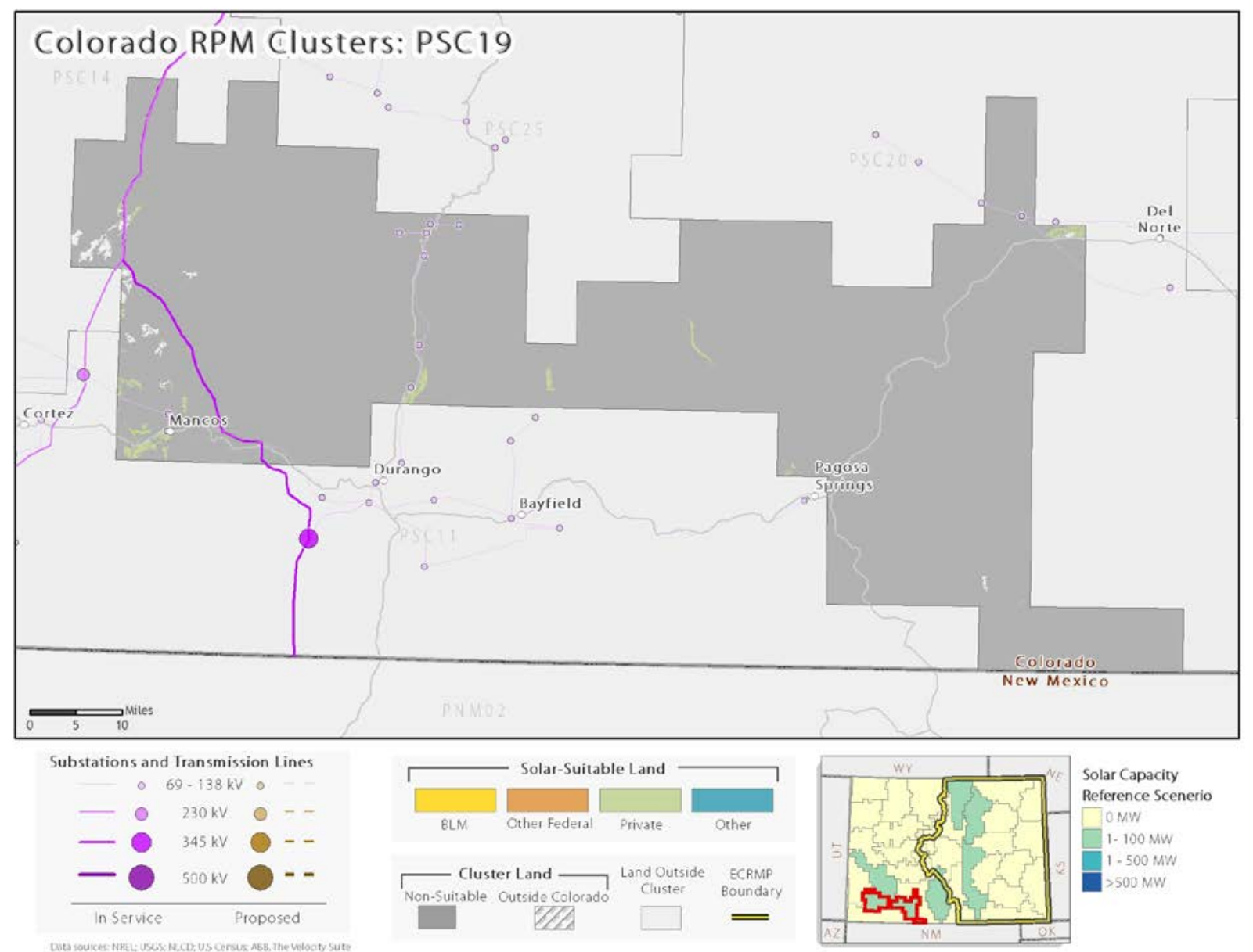

\begin{tabular}{c|cc|cc|cc|cc}
\hline \hline \multicolumn{10}{c}{ PSC19-Solar-Suitable Land: Area and MW Potential } \\
\hline Distance to & \multicolumn{2}{c|}{$\mathbf{0 - 1}$ Miles } & \multicolumn{2}{c|}{$\mathbf{1 - 5}$ Miles } & \multicolumn{2}{c}{5 -10 Miles } & \multicolumn{2}{c}{$>$ >10 Miles } \\
Transmission & Acres & MW & Acres & MW & Acres & MW & Acres & MW \\
\hline BLM & 0 & 0 & 58 & 17 & 0 & 0 & 0 & 0 \\
Federal & 0 & 0 & 145 & 42 & 3,679 & 1,054 & 3,308 & 948 \\
Other & 0 & 0 & 221 & 63 & 0 & 0 & 289 & 83 \\
Private & 1,038 & 297 & 8,229 & 2,358 & 737 & 211 & 1,618 & 464 \\
\hline \hline
\end{tabular}

\begin{tabular}{ccccc}
\hline \hline \multicolumn{5}{c}{ PSC19-Modeled Solar Capacity } \\
\hline Ref & HI-NG & LO-NG & C02 & HI-RPS \\
7 & 442 & 0 & 23 & 9 \\
\hline \hline
\end{tabular}




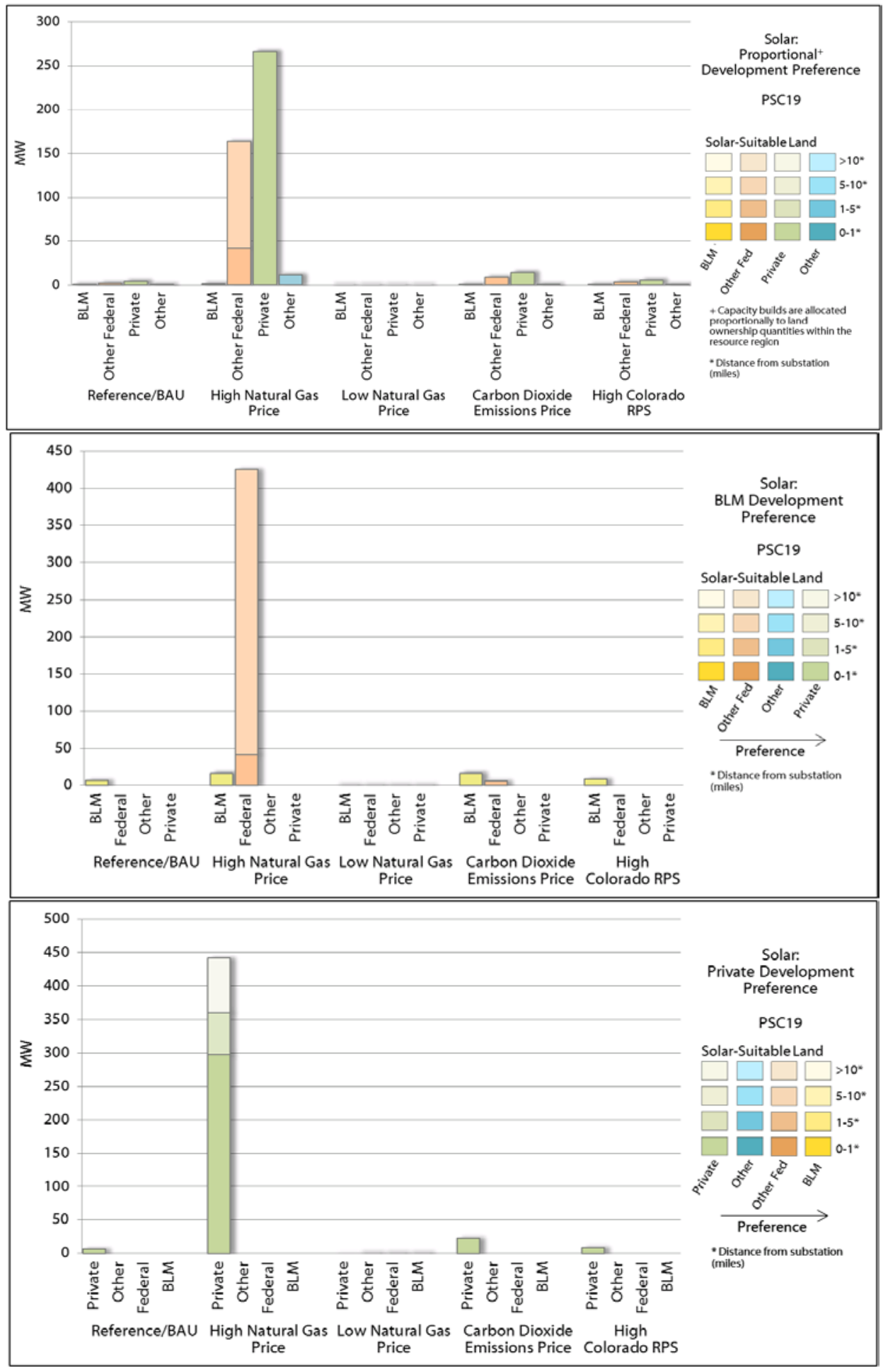

This report is available at no cost from the National Renewable Energy Laboratory (NREL at www.nrel.gov/publications. 


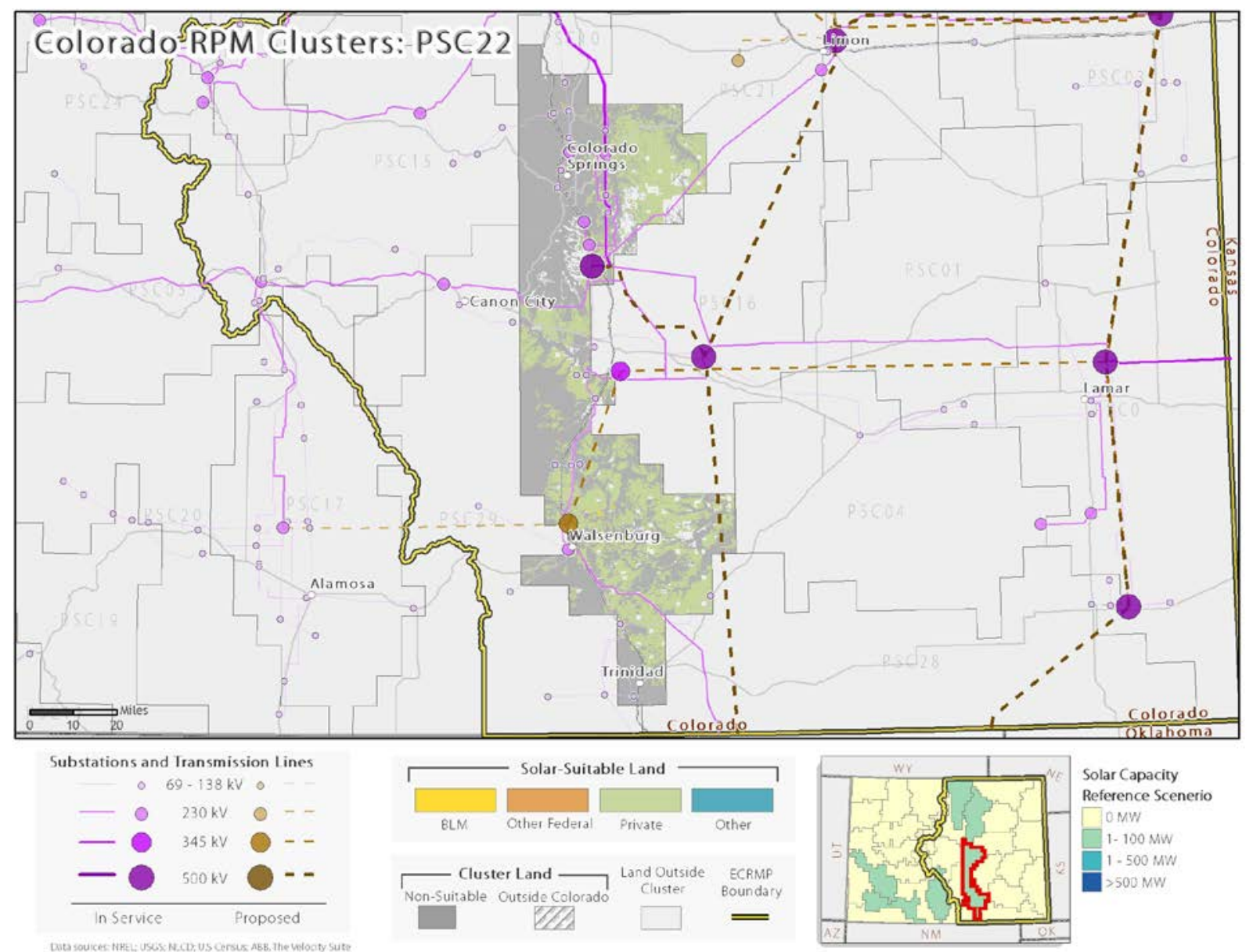

\begin{tabular}{c|cc|cc|cc|cc}
\hline \hline \multicolumn{10}{c|}{ PSC22-Solar-Suitable Land: Area and MW Potential } \\
\hline Distance to & \multicolumn{2}{c|}{$\mathbf{0 - 1}$ Miles } & \multicolumn{2}{c}{$\mathbf{1 - 5}$ Miles } & \multicolumn{2}{c}{5 -10 Miles } & \multicolumn{2}{c}{$>$ 10 Miles } \\
Transmission & Acres & MW & Acres & MW & Acres & MW & Acres & MW \\
\hline BLM & 0 & 0 & 506 & 145 & 1,651 & 473 & 718 & 206 \\
Federal & 14 & 4 & 17,372 & 4,978 & 12,380 & 3,547 & 2,879 & 825 \\
Other & 613 & 176 & 17,010 & 4,874 & 26,880 & 7,702 & 55,287 & 15,842 \\
Private & 15,939 & 4,567 & 209,334 & 59,981 & 301,807 & 86,478 & 311,033 & 89,121 \\
\hline \hline
\end{tabular}

\begin{tabular}{ccccc}
\hline \hline \multicolumn{5}{c}{ PSC22-Modeled Solar Capacity } \\
\hline Ref & HI-NG & LO-NG & C02 & HI-RPS \\
8 & 8 & 8 & 8 & 8 \\
\hline \hline
\end{tabular}



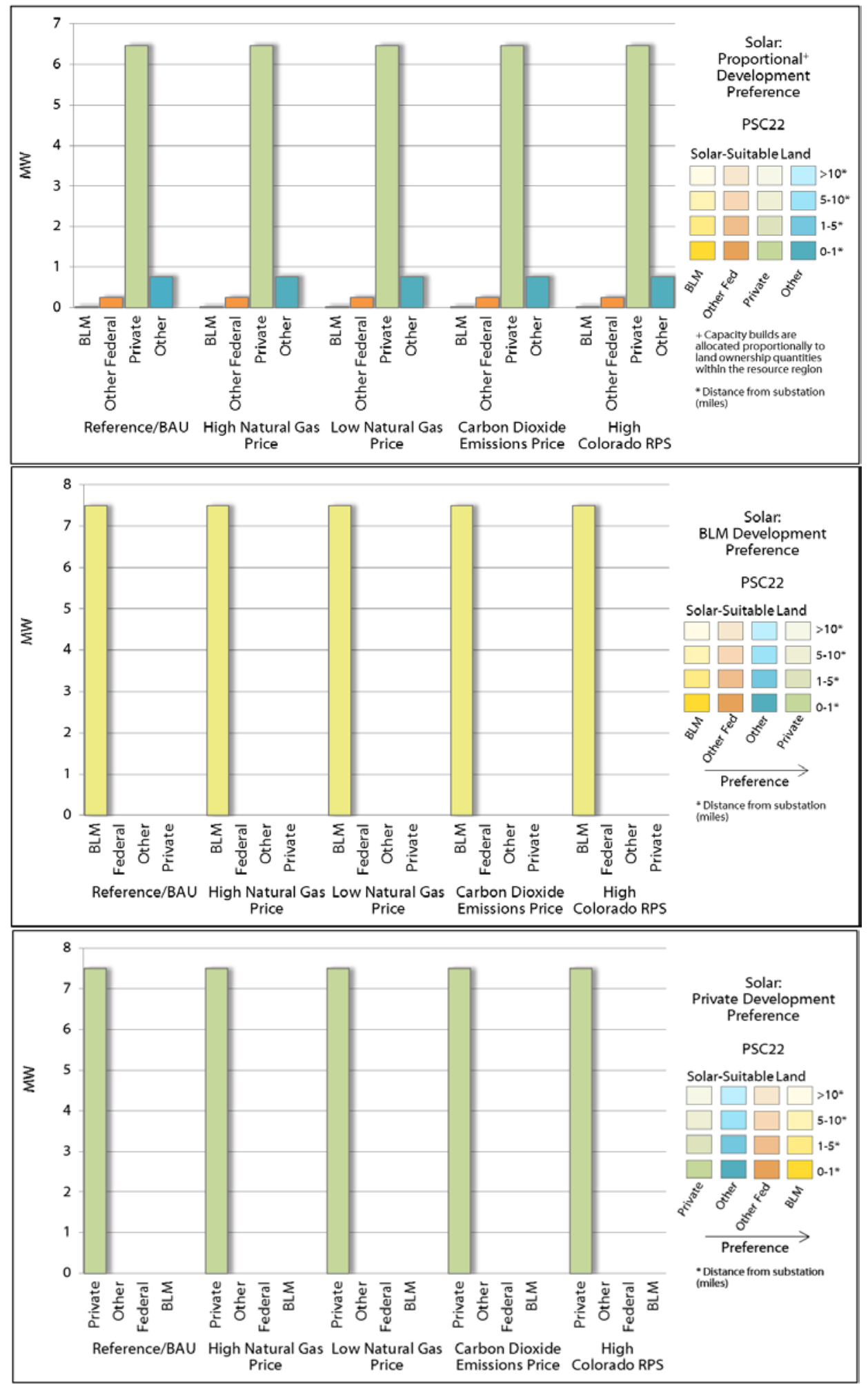


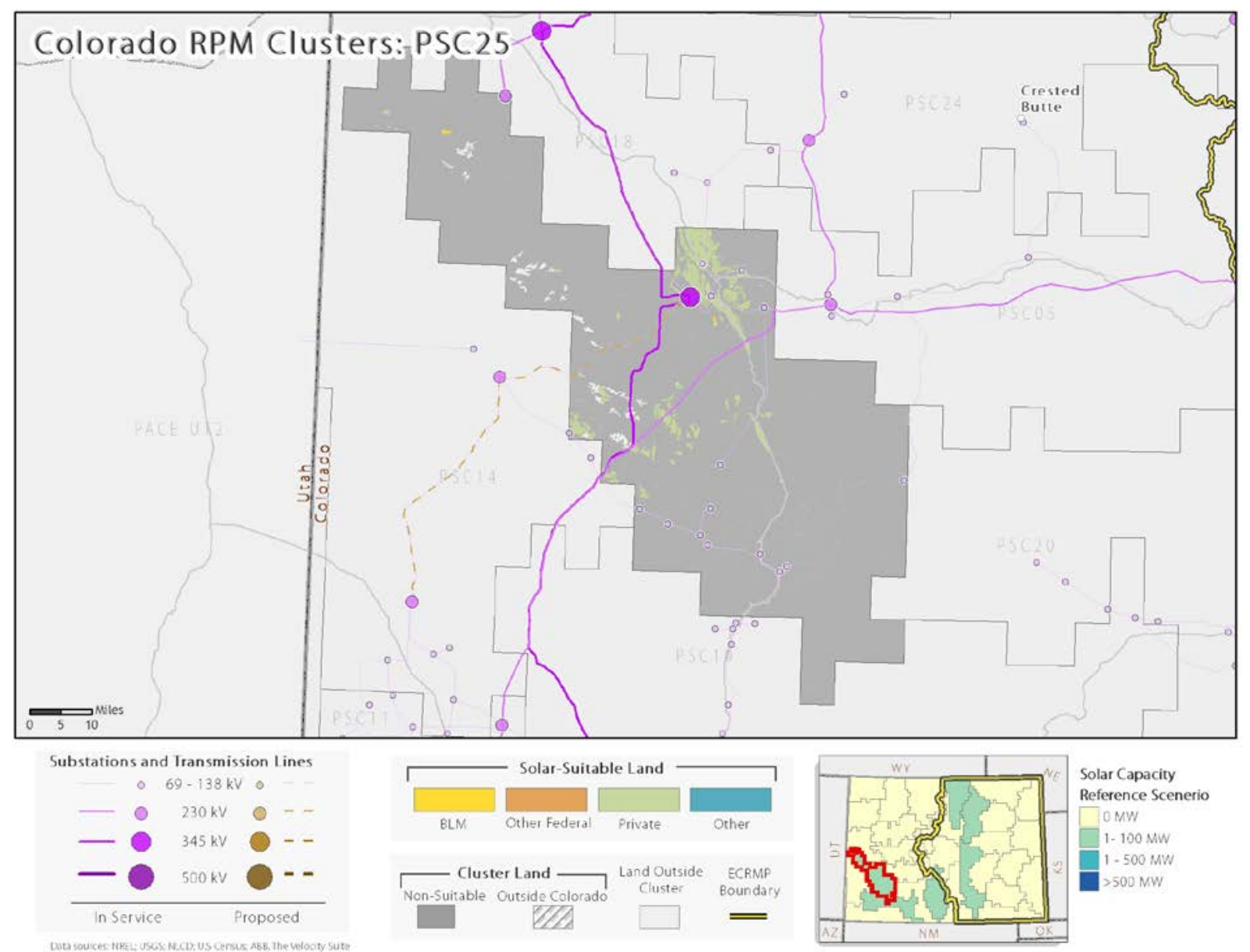

\begin{tabular}{c|cc|cc|cc|cc}
\hline \hline \multicolumn{10}{c}{ PSC25-Solar-Suitable Land: Area and MW Potential } \\
\hline $\begin{array}{c}\text { Distance to } \\
\text { Transmission }\end{array}$ & \multicolumn{2}{c|}{-1 Miles } & \multicolumn{2}{c|}{$\mathbf{1 - 5}$ Miles } & \multicolumn{2}{c}{$\mathbf{5 - 1 0}$ Miles } & \multicolumn{2}{c}{$>$ 10 Miles } \\
\hline BLres & MW & Acres & MW & Acres & MW & Acres & MW \\
\hline Federal & 25 & 7 & 433 & 124 & 57 & 16 & 443 & 127 \\
Other & 0 & 0 & 241 & 69 & 5,756 & 1,649 & 9,800 & 2,808 \\
Private & 0 & 0 & 338 & 97 & 75 & 21 & 0 & 0 \\
\hline \hline
\end{tabular}

\begin{tabular}{ccccc}
\hline \hline \multicolumn{5}{c}{ PSC25-Modeled Solar Capacity } \\
\hline Ref & HI-NG & LO-NG & C02 & HI-RPS \\
1 & 1 & 1 & 1 & 1 \\
\hline \hline
\end{tabular}




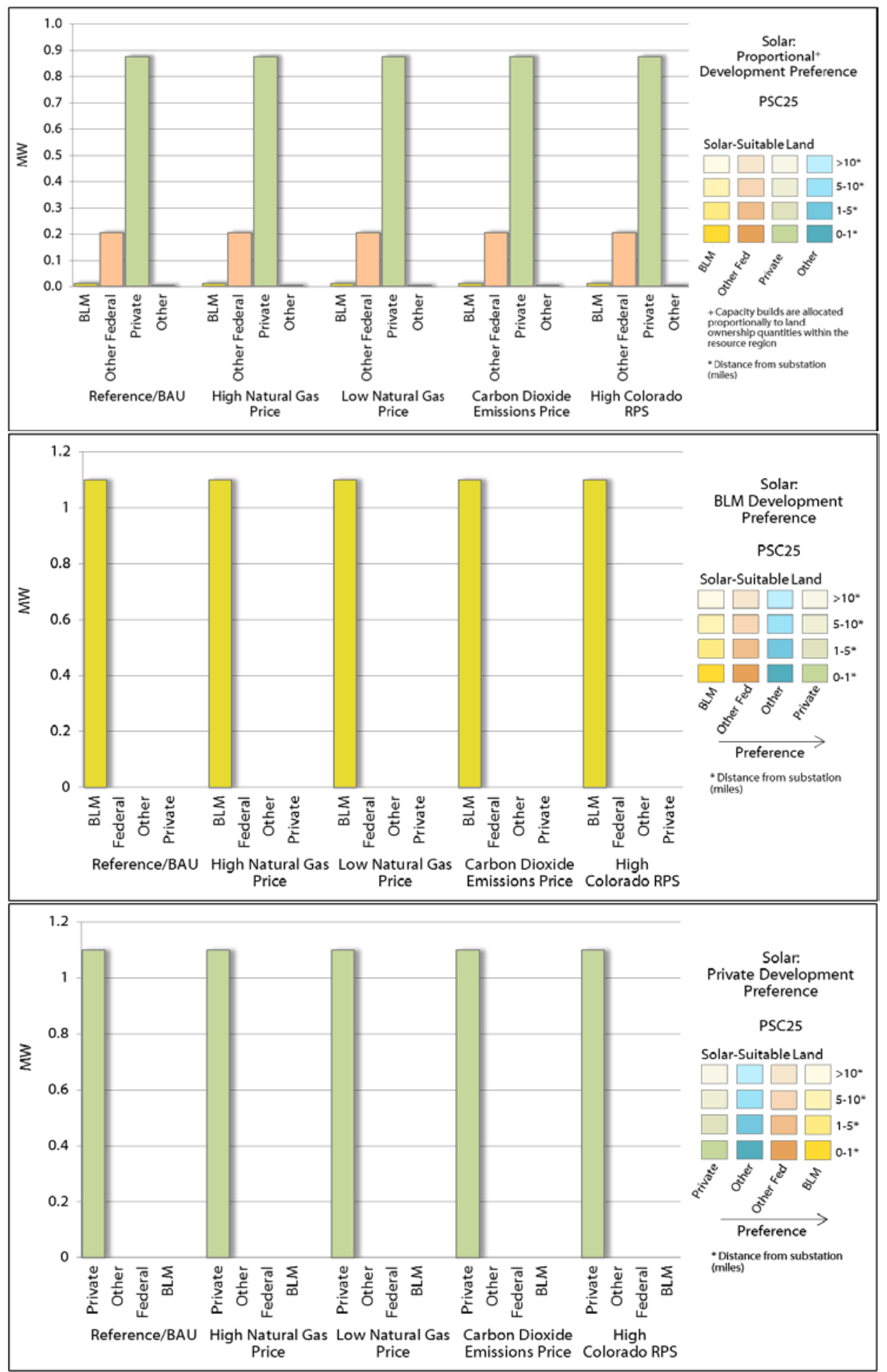

